HELENA GABRIELA TURANO

\title{
ALTERNATIVAS TERAPÊUTICAS PARA O TRATAMENTO DE INFECÇÕES POR Pseudomonas aeruginosa MULTIRRESISTENTES ENDÊMICAS NO BRASIL
}

Dissertação apresentada ao Programa de Pós-Graduação em Microbiologia do Instituto de Ciências Biomédicas da Universidade de São Paulo, para obtenção do Título de Mestre em Ciências. 
HELENA GABRIELA TURANO

\section{ALTERNATIVAS TERAPÊUTICAS PARA O TRATAMENTO DE INFECÇÕES POR Pseudomonas aeruginosa MULTIRRESISTENTES ENDÊMICAS NO BRASIL}

Dissertação apresentada ao Programa de Pós-Graduação em Microbiologia do Instituto de Ciências Biomédicas da Universidade de São Paulo, para obtenção do Título de Mestre em Ciências.

Área de Concentração: Microbiologia

Orientador: Prof. Dr. Nilton Ebert Lincopan Huenuman

Versão corrigida. Versão original eletrônica encontra-se disponível tanto na Biblioteca do ICB quanto na Biblioteca de Teses e Dissertações da USP (BDTD). 
DADOS DE CATALOGAÇÃO NA PUBLICAÇÃO (CIP)

Serviço de Biblioteca e Informação Biomédica do

Instituto de Ciências Biomédicas da Universidade de São Paulo

reprodução não autorizada pelo autor

Turano, Helena Gabriela.

Alternativas terapêuticas para o tratamento de infecções por Pseudomonas aeruginosa multirresistentes endêmicas no Brasil / Helena Gabriela Turano. -- São Paulo, 2012.

Orientador: Prof. Dr. Nilton Ebert Lincopan Heunuman.

Dissertação (Mestrado) - Universidade de São Paulo. Instituto de Ciências Biomédicas. Departamento de Microbiologia. Área de concentração: Microbiologia. Linha de pesquisa: Resistência bacteriana e alternativas terapêuticas.

Versão do título para o inglês: Alternative therapies for the treatment of infections produced by multidrug-resistant Pseudomonas aeruginosa strains endemic in Brazil.

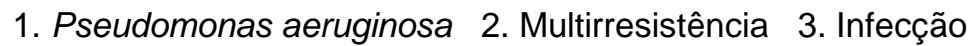
hospitalar 4. Metalo-Beta-Lactamase 5. Sinergismo 6. DDA I. Huenuman, Prof. Dr. Nilton Ebert Lincopan II. Universidade de São Paulo. Instituto de Ciências Biomédicas. Programa de Pós-Graduação em Microbiologia III. Título. 
Candidato(a):

Título da Dissertação:

Orientador(a):
Helena Gabriela Turano.

Alternativas terapêuticas para o tratamento de infecções por Pseudomonas aeruginosa multirresistentes endêmicas no Brasil.

A Comissão Julgadora dos trabalhos de Defesa da Dissertação de Mestrado, em sessão pública realizada a , considerou
( ) Aprovado(a)
( ) Reprovado(a)

Examinador(a): Assinatura:

Nome:

Instituição:

Examinador(a): Assinatura:

Nome:

Instituição:

Presidente: Assinatura:

Nome:

Instituição: 


\section{CERTIFICADO DE ISENÇÃO}

Certificamos que o Protocolo CEP-ICB N ${ }^{\circ}$ 414/10 referente ao projeto intitulado: "Alternativas terapêuticas para o tratamento de infecções por bactérias Gram negativas multirresistentes produtoras de metalo-beta-lactamases" sob a responsabilidade de Helena Gabriela Turano, foi analisado na presente data pela CEUA - COMISSÃO DE ÉTICA NO USO DE ANIMAIS e pela CEPSH- COMISSÃO DE ÉTICA EM PESQUISA COM SERES HUMANOS, tendo sido deliberado que o referido projeto não envolve manipulação animal ou humana que justifique uma aprovação quanto aos princípios éticos exigidos por ambas as Comissões.

São Paulo, 10 de agosto de 2010.
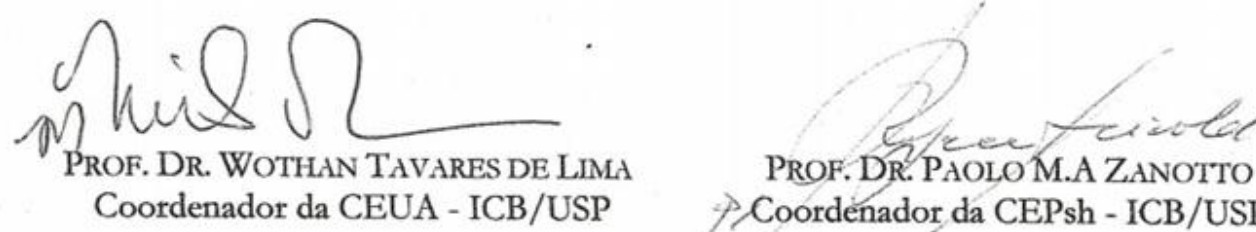
† Coordenador da CEPsh - ICB/USP 
Q Dedica este trabalho ao meuf flho Enga, motiva de minha determinasãa e forsa. Mtos meus pais, Qfúcia e Yestar, excmplos de luta e trabalho, que sempre me apoiaram e, nunca negaxam cuidados paxa comigo e com meu fitho. Ha meu irmãa Mestor Luiniox que, apesase de seu tempo extremamente escassa, sempre esteve aa meu lada. Afmo vacés!

Este trabalho também é dedicado ao meu noivo amado, Frennando, pox toda ajuda e compreensãa sem limite. Eeu te amo! 


\section{AGRADECIMENTOS}

Em primeiro lugar, agradeço a Deus, por ter permitido a realização deste meu sonho e pelo cumprimento desta promessa na minha vida.

Ao meu filho Enzo, razão do meu ingresso na Pós-Graduação, meu motivo diário de continuar, apesar de toda dificuldade enfrentada. Eu amo você!

Agradeço a minha mãe Lúcia, por todo amor incondicional e esforço em me ajudar a realizar esse objetivo, cuidando de meu filho, dia após dia, sem folgas, muitas vezes deixando de ir trabalhar para me auxiliar. Não tenho palavras para agradecer.

Ao meu pai Nestor, por prover tudo quanto fosse necessário, sem nenhuma cobrança e, estando sempre disposto a ajudar a qualquer momento.

Ao meu irmão Nestor Júnior, por todo cuidado, apoio e carinho dedicado a mim e ao meu filho, que mesmo com seu tempo curto, sempre esteve solícito a ficar com o Enzo.

Agradeço imensamente ao verdadeiro amor da minha vida, meu noivo Fernando. Por estar sempre disposto a me ajudar, a me ensinar e me apoiar incondicionalmente em todos os momentos. Por ter muita paciência; por compreender minhas dificuldades, por estar disposto a crescer e, dividir comigo e com o Enzo, toda essa imensa jornada. Eu te amo!

A minha avó Marina, por todos os conselhos, todas as conversas e exemplo de vida e de fé!

Aos meus avós que já não estão nesse mundo, mas que sempre estiveram em meus pensamentos me encorajando a continuar.

A toda minha família, que sempre me apoiaram e compreenderam minha ausência em tantos momentos.

Agradeço a Jacinta pelo empurrão definitivo na minha escolha e pelo apoio prestado em todo momento.

Ao meu orientador Prof. Dr. Nilton Lincopan, pela oportunidade oferecida, por me compreender, acreditar no meu crescimento como pesquisadora e por confiar no meu trabalho.

Ao meu amigo Juan, em princípio pelo auxílio com o Inglês, depois, por todo resto, toda paciência, força, apoio e ensinamentos. Obrigada por estar sempre disposto a ouvir, a auxiliar, a ensinar e, acima de tudo, pela sua amizade.

Agradeço a Lucianne, Lívia, Ketrin, Patrícia, Silvane, Manu, Andreza, Isabela, Luana, Leandro, Rodrigo C., Rodrigo, Shila, Priscila, Micheli, pelo companheirismo diário no laboratório e, ao Prof. Dr Antônio Fernando Pestana, por passar a dividir seu dia-a-dia conosco. Finalmente, a todos que contribuíram direta ou indiretamente para a realização do meu trabalho, meu muito obrigada! 
"Preocupe-se mais com seu caráter do que com sua reputaçâo. Caráter é aquilo que você é, reputaçấ é apenas o que os outros pensam que você $\dot{e}$."

John Wooden

"Nâo quers reconhecimento nesta vida e nem depois da morte. Caso exista alguém que tenha sido favorecido por alguma das minhas boas açöes, estarei feliz.” 


\section{RESUMO}

Turano HG. Alternativas terapêuticas para 0 tratamento de infecções por Pseudomonas aeruginosa multirresistentes endêmicas no Brasil. [dissertação (Mestrado em Microbiologia)]. São Paulo: Instituto de Ciências Biomédicas, Universidade de São Paulo; 2012.

Pseudomonas aeruginosa é um dos principais agentes de infecção hospitalar que tem adquirido um caráter endêmico decorrente a sua resistência intrínseca e/ou adquirida aos antibacterianos comercialmente disponíveis. O objetivo do estudo foi avaliar, "in vitro", opções terapêuticas baseadas na atividade sinérgica. Dez cepas de $P$. aeruginosa clonalmente não relacionadas, previamente caracterizadas como produtoras de metalo-beta-lactamase (M $3 \mathrm{~L})$ do tipo SPM-1, VIM-1 e GIM-1, foram avaliadas. O efeito sinérgico foi investigado por "Checkerboard" e "Time-Kill". As combinações [Piperacilina/Tazobactam $x$ Aztreonam] e [Tigeciclina $x$ nanofragmentos de bicamada de brometo de dioctadecildimetilamônio (DDA)] mostraram atividade sinérgica para 90 e $100 \%$ das cepas, respectivamente. Os resultados respaldam o uso terapêutico combinado de [Piperacilina/Tazobactam $x$ Aztreonam], contra infecções produzidas por cepas de $P$. aeruginosa multirresistentes produtoras de M $\beta L s$, além disso, [DDA/Tigeciclina] pode constituir a base para consolidar uma nova forma farmacêutica de uso clínico.

Palavras-chave: Pseudomonas aeruginosa. Multirresistência. Infecção hospitalar. Metalo-beta-lactamase. SPM-1. Sinergismo. DDA. 


\begin{abstract}
Turano HG. Alternative therapies for the treatment of infections produced by multidrug-resistant Pseudomonas aeruginosa strains endemic in Brazil. [dissertation (Microbiology)]. São Paulo: Instituto de Ciências Biomédicas, Universidade de São Paulo; 2012.

Pseudomonas aeruginosa is a leading cause of nosocomial infections, which it has acquired an endemic status due to their intrinsic or acquired resistance to antibacterial agents commercially available. The aim of the study was to evaluate "in vitro" therapeutic options based on the synergistic activity. Ten clonally unrelated strains of $P$. aeruginosa, previously characterized as metallo-beta-lactamase (M $\beta \mathrm{L})$ producers (i.e., SPM-1, VIM-1 and GIM-1) were evaluated. The synergistic effect was investigated by checkerboard" and Time-Kill assays. The combinations [Piperacillin/Tazobactam $\times$ Aztreonam] and [Tigecycline $\mathrm{x}$ bilayer fragments of dioctadecyldimethylammonium bromide (DDA)] showed synergistic activity for 90 and $100 \%$ of the strains, respectively. The results support the use of combined therapy by using [Piperacillin/Tazobactam $x$ Aztreonam] against infections produced by strains of $P$. aeruginosa producing M $\beta L s$, moreover, [DDA / Tigecycline] may be the basis for build a new pharmaceutical form for clinical use.
\end{abstract}

Keywords: Pseudomonas aeruginosa. Multiresistance. Nosocomial infection. Metallo-beta-lactamase. SPM-1. Synergism. DDA. 


\section{LISTA DE ABREVIATURAS E SIGLAS}

$\mu \mathrm{g}$

Micrograma

$\mu \mathrm{L}$

Microlitro

AMI

Amicacina

ATCC

American Type Culture Collection

ATM

Aztreonam

$\mathrm{BHI}$

Brain Heart Infusion

CAZ

Ceftazidima

$\mathrm{CCIH}$

Comissão de Controle de Infecção Hospitalar

CIM

Concentração Inibitória Mínima

CIP

Ciprofloxacina

CLSI Clinical and Laboratory Standards Institute

CPM Cefepima

CT Colistina

DDA Brometo de Dioctadecildimetilamônio

EDTA Ácido etilenodiamino tetracético

EUCAST The European Committee on Antimicrobial Susceptibility Testing

FDA Food and Drug Administration

FIC Índice Fracional de Concentração Inibitória

GEN Gentamicina

GIM German Imipenemase

h Hora

I Intermediário

ICB Instituto de Ciências Biomédicas

IGP Isotonic Glucose Phosphate

IPM Imipinem

$\mathrm{Kb} \quad$ Kilobase

L Litro

LVX Levofloxacina

MER Meropenem

mg Miligrama

$\mathrm{MH} \quad$ Mueller-Hinton 


\begin{tabular}{ll} 
min & Minuto \\
mL & Mililitro \\
mm & Milímetro \\
mM & Milimolar \\
MR & Microrganismo Multirresistente \\
MPA & 2-mercaptopropiônico \\
MßL & Metalo-Beta-Lactamase \\
N & Número \\
NCCLS & National Committee for Clinical Laboratory Standards \\
nm & Nanômetro \\
OMS & Organização Mundial da Saúde \\
Pa & Pseudomonas aeruginosa \\
pb & Pares de bases \\
PBP & Penicillin Binding Protein \\
POL & Polimixina B \\
PPT & Piperacilina/Tazobactam \\
R & Resistente \\
rpm & Rotações Por Minuto \\
S & Sensível \\
SPM & São Paulo metalo- $\beta$-lactamase \\
TGC & Tigeciclina \\
UFC & Unidade Formadora de Colônia \\
USP & Universidade de São Paulo \\
UTI & Unidade de Tratamento Intensivo \\
VIM & Verona Imipenemase \\
\hline
\end{tabular}




\section{LISTA DE ILUSTRAÇÕES}

Figura 1 - Algumas vias de transmissão de agentes patogênicos ou da microbiota, entre animais, ecossistemas e seres humanos

Figura 2 - Números de enzimas $\beta$-lactamases identificadas desde a introdução dos primeiros $\beta$-lactâmicos

Quadro 1 - Classificação das queimaduras segundo a profundidade. 23

Quadro 2 - Critérios para os estágios microbianos nas queimaduras.

Figura 3 - Estrutura química do DDA (A) e Tigeciclina (B)

Quadro 3 - Cepas cedidas pela Dra. Patrícia Neves.

Quadro 4 - Sensibilidade antimicrobiana de 10 cepas a 12 antimicrobianos.

Figura 4 - Curva de morte (gráfico "Time-Kill') da cepa de P. aeruginosa 111ER para a combinação [Tigeciclina $\times$ DDA].

Figura 5 - Curva de morte (gráfico "Time-Kill") da cepa de $P$. aeruginosa 48-1997A SPM-1 para a combinação [Tigeciclina x DDA]

Figura 6 - Curva de morte (gráfico "Time-Kill") da cepa de P. aeruginosa 247B VIM-1 para a combinação [Tigeciclina x DDA].

Figura 7 - Curva de morte (gráfico "Time-Kill") da cepa de $P$. aeruginosa PA GIM-1 para a combinação [Tigeciclina $x$ DDA]

Figura 8 - Espectro de absorção UV visível de Tigeciclina $(16 \mu \mathrm{g} / \mathrm{mL})$ e da combinação [Tigeciclina/DDA] [16/32 $\mu \mathrm{g} / \mathrm{mL}]$.

Figura 9 - Distribuição de tamanhos (diâmetro médio) e potencial zeta $(\zeta)$ resultante da interação $P$. aeruginosa e DDA.

Figura 10 - Distribuição de tamanhos (diâmetro médio) e potencial zeta $(\zeta)$ resultante da interação $P$. aeruginosa, DDA e Tigeciclina

Figura 11 - Atividade bactericida da combinação [Piperacilina/Tazobactam x Aztreonam] para a cepa 247B VIM-1

Figura 12 - Atividade bactericida da combinação [Piperacilina/Tazobactam $x$ Aztreonam] para a cepa PA GIM-1

Figura 13 - Atividade bactericida da combinação [Piperacilina/Tazobactam x Aztreonam] para a cepa 48-1997A SPM-1

Figura 14 - Teste confirmatório de sinergismo para a combinação de [Piperacilina/Tazobactam x Aztreonam] para a cepa 247B VIM-1 
Figura 15 - Teste confirmatório de sinergismo para a combinação de [Piperacilina/Tazobactam x Aztreonam] para a cepa PA GIM-1

Figura 16 - Teste confirmatório de sinergismo para a combinação de [Piperacilina/Tazobactam x Aztreonam] para a cepa 48-1997A SPM1

Figura 17 - Curva de morte (gráfico "Time-Kill") da cepa de P. aeruginosa 247B VIM-1 para a combinação [Piperacilina/Tazobactam $x$ Aztreonam]

Figura 18 - Curva de morte (gráfico "Time-Kill") da cepa de $P$. aeruginosa PA GIM-1 para a combinação [Piperacilina/Tazobactam $x$ Aztreonam].

Figura 19 - Curva de morte (gráfico "Time-Kill") da cepa de P. aeruginosa 48-1997A SPM-1 para a combinação [Piperacilina/Tazobactam $x$ Aztreonam].

Figura 20 - Esquema da interação entre Tigeciclina e um fragmento de bicamada de DDA 


\section{LISTA DE TABELAS}

Tabela 1 - Valores da concentração inibitória mínima (CIM), concentração inibitória fracional (FIC) e somatório das FIC $(\Sigma F I C)$ para duas cepas de $P$. aeruginosa MR.

Tabela 2 - Valores da concentração bactericida mínima (CBM), concentração bactericida fracional (FBC) e somatório das FBC ( $\Sigma F B C)$ para cepas de $P$. aeruginosa na combinação [Tigeciclina e DDA]

Tabela 3 - Valores da concentração inibitória mínima (CIM), concentração inibitória fracional (FIC) e somatório das FIC ( $\mathrm{FIC})$ para cepas de $P$. aeruginosa na combinação [Piperacilina/Tazobactam e

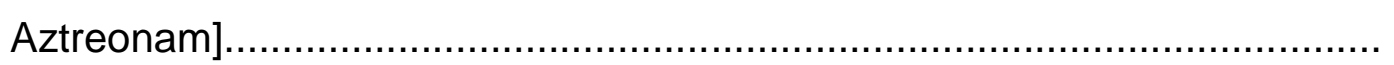

Tabela 4 - Valores da concentração inibitória mínima (CIM), concentração inibitória fracional (FIC), somatório das FIC ( $\Sigma F I C)$ para cepas de $P$. aeruginosa na combinação [Amicacina $x$ Polimixina B]

Tabela 5 - Valores dos diâmetros dos halos de inibição do teste confirmatório de sinergismo.

Tabela 6 - Picos séricos e "breakpoints" dos antimicrobianos avaliados 
1 INTRODUÇÃO

1.10 uso excessivo de antibióticos e a Infecção Hospitalar................... 18

1.2 Pseudomonas aeruginosa ......................................................... 20

1.2.1 Pseudomonas aeruginosa e infecções em pacientes com queimaduras.

1.2.2 Pseudomonas aeruginosa e fibrose cística...................................... 24

1.3 Metalo-bela-lactamases (MßL)................................................... 26

1.4 Principais antimicrobianos utilizados no estudo............................. 27

1.4.1 DDA - brometo de dioctadecildimetilamônio.......................................... 27

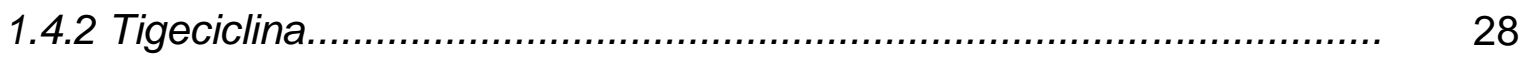

1.4.3 Piperacilina-Tazobactam............................................................ 29

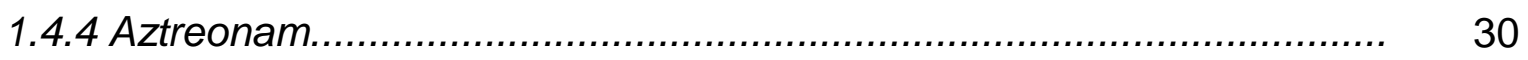

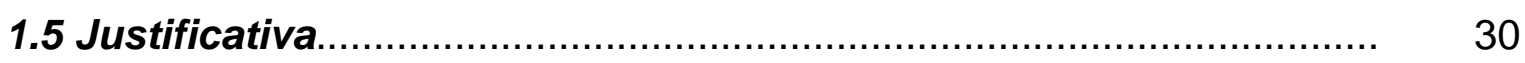

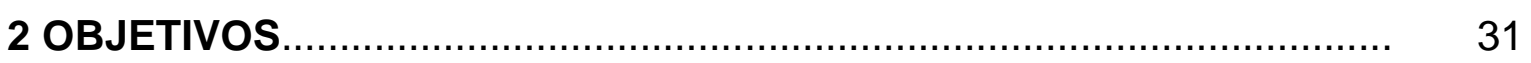

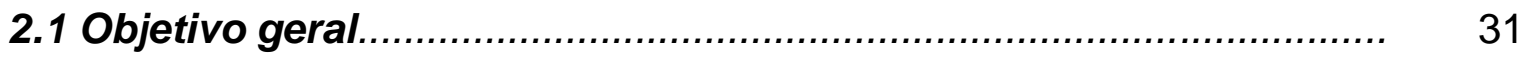

2.2 Objetivos específicos...................................................................

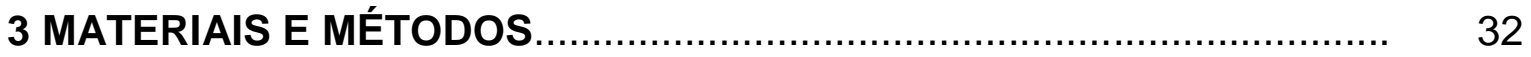

3.1 Cepas bacterianas................................................................... 32

3.2 Condições de cultivo e armazenamento das cepas.......................... 33

3.3 Testes de sensibilidade de antimicrobianos pelo método "Kirby-

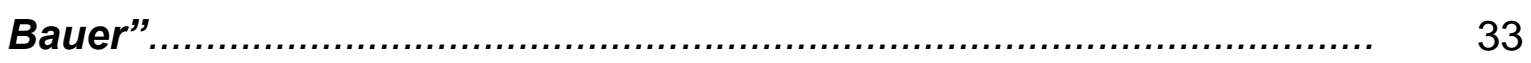

3.4 Determinação da concentração inibitória mínima (CIM).................... 33

3.5 Teste de sinergismo pelo método de microdiluição em caldo (“Checkerboard"),.......................................................................... 34

3.6 Realização de atividade bactericida (Concentração Bactericida Mínima - CBM)

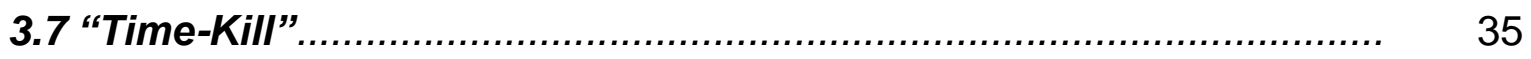

3.8 Preparação dos nanofragmentos de bicamada de DDA................... 36

3.9 "Light Scattering" e Potencial Zeta ..................................... 37

3.10 Espectrofotometria UV Visível.................................................. 37

3.11 Teste Confirmatório de Sinergismo.............................................. 38 


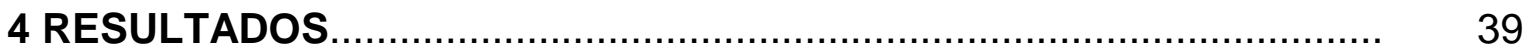

4.1 Antibiograma

4.2 Concentração Inibitória Mínima e Sinergismo................................... 39

4.3 "Time-Kill” da Combinação [Tigeciclina x DDA] ............................... 44

4.4 Espectrofotometria UV Visível.................................................... 48

4.5 "Light Scattering" e Potencial Zeta ..................................... 49

4.6 Sinergismo de Piperacilina/Tazobactam e Aztreonam...................... 51

4.7 Teste Confirmatório de Sinergismo de [Piperacilina/Tazobactam $x$

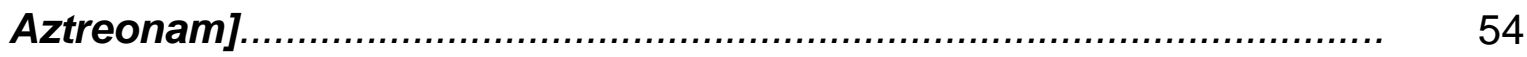

4.8“Time-Kill" da combinação [Piperacilina/Tazobactam x Aztreonam] 57

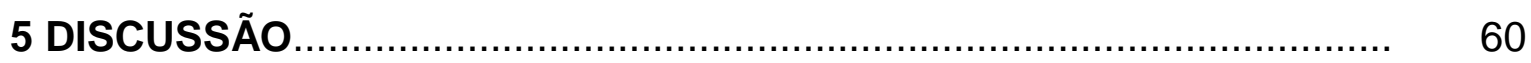

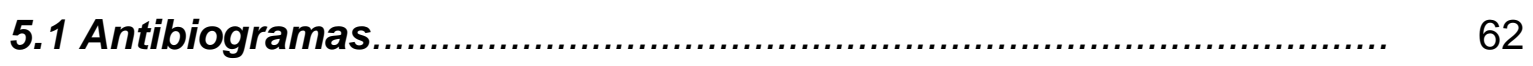

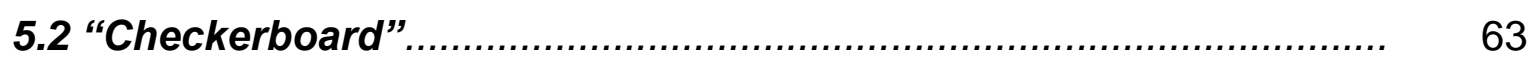

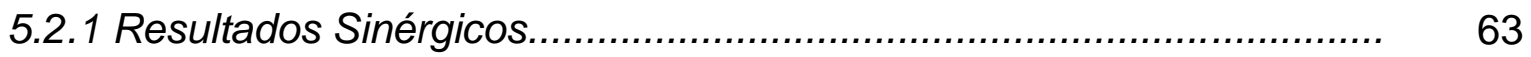

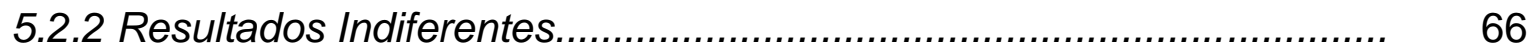

5.3 Teste Confirmatório de Sinergismo.............................................. 67

5.4 "Time-Kill" da combinação [Tigeciclina x DDA]............................... 69

5.5"Time-Kill" da combinação [Piperacilina/Tazobactam x Aztreonam] 70

5.6 Ensaios Adicionais.................................................................. 71

5.7 Considerações finais................................................................

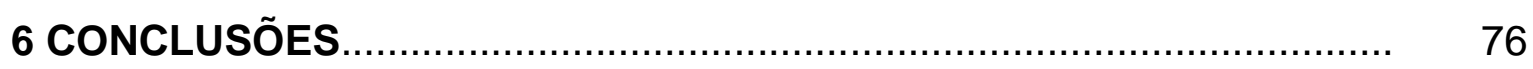

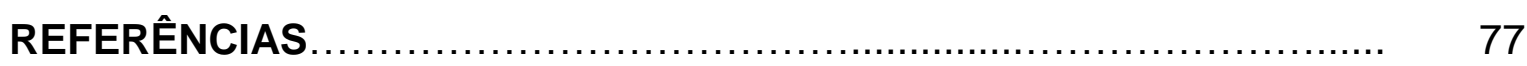




\section{INTRODUÇÃO}

A descoberta dos antimicrobianos revolucionou a medicina, salvando inúmeras vidas, passando a ser altamente utilizados nos tratamentos terapêuticos. Diante desse elevado uso, várias melhorias nas produções desses medicamentos proporcionaram redução nos custos, tornando-os mais acessíveis e incentivando o uso sem prescrição médica (Davies, Davies, 2010).

Milhões de toneladas de antimicrobianos são produzidos para diversas finalidades, desde tratamentos terapêuticos curativos na medicina humana e animal; no tratamento profilático, como aditivos nas rações de animais; na agricultura, entre outros usos. Adicionalmente, diversas atividades antropogênicas, acabam por contaminar o meio-ambiente (córregos, rios, mares, oceanos e terra). Estes, por sua vez, têm sido constantemente alterados por influências humanas, com os descartes de resíduos de processos industriais, resíduos tóxicos, desinfetantes e agentes antimicrobianos, criando grandes reservas ambientais de resistência.

Outro ambiente extremamente rico em diversidade microbiológica é o esgoto, que também favorece a seleção de organismos resistentes (Davies, Davies, 2010; Fontes et al., 2011; Moura et al., 2010). Na Figura 1 podem ser observadas algumas das principais vias de transmissão de agentes patogênicos.

Para sobreviver a essas condições, várias adaptações moleculares foram desenvolvidas pelas bactérias, como adquirindo DNA exógeno, através de plasmídeos, transposons ou por captação direta e incorporação por recombinação homóloga, obtendo genes que codificam novas vias metabólicas, através da transferência gênica horizontal, contribuindo para a evolução dessas espécies e sendo um importante alvo de investigação devido a sua significância médica, pois mutantes espontâneos de resistência podem espalhar em uma população bacteriana os genes de resistência, conduzindo a uma potencial pandemia (Frost et al., 2005; Moura et al., 2010; Norman et al., 2009). 
Figura 1 - Algumas vias de transmissão de agentes patogênicos ou da microbiota, entre animais, ecossistemas e seres humanos.

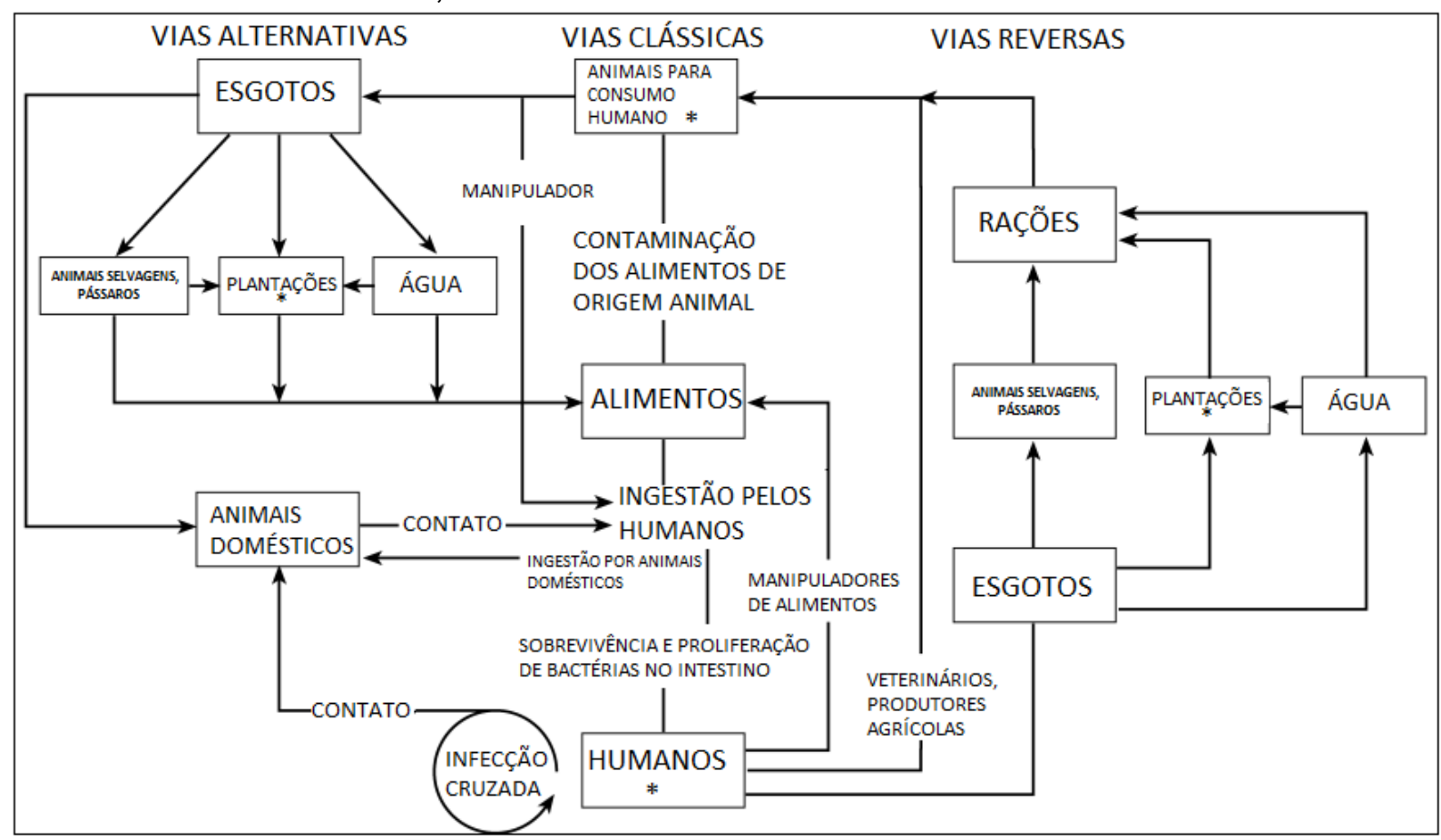

Nota: * Uso de antibióticos, selecionando resistência.

Fonte: Adaptado de Phillips et al. (2004).

\subsection{0 uso excessivo de antibióticos e a Infecção Hospitalar}

São denominados microrganismos multirresistentes aqueles que são resistentes a pelo menos três antibióticos de classes diferentes (Magiorakos et al., 2012). Antibióticos de amplo espectro têm sido usados excessivamente, de forma empírica, favorecendo a seleção de bactérias multirresistentes (MR), à endemicidade das cepas, as quais são associadas às infecções hospitalares (IH) ou nosocomiais e, aos altos índices de morbidade e mortalidade (Gales et al., 2003a; Moura, 2007; Theuretzbacher, 2012).

A correlação entre o uso de antibióticos e aparecimento da resistência é especialmente aparente na classe de $\beta$-lactâmicos, os quais são inativados pelas enzimas $\beta$-lactamases. Como exemplo representante dessa classe temos a penicilina que, posteriormente a sua descoberta, passou a ser produzida em larga escala, tornou-se disponível para uso geral e veio a ser amplamente utilizada. Concomitantemente ao seu uso, surgiram os isolados apresentando resistência, como pode ser observado na Figura 2 (Davies, Davies, 2010). 
De acordo com o Ministério da Saúde (Brasil, 1998) temos como definição de IH qualquer infecção adquirida (48 - 72 h) após a entrada do paciente, que se revele enquanto internado, ou até mesmo após a alta, se for relacionada com os procedimentos hospitalares ou internação.

Estudos têm mostrado que as principais espécies Gram-negativas relacionadas às infecções hospitalares são: Pseudomonas aeruginosa, Escherichia coli, Klebsiella pneumoniae, Acinetobacter baumannii e Enterobacter spp (Gales et al., 2012; Girão et al., 2008; Kiffer et al., 2005; Lincopan et al., 2005; 2006; Pavez et al., 2009; Rossi, 2011; Sader et al., 2001; Theuretzbacher, 2012).

Figura 2 - Números de enzimas $\beta$-lactamases identificadas desde a introdução dos primeiros $\beta$-lactâmicos

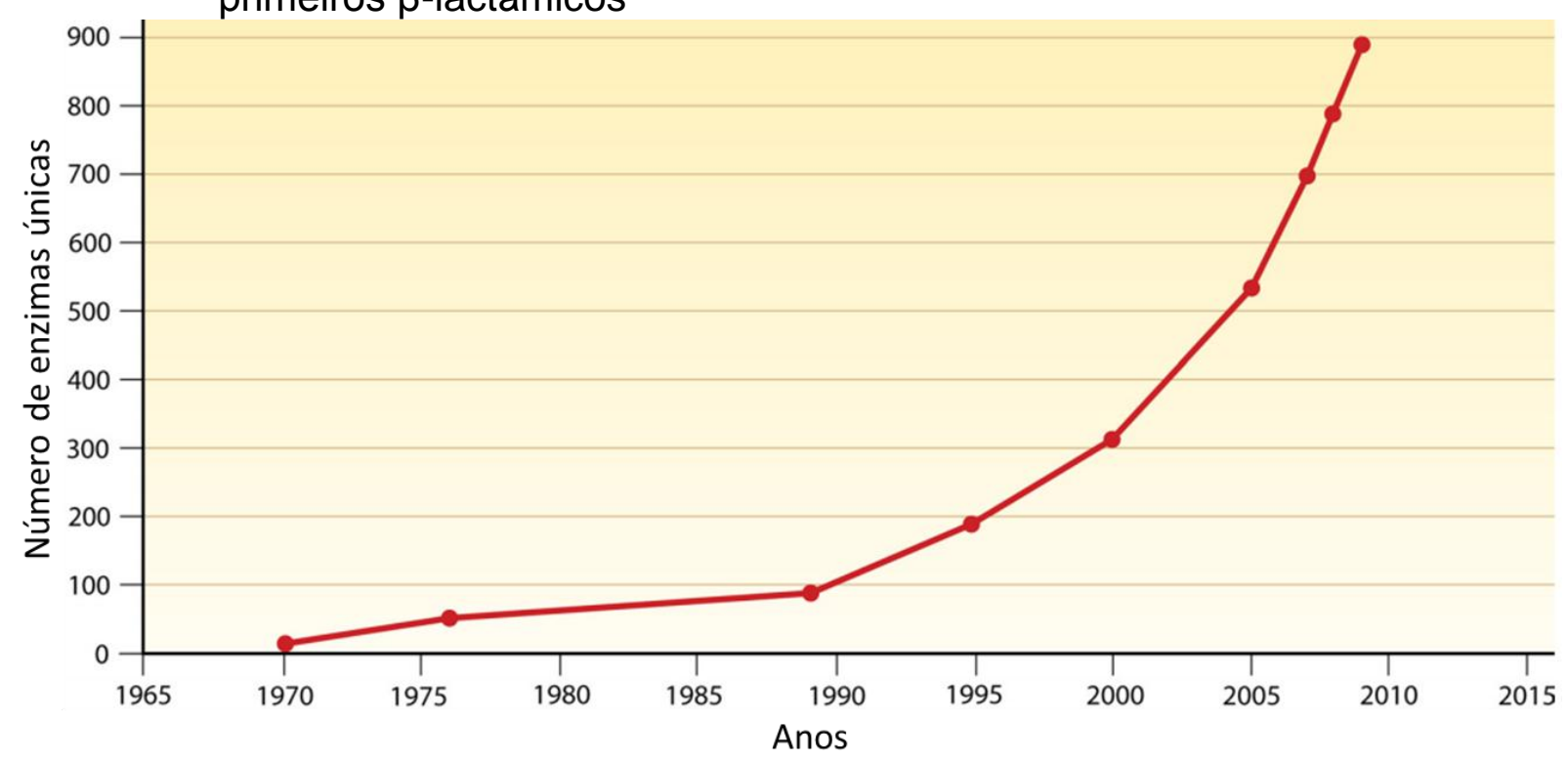

Nota: Enzimas $\beta$-lactamases identificadas durante a era dos antibióticos.

Fonte: Adaptado de Davies e Davies (2010).

O tratamento de pacientes com infecções hospitalares graves utilizando antibióticos de amplo espectro de atividade, como os carbapenêmicos, deve-se a sua boa permeabilidade através da membrana externa bacteriana e estabilidade frente a muitas $\beta$-lactamases (Franco et al., 2010; Fritsche et al., 2005; Gales et al., 2003). No entanto, essa escolha acaba exercendo maior pressão seletiva sobre a microbiota hospitalar, ocasionando a seleção natural de bactérias resistentes ao imipenem e disseminação dos clones (Davies, Davies, 2010; Rodloff et al., 2006).

Um estudo de Rahal et al. (1998) avaliou a restrição de cefalosporinas para infecções por Klebsiella produtoras de ESBL. O estudo indicou que a restrição levou 
a uma redução na frequência de isolados produtores de ESBL, porém também originou um aumento de $140 \%$ no uso de carbapenêmicos, como o imipenem, que por sua vez ocasionou a um aumento de $69 \%$ na frequência de $P$. aeruginosa resistente ao imipenem e na emergência de espécies de Acinetobacter resistentes. Essas escolhas, portanto, apontam para a necessidade do controle de infecção dos hospitais (Rodloff et al., 2006).

De acordo com Sader e Jones (2005) é de extrema importância buscar alternativas para reduzir o desenvolvimento a resistência e usar de maneira eficaz os antimicrobianos já existentes.

Devido à resistência aos carbapenêmicos e a dificuldade no desenvolvimento de novas drogas (Tillotson, 2008), muitos autores têm previsto um retorno à era préantibiótica, postulando a volta de antibióticos abdicados atualmente (Levin, Oliveira, 2008; Paterson, Lipman, 2007; Schurek et al., 2009; Theuretzbacher, 2012; Timurkaynak et al., 2006), porém, uma alternativa mais sustentável é o estudo de combinações de antibióticos que alcancem efeitos sinérgicos (Choi et al., 2004; Tripodi et al., 2007; Zhanel et al., 2006).

Segundo Lyczak et al. (2002) a monoterapia pode ser utilizada para cepas suscetíveis de $P$. aeruginosa, porém o estudo de combinações permite a identificação de combinações de antibióticos sinérgicos e, essa combinação é mais efetiva contra cepas que podem desenvolver a resistência, sendo, portanto mais indicado.

De acordo com Yim et al. (2011) a combinação de antimicrobianos com imipenem pode proporcionar uma opção de tratamento para infecções complicadas ocasionadas por Enterobacteriaceae produtoras de ESBL ou AmpC e que, a combinação de antimicrobianos pode reduzir o surgimento de resistência e elevar o espectro de atividade.

Para os casos de pneumonia nosocomial, o tratamento através de combinações de antimicrobianos pode ser uma opção, se for ocasionada por $P$. aeruginosa, Serratia, Enterobacter e Acinetobacter (Bouza, Muñoz, 2000).

\subsection{Pseudomonas aeruginosa}

Pseudomonas aeruginosa é um organismo Gram-negativo aeróbio e ubíquo, que dificilmente causa doenças em pessoas saudáveis (Hancock, Speert, 2000), 
porém é uma das principais espécies bacterianas que ocasionam infecção em pacientes hospitalizados (Goldberg, 2010).

Na América Latina Pseudomonas spp. é responsável por 7,5\% das infecções de corrente sanguínea, por $31,2 \%$ dos casos de pneumonia e, por $13,8 \%$ das infecções da pele e dos tecidos moles (Gales et al., 2012).

Sua importância se deve pela expressão de múltiplos mecanismos de resistência, dificultando a ação de antibacterianos, ocasionando elevados índices de morbidade e mortalidade (Gales et al., 2004; Lambert et al., 2011; Pellegrino et al., 2002; Poole, 2011; Sader et al., 2001).

Dentre os múltiplos mecanismos de resistência ressaltam-se: enzimas modificadoras de aminoglicosídeos, super expressão de bombas de efluxo, perda de porina, alterações no sítio alvo (Kanj, Kanafani, 2011; Muller et al., 2011; Poole, 2011; Strateva, Yordanov, 2009; Zavascki et al., 2010).

Esse microrganismo pode apresentar resistência natural ou adquirida a um grande número de antibióticos utilizados na prática clínica, como cefalosporinas de primeira e segunda geração, tetraciclinas, cloranfenicol e macrolídeos (Strateva, Yordanov, 2009; Yoneda et al., 2005). De acordo com Bouza e Muñoz (2000) mesmo as drogas com boa atividade contra $P$. aeruginosa não são sempre $100 \%$ eficientes contra ela.

$P$. aeruginosa pode co-produzir mecanismos de resistência para outra classe de antibióticos, como por exemplo, a proteína RmtD, uma metilase 16S RNAr (Doi et al., 2007) que confere um nível elevado de resistência a aminoglicosídeos utilizados clinicamente, como Amicacina, Tobramicina e Gentamicina. As metilases 16S RNAr favorecem a disseminação entre as espécies, uma vez que são associadas com elementos genéticos móveis, como os transposons (Doi et al., 2007; Yamane et al., 2007).

Outro mecanismo descreve a super expressão de bombas de efluxo, as quais têm como função exportar metabólitos secundários e substâncias tóxicas (incluindo os antibióticos), além de excretar moléculas sinalizadoras para a comunicação celular (Pearson et al., 1999; Poole, 2011; Strateva, Yordanov, 2009). A habilidade do efluxo favorece a sobrevivência da bactéria na presença de desinfetantes e de antibióticos (Poole, 2005). Além disso, P. aeruginosa pode ser intrinsecamente resistente a diversos antimicrobianos devido à expressão constitutiva de genes 
codificadores de bombas de efluxo para os mesmos (Neves et al., 2011; ; Poole, 2011; Strateva, Yordanov, 2009).

$P$. aeruginosa é produtora de biofilme, este é uma associação de bactérias em uma matriz polímera de polissacarídeos, DNA extracelular e proteínas. Seu biofilme permite o estabelecimento de comunicação entre as bactérias para a coordenação de atividades metabólicas, produção de fatores de virulência em recíproco benefício, protege contra o sistema de defesa do hospedeiro, dificulta a difusão de antibióticos e desinfetantes, além de permitir a troca de material genético (Lincopan, Trabulsi, 2008).

Segundo Hauser e Ozer (2011) as principais doenças clínicas relacionadas à Pseudomonas aeruginosa são: Infecções oculares, otológicas, respiratórias (acometendo também pacientes portadores de fibrose cística), do trato urinário, sanguíneas e de peles e tecidos moles (incluindo as feridas de pacientes com queimaduras).

\subsubsection{Pseudomonas aeruginosa e infecções em pacientes com queimaduras}

A queimadura é uma grave lesão, que acomete indivíduos, independente de sexo e de faixa etária, estando entre as principais causas de morbidade, devido ao desenvolvimento e sequelas, como a incapacidade funcional e deformidades estéticas; e a mortalidade, ocasionada pelas infecções, podendo progredir para septicemia, sendo de elevado grau de complexidade e de dificuldade de tratamento. As mais comuns causas de queimaduras são por escaldaduras, exposição às chamas, substâncias químicas, elétricas e radioativas, devido a atividades profissionais e/ou acidentes domésticos (De-Souza et al., 1998; Lacerda et al., 2010; Montes et al., 2011; Souza et al., 2009).

O ambiente hospitalar proporciona um grande número de fatores de riscos para os pacientes com queimaduras, possibilitando a infecção por microrganismos, que podem vir a se espalharem pela via linfática ou sanguínea, uma vez que a barreira mecânica que a pele oferece foi destruída. Ao mesmo tempo a lesão dos vasos sanguíneos na área afetada torna mais difícil a penetração de antibióticos e a chegada de células do sistema imune. Em $75 \%$ dos casos de óbitos de pacientes queimados, as infecções foram a grande responsável (Hammond et al., 2011; Macedo et al., 2005; Pruitt, McManus, 1992; Rempel et al., 2011). 
Dependendo da localização das queimaduras podem acontecer variados tipos de complicações, como oftalmológicas, neurológicas e geniturinárias, além disso, a inalação dos produtos da combustão, como gases tóxicos, causam inflamação com edema da mucosa traqueobrônquica, levando a lesões graves, piorando o prognóstico, aumentando assim a mortalidade (Vale, 2005). A incidência de complicações no tratamento das queimaduras geralmente é proporcional a extensão da área afetada (Macedo et al., 2005). O comprometimento da pele, a barreira física de proteção, interfere entre a microbiota normal e o tecido sadio, deixando o paciente suscetível a invasão de microrganismos patogênicos (Rempel et al., 2011).

Sendo assim, as queimaduras devem ser protegidas por agentes antimicrobianos de uso tópico para evitar a proliferação e migração dos microrganismos do tecido necrosado para as regiões sadias (Hammond et al., 2011; Pruitt, McManus, 1992).

Conforme Vale (2005), as queimaduras podem ser classificadas de acordo com a gravidade da lesão, como de primeiro grau, segundo grau ou terceiro grau. As características de cada grau podem ser observadas no Quadro 1. De acordo com Pruitt e McManus (1992), o patologista pode interpretar o estado da infecção por microrganismos através de um esquema, apresentado no Quadro 2. O aumento da mortalidade pode ser observado conforme o aumento do estágio.

Quadro 1 - Classificação das queimaduras segundo a profundidade

\begin{tabular}{|c|c|c|}
\hline $\begin{array}{l}\text { Primeiro grau } \\
\text { - Compromete apenas } \\
\text { a epiderme; } \\
\text { - Apresenta eritema, } \\
\text { calor e dor; } \\
\text { - Não há formação de } \\
\text { bolhas; } \\
\text { - Evolui com } \\
\text { descamação em } \\
\text { poucos dias; } \\
\text { - Regride sem deixar } \\
\text { cicatrizes; } \\
\text { Repercussão } \\
\text { sistêmica é } \\
\text { desprezível; } \\
\text { Não é considerada na } \\
\text { avaliação da área } \\
\text { atingida. }\end{array}$ & $\begin{array}{l}\text { Segundo grau } \\
\text { - } \quad \text { Compromete } \\
\text { totalmente a epiderme } \\
\text { e parcialmente a derme; } \\
\text { - } \quad \text { Apresenta dor, eritema, } \\
\text { edema, bolhas, erosão } \\
\text { ou ulceração; } \\
\text { - Há regeneração } \\
\text { espontânea; } \\
\text { Ocorre reepitelização a } \\
\text { partir dos anexos } \\
\text { cutâneos (folículos } \\
\text { pilosos e glândulas); } \\
\text { Cicatrização mais lenta } \\
\text { (2-4 semanas); } \\
\text { Pode deixar sequelas: } \\
\text { discromia (superficial), } \\
\text { cicatriz (profunda). }\end{array}$ & $\begin{array}{l}\text { Terceiro grau } \\
\text { Destrói todas as } \\
\text { camadas da pele, } \\
\text { atingindo até o } \\
\text { subcutâneo, podendo } \\
\text { atingir tendões, } \\
\text { ligamentos, músculos e } \\
\text { ossos; } \\
\text { Causa lesão branca ou } \\
\text { marrom, seca, dura, } \\
\text { inelástica; } \\
\text { É indolor; } \\
\text { Não há regeneração } \\
\text { espontânea, } \\
\text { necessitando de } \\
\text { enxertia; } \\
\text { Eventualmente pode } \\
\text { cicatrizar, porém com } \\
\text { retração das bordas. }\end{array}$ \\
\hline
\end{tabular}

Fonte: Adaptado de Vale (2005). 
Quadro 2 - Critérios para os estágios microbianos nas queimaduras

\begin{tabular}{|c|c|c|c|}
\hline \multicolumn{2}{|c|}{ Estágio I - Colonização } & \multicolumn{2}{|l|}{ Estágio II - Invasão } \\
\hline A - Superficial & $\begin{array}{l}\text { População microbiana esparsas na superficie } \\
\text { da queimadura; }\end{array}$ & A - Micro Invasäo & $\begin{array}{l}\text { Focos microscópicos de microrganismos em } \\
\text { tecido viável imediatamente subjacente a } \\
\text { escara }\end{array}$ \\
\hline B - Penetração & $\begin{array}{l}\text { Microrganismos presentes na variável } \\
\text { espessura da escara }\end{array}$ & B - Generalizada & $\begin{array}{l}\text { Penetração profunda generalizada de } \\
\text { microrganismos nos tecidos subcutâneos } \\
\text { viáveis }\end{array}$ \\
\hline C - Proliferação & $\begin{array}{l}\text { Densa populaçäo de microrganismos na } \\
\text { interface inviável/viável do tecido }\end{array}$ & C - Microvascular & $\begin{array}{l}\text { Envolvimento de vasos linfáticos e da } \\
\text { microvasculatura }\end{array}$ \\
\hline
\end{tabular}

Fonte: Adaptado de Pruitt e McManus (1992).

Devido à complexidade de tratamento das lesões ocasionadas pelas queimaduras, um elevado gasto do Sistema Único de Saúde (SUS) é necessário por paciente queimado internado. De acordo com Mello-Jorge e Koizumi (2004), o gasto médio diário por paciente queimado internado é de $R \$ 650,00$ (casos não fatais), e de $\mathrm{R} \$ 1.620,00$ diários para os casos que vão a óbito.

De acordo com os dados do SUS (2009), no Brasil, as queimaduras representam cerca de $1,6 \%$ do total de mortes decorrentes de causas externas, já em relação aos casos não fatais, representam cerca de $9 \%$ (80.607 pessoas) das internações no sistema público de saúde brasileiro, do grupo das causas externas.

Os patógenos mais encontrados em pacientes hospitalizados com queimaduras são: Pseudomonas aeruginosa, Staphylococcus aureus, Acinetobacter spp. e Candida spp. (Branski et al., 2009; Rempel et al., 2011). As infecções por Pseudomonas aeruginosa em pacientes queimados vai de pneumonias até bacteremias, tendo como fontes de origem a água, superfícies das grades das camas, o colchão do paciente, além de poder ocorrer através do contato pessoal, entre outras fontes (Rempel et al., 2011).

\subsubsection{Pseudomonas aeruginosa e fibrose cística}

A fibrose cística (ou mucoviscidose) é uma doença genética autossômica recessiva, que apresenta maior incidência em populações caucasianas de descendência europeia. Ela atinge vários sistemas do organismo e caracteriza-se por uma ampla disfunção das glândulas exócrinas. O paciente portador dessa doença possui secreções mucosas espessas e viscosas que, acabam por bloquear os canais das glândulas exócrinas. Essa obstrução contribui para o aparecimento de 
altos níveis de eletrólitos no suor, insuficiência pancreática (ocasionando um quadro secundário de desnutrição), diabetes mellitus, má absorção intestinal de gordura, comprometimento dos sistemas reprodutores e, doenças pulmonares obstrutivas crônicas (Fiates et al., 2001; Firmida, Lopes, 2011; Rosa et al., 2008).

Cerca de 70.000 pessoas no mundo são afetados pela fibrose cística (Cystic Fibrosis Foundation, 2012). De acordo com WHO (2004), a incidência de fibrose cística no Brasil é de 1 caso a cada 6.902 nascimentos. Um estudo de Raskin et al. (2008) indica que há um decréscimo na incidência de fibrocísticos da região Sul para a Sudeste do Brasil, uma vez que há mais pessoas com ascendência europeia no Sul.

As alterações do transporte iônico ocasionam um aumento das secreções mucosas, a hiperviscosidade dessas secreções e a consequente redução da atividade mucociliar nos pulmões, levando a uma diminuição da depuração das vias aéreas. Na fibrose cística as complicações respiratórias são as causas mais comuns de morbidade e mortalidade (Nichols et al., 2008).

Os microrganismos que mais acometem os pacientes com fibrose cística são: Staphylococcus aureus, Haemophilus influenza, Complexo Burkholderia Cepacia e Pseudomonas aeruginosa (Hauser et al., 2011; Lyczak et al., 2002).

Pseudomonas aeruginosa infecta tanto a zona respiratória quanto a zona condutora, além disso, ela pode acarretar em infecção crônica em pacientes com fibrose cística devido às mudanças adaptativas em seu modo de crescimento de não mucoide para mucoide (ocasionado por mutações), tornando-a mais resistente a fagocitose, reduzindo a função pulmonar, podendo levar a insuficiência respiratória e aumentando a mortalidade. Esse patógeno ocasiona lesões no epitélio, bloqueando progressivamente as vias aéreas (Doring et al., 2000; Lyczak et al., 2002; Perez et al., 2012).

O tratamento de infecções por $P$. aeruginosa é dificultado inicialmente por sua resistência intrínseca a muitos antibióticos e, tem-se especulado que parte de sua resistência seria devido à estrutura da sua parede celular, juntamente com a formação de biofilme, que oferece proteção contra o sistema imune e, a falta de eliminação da secreção espessa por pacientes com fibrose cística (Doring et al., 2000; Lyczak et al., 2002; Perez et al., 2012).

Devido a dificuldade de penetração e, algumas vezes do mau rendimento das drogas, seja por via oral, ou sistêmica, para o tratamento de doenças brônquicas e 
pulmonares, é necessário um novo método de administração, como a instituição de tratamento por via inalatória, o que pode ocasionar um maior efeito terapêutico e possivelmente diminuir os efeitos colaterais (Mariné, 2009).

A inalação, através de nebulizadores ou através de pó seco (“dry powder"), oferece diversos benefícios quando comparada aos métodos comuns de administração dos antimicrobianos, pois pode produzir altas concentrações dos antibióticos no sítio da infecção, sem o risco de toxicidade sistêmica, além disso, a inalação é menos incômoda aos pacientes, abrindo possibilidades para a utilização de drogas abandonadas por causarem elevada toxicidade, como a Polimixina $B$, e trazendo novas formas de uso de antibióticos, como Aztreonam, Levofloxacina e Fosfomicina (Labiris et al., 1999; Van Westreenen, Tiddens, 2010).

\subsection{Metalo-beta-lactamases (MßL)}

As MßLs pertencem à classe molecular $B$, de acordo com a classificação proposta por Ambler (1980). Esta classe de B-lactamases é caracterizada pela capacidade de hidrolisar carbapenêmicos e por sua resistência aos inibidores comercialmente disponíveis, como o ácido clavulânico, mas são inibidas por agentes ou compostos quelantes de íons de metal (Queenan, Bush, 2007).

A primeira metalo- $\beta$-lactamase codificada cromossomicamente foi descrita em 1966 (Sabath, Abraham, 1966), em uma amostra de Bacillus cereus. A segunda MßL foi descrita em 1982 em Stenotrophomonas maltophilia (Saino et al., 1982).

Osano et al. (1994) relatou o primeiro caso de MBL adquirida, descrevendo IMP-1 como uma nova subclasse. Essa enzima foi isolada no Japão, em uma cepa de Serratia marcescens, apresentando resistência ao imipenem.

No Brasil, os genes que codificam as MßL móveis já foram observados em vários patógenos clinicamente importantes, tais como os bacilos não fermentadores P. aeruginosa (Gales et al., 2003a; Lincopan et al., 2010) e Acinetobacter spp. (Gales et al., 2003b), e em várias espécies da família Enterobacteriaceae, como Klebsiella pneumoniae (Lincopan et al., 2005; 2006).

Pellegrino et al. (2002) relatou a primeira MßL adquirida no Brasil, entretanto o determinante da resistência não foi caracterizado. Em 2003 foi isolada uma cepa de $A$. baumannii produtora de IMP-1, em São Paulo (Gales et al., 2003b). 
Genes que codificam a MBL foram encontrados inseridos em estruturas genéticas que fornecem mobilidade ao gene. Seis grandes importantes grupos de MBL foram identificados: IMP (imipenemase) (Watanabe et al., 1991), VIM (Verona imipenemase) (Lauretti et al., 1999), SPM (São Paulo metalo-ß-lactamase) (Toleman et al., 2002), GIM (German imipenemase) (Castanheira et al., 2004), SIM (Seoul imipenemase) (Lee et al., 2005) e NDM (New Delhi metalo- $\beta$-lactamase) (Yong et al., 2009).

A primeira identificação do gene que codifica para a enzima SPM-1 ocorreu na cidade de São Paulo, Brasil (Toleman et al., 2002). Desde o seu primeiro relato, em clones de Pseudomonas aeruginosa produtora de SPM-1, ocorreu elevada mortalidade entre os pacientes hospitalizados (Furtado et al., 2011; Gales et al., 2003a; Queenan, Bush, 2007; Santos Filho et al., 2002; Zavascki et al., 2006). O gene desta enzima apresentou conteúdo GC na ordem de $47 \%$, indicando que ele tem uma procedência não intrínseca a $P$. aeruginosa (Toleman et al., 2002).

Atualmente apenas a enzima SPM-1 é codificada por um gene localizado em plasmídeo de aproximadamente $180 \mathrm{~kb}$ (Walsh et al., 2005), as demais enzimas MBL ficam em integrons da classe 1 (Mendes et al., 2006; Toleman et al., 2002).

A enzima SPM-1 hidrolisa todos os antimicrobianos $\beta$-lactâmicos, preferencialmente cefalosporinas, sendo incapaz de hidrolisar Aztreonam (Murphy et al., 2003). Até o presente período, SPM-1 só foi encontrada em $P$. aeruginosa e sua disseminação epidêmica já foi evidenciada em vários estados brasileiros (Gales et al., 2003a; Poirel et al., 2004; Zavascki et al., 2005). Salabi et al. (2010) publicou o primeiro caso de $P$. aeruginosa produtora de SPM-1 na Europa, de um paciente suíço que recebeu o primeiro atendimento em um hospital em Recife.

\subsection{Principais antimicrobianos utilizados no estudo}

\subsubsection{DDA - brometo de dioctadecildimetilamônio}

O brometo de dioctadecildimetilamônio (DDA) (Sigma-Aldrich, Saint Louis, EUA) é um lipídio catiônico, com duas longas cadeias hidrocarbonadas $\left(\mathrm{C}_{18}\right)$ altamente hidrofóbica e uma cabeça polar catiônica hidrofílica com um contra-ión monovalente $\left(\mathrm{Br}^{-}\right)$, Figura 3A. Suas cadeias hidrofóbicas the permitem formar 
bicamadas em solução aquosa, o método de preparação determina as propriedades físicas e funcionais das vesículas ou dos fragmentos de bicamada formados. Mediante o uso da metodologia de sonicação com sonda (Tip) formam-se vesículas unilamelares pequenas ou fragmentos de bicamada assim como também vesículas interrompidas. Fragmentos de bicamada oferecem convenientemente uma grande área de nano superfícies hidrofóbicas adequadas para a solubilização de substâncias hidrofóbicas ou fármacos (Lincopan et al., 2004).

Vesículas de bicamadas de DDA têm sido usadas de diversas maneiras, seja como agentes de interface e imunoadjuvantes, como agentes biocidas contra bactérias e fungos. Estas características são atribuídas ao fato delas possuírem uma região altamente hidrofóbica que lhe permite interagir com diversos compostos (Lincopan et al., 2003).

Figura 3 - Estrutura química do DDA (A) e Tigeciclina (B).

A<smiles>CCCCCCCCCCCCCCCCCCCCCCCCCCCCC[N+](C)(C)CCCCCCCCCCC</smiles>

B<smiles>CN(C)c1cc(NC(=O)CNC(C)(C)C)c(O)c2c1C[C@H]1C[C@H]3[C@H](N(C)C)C(O)=C(C(N)=O)C(=O)[C@@]3(C)C(O)=C1C2=O</smiles>

Fonte: Adaptado de Lincopan e Carmona (2006); Livermore (2005).

\subsubsection{Tigeciclina}

A Tigeciclina é o primeiro antibiótico da nova classe das glicilciclinas (Figura 3B). As glicilciclinas tem estrutura semelhante às tetraciclinas, possuindo alterações estruturais. Apresenta atividade contra gram-positivos, gram-negativos, espécies anaeróbias, incluindo cepas multirresistentes (Rose, Rybak, 2006). Ela é alvo das bombas de efluxo cromossomicamente codificadas, como em Proteeae e Pseudomonas aeruginosa. Sua função é de inibir a síntese proteica através da união à subunidade do ribossomo bacteriano 30S. A Tigeciclina é considerada um 
antibiótico bacteriostático (Livermore, 2005), tem um grande potencial de utilidade, mas nem sempre é eficaz em monoterapia (Yim et al., 2011). As indicações permitidas pelo FDA são infecções de pele e tecidos moles complicadas e infecções intrabdominais complicadas (Rodvold et al., 2006).

A estrutura química da Tigeciclina é demonstrada na figura 3B. A Tigeciclina é um composto altamente solúvel em uma ampla faixa de $\mathrm{pH}$ devido sua estrutura química apresentar diversos grupos ionizáveis com diferentes valores de pKa. No interior da molécula, existem três grupamentos básicos e dois acídicos. Os valores de pKa de cada um desses grupamentos variam de 2.8 à 9.5. Portanto, a solubilidade da Tigeciclina é independente do $\mathrm{pH}$ devido sua estrutura química apresentar grupamentos químicos que se ionizam em uma ampla faixa de pH (FDA, 2005). Esta característica é de interesse uma vez que, dependendo da faixa de $\mathrm{pH}$, a molécula pode estar protonada ou desprotonada favorecendo interações eletrostáticas com biomoléculas que podem ser carregadoras de drogas, favorecendo possíveis efeitos sinérgicos.

\subsubsection{Piperacilina-Tazobactam}

A Piperacilina é uma Penicilina semi-sintética da classe ureidopenicilina, com atividade bactericida pela inibição da formação do septo e síntese da parede celular, que possui amplo espectro de ação contra infecções ocasionadas por anaeróbios, Gram positivos e Gram negativos, incluindo isolados de Pseudomonas aeruginosa (Lister, 2000). Segundo Noguchi et al. (1979), a Piperacilina tem alta afinidade pela PBP-3 tanto em E. coli quanto em P. aeruginosa.

A Piperacilina foi diminuindo sua utilidade conforme bactérias produtoras de $\beta$ lactamase foram surgindo. O Tazobactam, um poderoso inibidor de várias enzimas $\beta$-lactamases cromossomais ou mediadas por plasmídeos, é um triazolilmetil penicilânico sulfônico. Ele foi associado à Piperacilina para aumentar sua atividade, passando a cobrir um número maior de bactérias produtoras de $\beta$-lactamase que, sem essa associação, seriam resistentes a Piperacilina (Drawz, Bonomo, 2010; Fass, Prior, 1989; Lister, 2000; Strayer et al., 1994).

Devido a sua ampla cobertura, Piperacilina/Tazobactam é altamente recomendado para infecções intra-abdominais, pneumonia hospitalar e infecções de pele e tecidos moles (Mah et al., 2012). 
Aztreonam é um antibiótico sintético bactericida, pertencente à classe dos monobactâmicos, que possui atividade contra uma grande variedade de bactérias Gram-negativas, incluindo membros da família Enterobacteriaceae e Pseudomonas aeruginosa, mas possui pouca atividade contra anaeróbios ou aeróbios Grampositivos (Fleiss et al., 1985; Ng et al., 1985; Romero-Vivaz et al., 1985). Além do uso sistêmico, novas formulações têm sido aprovadas para o Aztreonam, como o Aztreonam lisina para inalação (Zeitler et al., 2012).

O mecanismo de ação desse antibiótico é devido a grande afinidade de ligação com a PBP-3, ocasionando o efeito bactericida em enterobactérias e Pseudomonas aeruginosa (Georgopapadakou et al., 1982).

Adicionalmente, o Aztreonam é bastante resistente as principais $\beta$-lactamases (cromossomais e plasmidiais) estudadas e, reduz distúrbios gastrointestinais, uma vez que pouco interfere com a microbiota normal de Gram-positivos e anaeróbios (Sykes et al., 1982).

\subsection{Justificativa}

São múltiplos os mecanismos de resistência que podem ser expressos por Pseudomonas aeruginosa: super expressão de bombas de efluxo, perda de porina, enzimas modificadoras de drogas, alterações no sítio alvo e produção de biofilme. Dentre as enzimas modificadoras encontram-se: enzimas modificadoras de aminoglicosídeos e diferentes beta-lactamases, entre elas, a Metalo-beta-lactamase. Esses mecanismos conferem uma resistência natural ou adquirida a um grande número de antibióticos utilizados na prática clínica para esse microrganismo, dificultando o tratamento de suas mais diversas infecções e reduzindo consideravelmente as opções terapêuticas. Considerando as poucas opções de tratamento nos casos de infecções por $P$. aeruginosa MR, esse trabalho estudou combinações de antimicrobianos que pudessem alcançar efeitos sinérgicos, para permitir possíveis alternativos esquemas terapêuticos. 


\section{OBJETIVOS}

\subsection{Objetivo geral}

Avaliar, in vitro, o efeito sinérgico de diferentes combinações de antimicrobianos para o estabelecimento de esquemas terapêuticos alternativos no tratamento de infecções por Pseudomonas aeruginosa multirresistentes endêmicas no Brasil.

\subsection{Objetivos específicos}

Diferentes classes de antibióticos e suas combinações antibacterianas foram avaliadas contra cepas clínicos de Pseudomonas aeruginosa MR, produtores de metalo-ß-lactamase (SPM-1, GIM-1 e VIM-1), recuperados de diferentes hospitais brasileiros, tendo como objetivos específicos:

1. Verificar o perfil de susceptibilidade para carbapenêmicos, cefalosporinas de terceira e quarta geração, aminoglicosídeos, quinolonas, polimixinas.

2. Demonstrar a ação sinérgica da combinação de dois antimicrobianos pelo teste de "Checkerboard" usando o método de microdiluição em caldo para obtenção do índice de concentração inibitória fracional (FIC) como medida de efeito sinérgico.

3. Avaliar a potência, in vitro, de combinações antibacterianas mediante o método de curvas de morte ("Time-Kill”). 


\section{MATERIAIS E MÉTODOS}

\subsection{Cepas bacterianas}

Foram selecionadas um total de 10 cepas de Pseudomonas aeruginosa. Todas elas foram previamente isoladas e não são clonalmente relacionadas.

A maioria das cepas é caracterizada como endêmicas em diferentes centros hospitalares brasileiros, apresentando perfil de multirresistência aos beta-lactâmicos, aminoglicosídeos e quinolonas (Neves, 2010). Entre as dez cepas selecionadas está inclusa a cepa de $P$. aeruginosa isolada na Alemanha, produtora da variante $\mathrm{M} \beta \mathrm{L}$ GIM-1.

Dentre as dez cepas utilizadas, temos a cepa PA01, cedida pela Profa. Dra. Sílvia F. Costa (Laboratório de Bacteriologia, HC, FMUSP) e nove cepas produtoras de $M \beta L$.

Das nove cepas produtoras de MBL foi utilizada a cepa 48-1997A SPM-1, cedida pela Profa. Dra. Ana Gales (Laboratório ALERTA, UNIFESP/EPM), a cepa PA0905, cedida pela Profa. Dra. Doroti O. Garcia (Instituto Adolfo Lutz) e a PA GIM1, cedida pela Profa. Dra. Mariana Castanheira (Castanheira et al., 2004).

As seis cepas restantes, também não clonalmente relacionadas, foram cedidas pela Dra. Patrícia Neves, conforme pode ser observado no Quadro 3.

Quadro 3 - Cepas cedidas pela Dra. Patrícia Neves.

\begin{tabular}{|c|c|c|}
\hline \multirow{2}{*}{ Cepas } & \multicolumn{2}{|c|}{ Genótipo de Resistência } \\
\hline & bla $a_{\mathrm{MBL}}$ & RNAr 16S \\
\hline $44 \mathrm{CIB}$ & bla $a_{\mathrm{SPM}-1}$ & $r m t D$ \\
\hline 111ER & bla $a_{\mathrm{SPM}-1}$ & $r m t D$ \\
\hline $36 \mathrm{C}$ & blasPM-1 & $r m t D$ \\
\hline $31 \mathrm{C}$ & blasPM-1 & $r m t D$ \\
\hline $10 \mathrm{C}$ & bla $a_{\mathrm{SPM}-1}$ & $r m t D$ \\
\hline $247 \mathrm{~B}$ & blavim -1 & - \\
\hline
\end{tabular}

Fonte: Adaptado de Neves (2010). 
Como cepas controle foram utilizadas Escherichia coli ATCC 25922 e Escherichia coli ATCC 35218 (para combinações de beta-lactâmicos com inibidores de beta-lactamase), conforme CLSI (2011).

\subsection{Condições de cultivo e armazenamento das cepas}

As cepas foram semeadas em ágar MacConkey (Oxoid, Hampshire, England), e incubadas por $24 \mathrm{~h}$ em estufa controlada a $37^{\circ} \mathrm{C}$. As colônias foram semeadas em $2 \mathrm{~mL}$ de caldo $\mathrm{BHI}$ (infusão cérebro-coração) e incubadas a $37^{\circ} \mathrm{C}$, por 24 horas sob agitação constante em shaker rotativo a $150 \mathrm{rpm}$. O resultado dessa semeadura foi acrescido de $20 \%$ de glicerol e congelado para preservação.

\subsection{Testes de sensibilidade de antimicrobianos pelo método "Kirby-Bauer"}

Foram realizados antibiogramas para a determinação do perfil de resistência das cepas de Pseudomonas aeuruginosa através o método de "Kirby-Bauer", seguindo as normas padronizadas do CLSI (2009). O critério de interpretação foi feito de acordo com o estabelecido pelo CLSI (2011), a fim de obter o perfil de resistência para os antibióticos Imipenem $(10 \mu \mathrm{g})$, Meropenem $(10 \mu \mathrm{g})$, Ceftazidima (30 $\mu \mathrm{g})$, Amicacina $(30 \mu \mathrm{g})$, Ciprofloxacina $(5 \mu \mathrm{g})$, Aztreonam $(30 \mu \mathrm{g})$, Piperacilina/Tazobactam (100/10 $\mu \mathrm{g})$, Cefepima (30 $\mu \mathrm{g})$, Gentamicina $(10 \mu \mathrm{g})$, Tigeciclina (15 $\mu \mathrm{g}$ ), Levofloxacina (5 $\mu \mathrm{g})$, Polimixina (300 UI) e Colistina (10 $\mu \mathrm{g})$, os discos foram cedidos pela Cefar (Sensifar-Cefar, Diagnóstica, São Paulo, Brasil). Para Tigeciclina, foi usado o critério de interpretação para Enterobacteriaceae do EUCAST (2012a), assim como o controle de qualidade EUCAST (2012b).

\subsection{Determinação da concentração inibitória mínima (CIM)}

Para determinação da concentração inibitória mínima (CIM) foi empregado o método de microdiluição em caldo, seguindo as normas padronizadas do CLSI (2009). As colônias foram inoculadas em um caldo de crescimento, incubado a $35 \stackrel{\circ}{\circ}$ até alcançar a turbidez padrão de 0,5 de McFarland $\left(\sim 1 \times 10^{8} \mathrm{UFC} / \mathrm{mL}\right)$. Foram realizadas diluições seriadas dos antimicrobianos em caldo Mueller-Hinton, já para Polimixina B foi utilizado Mueller-Hinton cátio ajustado (Difco, Le Pont de Claix, 
France) e plaqueado $100 \mu \mathrm{L}$ de cada concentração em poços de placa de ELISA estéril. Foi acrescentado $5 \mu \mathrm{L}$ do inóculo diluído 1:10 que foi previamente preparado na escala 0,5 de McFarland. Os critérios de interpretação foram baseados no documento CLSI (2011). Para Tigeciclina, o critério de interpretação e controle de qualidade foi baseado no EUCAST (2012a).

\subsection{Teste de sinergismo pelo método de microdiluição em caldo ("Checkerboard")}

Para realizar a combinação de vários antimicrobianos para as cepas multirresistentes foi utilizado o método de microdiluição em caldo, seguindo as normas padronizadas do CLSI (2009), sendo executado em triplicata.

Cada bactéria foi inoculada em Mueller-Hinton, incubado a 35ํㅡ até alcançar a turbidez padrão de 0,5 de McFarland. As diluições dos antibióticos foram feitas em caldo Mueller-Hinton. Em seguida esta suspensão foi pipetada em cada poço de uma placa de ELISA estéril, acrescentando-se a mesma concentração do segundo antibiótico. Posteriormente $5 \mu \mathrm{L}$ do inóculo 1:10, que foi previamente preparado na escala 0,5 de McFarland, foi acrescentado em cada poço da microplaca. As microplacas com as diferentes combinações de antibióticos, nas diferentes concentrações, foram incubadas por 24 horas. A leitura foi feita observando turvação macroscópica visível, levando-se em consideração os breakpoints (pontos de corte) recomendados pelo CLSI (2011). Para Tigeciclina, o critério de interpretação e controle de qualidade foi baseado no EUCAST (2012). O mesmo protocolo foi utilizado quando foi testado o DDA, porém, na preparação das diluições foi utilizado um meio de baixa força iônica [tampão IGP (Isotonic Glucose Phosphate), solução isotônica de glicose e fosfato] em vez do caldo Mueller-Hinton.

A interpretação do sinergismo entre os antimicrobianos foi medida pelo índice de concentração inibitória fracional (FIC), onde o FIC menor ou igual a 0,5 corresponde ao sinergismo, FIC maior a 4,0 equivale ao antagonismo, e FIC maior que 0,5 e menor que 4,0 equivale a indiferença (HALL et al., 1983). O FIC é calculado seguindo a fórmula: $F I C=F I C A+F I C B=(A) /(C I M A)+(B) /(C I M B)$, sendo que "A" representa a menor concentração inibitória do antimicrobiano $A$ em combinação, e "CIM A" é a menor concentração inibitória do antimicrobiano A sozinho (o mesmo se aplica para o antimicrobiano B). 
Os antimicrobianos avaliados independentemente e em combinação foram: Piperacilina/Tazobactam, Imipenem, Aztreonam, Amicacina, Polimixina B, Levofloxacina, Tigeciclina e nanofragmentos do lipídio catiônico brometo de dioctadecildimetilamônio (DDA).

\subsection{Realização de atividade bactericida (Concentração Bactericida Mínima - CBM)}

Foi preparada uma diluição seriada seguindo as normas padronizadas do CLSI/NCCLS (2003). A turbidez do inóculo foi ajustada na escala 0,5 de McFarland. Foi preparada diluição seriada seguindo as normas padronizadas do CLSI. Foi realizada uma subcultura de uma alíquota de cada poço correspondendo à CIM, em placa de Ágar Mueller-Hinton (Oxoid, Hampshire, England) sem antibiótico, sendo incubadas por 18-24 horas. A atividade bactericida foi interpretada como a mínima concentração do antimicrobiano em diluição produzindo inibição do crescimento macroscopicamente visível (menor ou igual a 99,9\%) (Lorian, 1980).

Também foi utilizado um indicador fluorescente/calorimétrico com propriedade redox, Alamar Blue ${ }^{\circledR}$ (também denominado resazurin) (Sigma Chemical Co, St Louis, USA) para medir a atividade bactericida. O Alamar Blue foi preparado segundo Nateche et al. (2006) e $30 \mu \mathrm{L}$ da solução foi adicionado em cada poço da microplaca, sendo posteriormente incubada. A leitura foi feita $24 \mathrm{~h}$ depois, e interpretada como a mínima concentração do antimicrobiano em diluição produzindo inibição do crescimento macroscopicamente visível, sendo a forma oxidada azul (célula não viável/não fluorescente) e a forma reduzida rosa (célula viável/fluorescente).

Nos testes em que o DDA foi avaliado, foi estimada a CBM como resultado do ensaio de CIM e, a interpretação foi medida através do índice de concentração bactericida fracional (FBC), seguindo as mesmas interpretações do FIC, utilizadas no "Checkerboard".

\section{7 "Time-Kill"}

O estudo de "Time-Kill" foi realizado com os antimicrobianos utilizados no teste de sinergismo ("Checkerboard") que obtiveram efeito sinérgico. A técnica 
proposta por Giamarellos-Bourboulis et al. (1997), foi utilizada para realizar a curva de morte em função do tempo. As concentrações de antimicrobianos foram determinadas de acordo com os valores obtidos na atividade bactericida das combinações que apresentaram efeito sinérgico através do teste de "Checkerboard". $\mathrm{Na}$ microplaca as CIMs, dos antibióticos, o ponto sinérgico e o controle positivo foram reproduzidos na concentração aproximada de $5 \times 10^{5} \mathrm{UFC} / \mathrm{mL}$, nos tempos 0 , 1, 6, 12 e 24 horas. Foi retirado $10 \mu \mathrm{L}$ de cada um desses pontos para atingir a concentração aproximada de $5 \times 10^{3} \mathrm{UFC} / \mathrm{mL}$, a partir desta concentração, foram feitas diluições seriadas de 1:10 e 1:100 a partir da concentração anterior em caldo Mueller-Hinton (o mesmo protocolo foi utilizado para DDA, porém, na preparação das diluições foi utilizado o tampão IGP em vez do caldo Mueller-Hinton). Em seguida foi retirado $100 \mu \mathrm{L}$ de cada diluição e semeado com alça de Drigalski em ágar MacConkey para cada uma das diluições $\left(10^{-1}, 10^{-2}\right.$ e $\left.10^{-3}\right)$, tanto para 0 controle quanto para a $P$. aeruginosa nos tempos 0 e 1 hora. Nos tempos 6, 12 e 24 horas foram semeadas somente as diluições $10^{3}$ e $10^{2}$ para a $P$. aeruginosa e para o controle positivo foram semeadas as diluições $10^{-1}, 10^{-2}$ e $10^{-3}$. As placas foram incubadas a $37^{\circ} \mathrm{C}$. A leitura foi realizada através da contagem direta nas placas de cada diluição, no seu respectivo tempo e depois o cálculo foi feito para a obtenção do número de UFC/mL.

\subsection{Preparação dos nanofragmentos de bicamada de DDA}

Os ensaios utilizando nanofragmentos de bicamada de DDA (Sigma Chemical Co, St Louis, USA) foram realizados utilizando tampão IGP (Isotonic Glucose Phosphate, 1mM de Tampão Fosfato de Potássio, pH 7.0 suplementado com 287 $\mathrm{mM}$ de glicose). Um litro deste tampão foi preparado através de uma mistura de fosfato de potássio monobásico $1 \mathrm{M}\left(\mathrm{KH}_{2} \mathrm{PO}_{4}\right)$ e fosfato de potássio dibásico $\left(\mathrm{K}_{2} \mathrm{HPO}_{4}\right) 1 \mathrm{M}(615 \mu \mathrm{L}$ e $385 \mu \mathrm{L}$, respectivamente), adicionado com 51,66g de glicose (Lincopan e Carmona-Ribeiro, 2006). A concentração utilizada do DDA foi 0,5 $\mathrm{mg} / \mathrm{mL}$ em tampão IGP. $25 \mathrm{mg}$ de DDA foram colocados em $50 \mathrm{~mL}$ de tampão IGP. Posteriormente vesículas de DDA formadas em solução aquosa foram rompidas por sonicação com macrotip (25\% de amplitude durante 25 minutos a temperatura ambiente) (Sonics Vibra Cell - Sonics \&. Materials, VC x 500, Newtown, CT, USA) para formação de nanofragmentos de bicamada coloidalmente estáveis. Após a 
sonicação, a solução foi centrifugada a $10.000 \mathrm{rpm}$ por 1 hora, sendo posteriormente filtrada em tubo Falcon $50 \mathrm{~mL}$, usando um filtro Millipore de 0,45 $\mu \mathrm{m}$ de diâmetro.

\subsection{Caracterização físico-química por "Light Scattering" e Potencial Zeta}

Os ensaios de "Light Scattering" (DLS ou Espalhamento de Luz Dinâmico) e Potencial Zeta foram conduzidos com o objetivo de inferir sobre a interação entre compostos apresentando atividade sinérgica, in vitro, assim como, para caracterizar interações antibacteriano-DDA, antibacteriano- $P$. aeruginosa, DDA- $P$. aeruginosa. A técnica "Light Scattering" permite determinar a distribuição de tamanhos das partículas em dispersão [diâmetro médio $(D z)$ ] e elas são medidas em escala manométrica. Esta técnica permite, também, a análise do grau de associação e dissociação entre elas (polidispersão) mediante o uso de luz dinâmica, já o Potencial Zeta fornece dados sobre a carga superficial (em $\mathrm{mV}$ ) destas partículas, permitindo inferir sua interação molecular por forças de interação mediada por atração eletrostática e/ou hidrofobicidade. Todas as análises foram realizadas usando o equipamento ZetaPlus-Zeta Potential Analyzer (Brookhaven Instruments Corporation, Holtsville, NY). A bactéria e todos os compostos foram preparados em água deionizada qualidade Milli-Q e/ou em IGP (Isotonic Glucose Phosphate). A P. aeruginosa foi preparada na escala 0,5 de McFarland e os compostos utilizados foram: Tigeciclina nas concentrações de 0,6 mg/mL, $2 \mu \mathrm{g} / \mathrm{mL}$ e $16 \mu \mathrm{g} / \mathrm{mL}$, DDA nas concentrações de $2 \mathrm{mM}$ e $4 \mu \mathrm{g} / \mathrm{mL}$. Após essa preparação foram feitas as seguintes combinações, todas com volume final de $1 \mathrm{~mL}$ : Tigeciclina a $16 \mu \mathrm{g} / \mathrm{mL}$ (o valor da CIM) e $P$. aeruginosa; DDA a $2 \mathrm{mM}$; Tigeciclina a $2 \mu \mathrm{g} / \mathrm{mL}$ e DDA $4 \mu \mathrm{g} / \mathrm{mL}$ (condições do sinergismo) e $P$. aeruginosa; Tigeciclina e DDA; $P$. aeruginosa, DDA e Tigeciclina também nas condições do sinergismo obtido previamente pelo método "Time Kill". As leituras foram feitas após trinta minutos de interação.

\subsection{Espectrofotometria UV Visível}

O ensaio de espectrofotometria UV visível foi realizado para avaliar mudanças conformacionais na Tigeciclina, decorrentes da interação com DDA. Essa técnica permite verificar a absorção da amostra, utilizando luz UV visível, em uma faixa de 
comprimentos de onda. O espectro UV visível da Tigeciclina associada ou não a nanofragmentos de DDA foi monitorado em um cumprimento de onda de 200 a 500 nm (Beckman DU 640 Spectrophotometer, Palo Alto, CA, USA), nas seguintes concentrações: $32,16,8,4,2$ e $1 \mu \mathrm{g} / \mathrm{mL}$. O DDA foi analisado nas concentrações: 64, 32, 16, 8, 4 e $2 \mu \mathrm{g} / \mathrm{mL}$, mantendo a proporção 2:1 DDA:Tigeciclina. Os valores finais das concentrações de ambos os compostos foram selecionados mantendo a proporção das concentrações individuais dos compostos na combinação resultante em efeito sinérgico.

\subsection{Teste Confirmatório de Sinergismo}

Para as combinações que demonstraram um efeito sinérgico, através do Teste de Sinergismo, foi realizado um experimento adicional para confirmação. Os antibióticos avaliados foram submetidos a diluições seriadas no caldo Mueller-Hinton em concentrações duas vezes acima e abaixo das CIMs anteriormente obtidas. Por exemplo, se a CIM fosse $16 \mu \mathrm{g} / \mathrm{mL}$, as concentrações avaliadas seriam: 4, 8, 16, 32 e $64 \mu \mathrm{g} / \mathrm{mL}$. O volume final foi de $20 \mathrm{~mL}$ de meio Ágar Mueller-Hinton e todas preparadas entre 45-50 ${ }^{\circ} \mathrm{C}$, homogeneizadas e vertidas em placas de petri estéreis. Cada cepa foi inoculada em caldo de cultura, incubado a $35{ }^{\circ} \mathrm{C}$ até alcançar a turbidez padrão de 0,5 de McFarland e então com auxílio de um swab as placas foram inoculadas. Paralelamente foi realizado o controle, no qual as bactérias foram inoculadas em placas desprovidas da droga no ágar. Posteriormente foi acrescentado os discos de antibióticos referentes às combinações com efeitos sinérgicos e incubados por 18-24 h. Foi selecionada a concentração que, dentre as diferentes concentrações de antibióticos no ágar, foi a primeira a permitir a formação do tapete e dos halos.

A concentração que permitiu a formação dos halos foi utilizada em uma nova placa, semeada, adicionada da fita de E-test (BioMérieux, Marcyl'Étoile, France) correspondente a combinação sinérgica e incubada. Uma outra placa controle, sem antibiótico no ágar, foi inoculada, acrescentada da fita de E-test e também incubada.

A leitura foi realizada a partir da observação da diminuição da CIM através da formação dos halos elípticos na placa que contém o antibiótico no ágar e comparada a placa sem antibiótico adicionado ao ágar. 


\section{RESULTADOS}

\subsection{Antibiograma}

Inicialmente, as nove cepas produtoras de MßL (Materiais e Métodos, seção 3.1) foram avaliadas pelo método de "Kirby-Bauer" e interpretadas de acordo com CLSI (2011), exceto a Tigeciclina, a qual foi avaliada usado os critérios para Enterobacteriaceae do EUCAST (2012a). As cepas apresentaram um perfil de multirresistência aos antimicrobianos habitualmente usados em planos terapêuticos normais para infecções por P. aeruginosa (i.e., Imipenem, Meropenem, Gentamicina, Ciprofloxacina e Ceftazidima) (Quadro 4).

Quadro 4 - Sensibilidade antimicrobiana de 10 cepas a 12 antimicrobianos.

\begin{tabular}{|lccccccccccccc|}
\hline \multirow{1}{*}{ CEPAS } & \multicolumn{1}{c}{ Antibiograma } \\
\cline { 2 - 11 } & CAZ & IPM & MER & AMI & TGC* & GEN & CIP & LVX & ATM & CPM & PPT & POL & CT \\
\hline PA01 & $\mathrm{S}$ & $\mathrm{S}$ & $\mathrm{S}$ & $\mathrm{S}$ & $\mathrm{R}$ & $\mathrm{S}$ & $\mathrm{S}$ & $\mathrm{S}$ & $\mathrm{S}$ & $\mathrm{S}$ & $\mathrm{S}$ & $\mathrm{S}$ & $\mathrm{S}$ \\
48-1997A (SPM-1) & $\mathrm{R}$ & $\mathrm{R}$ & $\mathrm{R}$ & $\mathrm{R}$ & $\mathrm{R}$ & $\mathrm{R}$ & $\mathrm{R}$ & $\mathrm{R}$ & $\mathrm{S}$ & $\mathrm{R}$ & $\mathrm{R}$ & $\mathrm{S}$ & $\mathrm{S}$ \\
111ER (SPM-1) & $\mathrm{R}$ & $\mathrm{R}$ & $\mathrm{R}$ & $\mathrm{R}$ & $\mathrm{R}$ & $\mathrm{R}$ & $\mathrm{R}$ & $\mathrm{R}$ & $\mathrm{S}$ & $\mathrm{R}$ & $\mathrm{R}$ & $\mathrm{S}$ & $\mathrm{S}$ \\
44CIB (SPM-1) & $\mathrm{R}$ & $\mathrm{R}$ & $\mathrm{R}$ & $\mathrm{R}$ & $\mathrm{R}$ & $\mathrm{R}$ & $\mathrm{R}$ & $\mathrm{R}$ & $\mathrm{S}$ & $\mathrm{R}$ & $\mathrm{R}$ & $\mathrm{S}$ & $\mathrm{S}$ \\
36C (SPM-1) & $\mathrm{R}$ & $\mathrm{R}$ & $\mathrm{R}$ & $\mathrm{R}$ & $\mathrm{R}$ & $\mathrm{R}$ & $\mathrm{R}$ & $\mathrm{R}$ & $\mathrm{S}$ & $\mathrm{R}$ & $\mathrm{R}$ & $\mathrm{S}$ & $\mathrm{S}$ \\
31C (SPM-1) & $\mathrm{R}$ & $\mathrm{R}$ & $\mathrm{R}$ & $\mathrm{R}$ & $\mathrm{R}$ & $\mathrm{R}$ & $\mathrm{R}$ & $\mathrm{R}$ & $\mathrm{S}$ & $\mathrm{R}$ & $\mathrm{R}$ & $\mathrm{S}$ & $\mathrm{S}$ \\
10C (SPM-1) & $\mathrm{R}$ & $\mathrm{R}$ & $\mathrm{R}$ & $\mathrm{R}$ & $\mathrm{R}$ & $\mathrm{R}$ & $\mathrm{R}$ & $\mathrm{R}$ & $\mathrm{S}$ & $\mathrm{I}$ & $\mathrm{R}$ & $\mathrm{S}$ & $\mathrm{S}$ \\
PA0905 (SPM-1) & $\mathrm{R}$ & $\mathrm{R}$ & $\mathrm{R}$ & $\mathrm{R}$ & $\mathrm{R}$ & $\mathrm{R}$ & $\mathrm{R}$ & $\mathrm{R}$ & $\mathrm{S}$ & $\mathrm{R}$ & $\mathrm{R}$ & $\mathrm{S}$ & $\mathrm{S}$ \\
Pa 247B (VIM-1) & $\mathrm{R}$ & $\mathrm{R}$ & $\mathrm{R}$ & $\mathrm{S}$ & $\mathrm{R}$ & $\mathrm{R}$ & $\mathrm{R}$ & $\mathrm{R}$ & $\mathrm{S}$ & $\mathrm{I}$ & $\mathrm{R}$ & $\mathrm{S}$ & $\mathrm{S}$ \\
Pa GIM-1 & $\mathrm{R}$ & $\mathrm{R}$ & $\mathrm{R}$ & $\mathrm{I}$ & $\mathrm{R}$ & $\mathrm{R}$ & $\mathrm{R}$ & $\mathrm{R}$ & $\mathrm{S}$ & $\mathrm{R}$ & $\mathrm{R}$ & $\mathrm{S}$ & $\mathrm{S}$ \\
\hline
\end{tabular}

Nota: CAZ (Ceftazidima), IPM (Imipinem), MER (Meropenem), AMI (Amicacina), GEN (Gentamicina), CIP (Ciprofloxacina), LVX (Levofloxacina), ATM (Aztreonam), CPM (Cefepima), PPT (Piperacilina/Tazobactam), POL (Polimixina B), CT (Colistina), TGC (Tigeciclina). R, resistente; I, intermediário; S, sensível.

Fonte: CLSI (2011), (*) EUCAST (2012a).

\subsection{Concentração Inibitória Mínima e Sinergismo}

Foram testadas 14 combinações de antimicrobianos, realizados em triplicata, inicialmente para as duas cepas de Pseudomonas aeruginosa multirresistentes, coprodutoras de metalo-beta-lactamase SPM-1 e metilase RNAr 16S RmtD [111ER e 
44CIB], conforme mostrado na Tabela $1 \mathrm{e}$, as combinações que apresentaram efeito sinérgico para essas duas cepas foram então testadas para as demais (PA01, 481997A SPM-1, 36C, 31C, 10C, VIM-1 247B, PA0905 e PA GIM-1).

As combinações que apresentaram sinergismo, in vitro, para as cepas 111ER e 44CIB foram: [Piperacilina/Tazobactam x Aztreonam], [Amicacina $x$ Polimixina B] e [Tigeciclina x DDA].

São apresentados os resultados dos efeitos sinérgicos das combinações [Tigeciclina $x$ DDA] na Tabela 2, [Piperacilina/Tazobactam $x$ Aztreonam] na Tabela 3, e [Amicacina $x$ Polimixina B] na Tabela 4, realizados em triplicata para as 10 cepas de $P$. aeruginosa.

A combinação [Tigeciclina $\times$ DDA] foi sinérgica para as 10 cepas e, a combinação [Piperacilina/Tazobactam $x$ Aztreonam] foi sinérgica para nove cepas (PA01, 111ER, 44CIB, 48-1997A SPM-1, 36C, 31C, 10C, VIM-1 247B e PA GIM-1). Já, a combinação [Polimixina $B \quad x$ Imipenem], [Levofloxacina $x$ Piperacilina/Tazobactam], [Levofloxacina $x$ DDA] e [Amicacina $x$ DDA] foram sinérgicos apenas para a cepa 111ER e, [Imipenem x Piperacilina/Tazobactam] foi sinérgica apenas para a cepa 44CIB.

As combinações [Aztreonam x Polimixina B], [Amicacina $\times$ Aztreonam], [Piperacilina/Tazobactam $x$ Polimixina B], [Levofloxacina $x$ Imipenem], [Levofloxacina $x$ Polimixina B] e [Aztreonam x Levofloxacina] apresentaram um resultado de indiferença (i.e., $\mathrm{FIC}=>0,5 \mathrm{e} \leq 4$ ) tanto para a cepa $111 \mathrm{ER}$ quanto para a $44 \mathrm{CIB}$.

Um resultado de indiferença foi obtido para oito cepas (PA0905, PA01, 481997A SPM-1, 36C, 31C, 10C, VIM-1 247B e PA GIM-1) para a combinação [Amicacina $\times$ Polimixina B), mostrado na Tabela 4.

A combinação [Imipenem $\times$ Piperacilina/Tazobactam] foi indiferente para a cepa 111ER. As combinações [Polimixina $B \times$ Imipenem], [Levofloxacina $x$ Piperacilina/Tazobactam], [Levofloxacina $x$ DDA], [Amicacina $x$ DDA] foram indiferentes para a cepa $44 \mathrm{CIB}$ e, a combinação [Piperacilina/Tazobactam $x$ Aztreonam] foi indiferente apenas para a cepa PA0905. Nenhuma combinação resultou em uma resposta antagônica. 
Tabela 1 - Valores da concentração inibitória mínima (CIM), concentração inibitória fracional (FIC) e somatório das FIC ( $\Sigma F I C)$ para duas cepas de $P$. aeruginosa MR.

\begin{tabular}{|c|c|c|c|c|c|c|c|c|c|c|c|c|}
\hline \multirow{2}{*}{$\begin{array}{l}\text { Combinação } \\
(A \times \text { B }) \mu \mathrm{g} / \mathrm{mL}\end{array}$} & \multicolumn{6}{|c|}{ Cepa 111ER (SPM-1) } & \multicolumn{6}{|c|}{ Cepa 44CIB (SPM-1) } \\
\hline & $\operatorname{CIM} A\left(^{*}\right)$ & CIM B $\left(^{*}\right)$ & ${ }^{a}$ FIC A & ${ }^{a}$ FIC B & $\begin{array}{r}{ }^{\mathrm{b}} \sum \text { FIC }=\text { FIC } \\
A+F I C B\end{array}$ & $\begin{array}{c}\text { c } \\
\text { Interpretação }\end{array}$ & $\operatorname{CIM} A\left(^{*}\right)$ & CIM B (*) & ${ }^{\mathrm{a}}$ FIC A & ${ }^{\mathrm{a}}$ FIC B & $\begin{array}{r}{ }^{\mathrm{b}} \sum \mathrm{FIC}=\mathrm{FIC} \\
\mathrm{A}+\mathrm{FIC} B\end{array}$ & $\begin{array}{c}\mathrm{c} \\
\text { Interpretação }\end{array}$ \\
\hline Aztreonam x Polimixina B & $16(4)$ & $1(0,5)$ & 0,25 & 0,50 & 0,75 & $\begin{array}{l}\text { Indiferente } \\
\text { (PS) }\end{array}$ & $16(4)$ & $1(0,5)$ & 0,25 & 0,50 & 0,75 & $\begin{array}{l}\text { Indiferente } \\
\text { (PS) }\end{array}$ \\
\hline Polimixina B x Imipenem & $\begin{array}{c}0,5 \\
(0,25)\end{array}$ & $\begin{array}{c}256 \\
(0,005)\end{array}$ & 0,50 & $\begin{array}{c}0,0000 \\
1\end{array}$ & 0,50 & Sinergismo & $1(1)$ & $\begin{array}{c}256 \\
(0,005)\end{array}$ & 1,00 & $\begin{array}{c}0,000 \\
01\end{array}$ & 1,00 & $\begin{array}{l}\text { Indiferente } \\
\text { (A) }\end{array}$ \\
\hline $\begin{array}{l}\text { Piperacilina/Tazobactam x } \\
\text { Aztreonam }\end{array}$ & $128(64)$ & $8(0,25)$ & 0,50 & 0,03 & 0,53 & Sinergismo & $128(0,06)$ & $8(4)$ & 0,0004 & 0,50 & 0,50 & Sinergismo \\
\hline Amicacina x Aztreonam & $\begin{array}{l}1024 \\
(256)\end{array}$ & $16(8)$ & 0,25 & 0,50 & 0,75 & $\begin{array}{l}\text { Indiferente } \\
\text { (PS) }\end{array}$ & $1024(512)$ & $16(8)$ & 0,50 & 0,50 & 1,00 & $\begin{array}{l}\text { Indiferente } \\
\text { (A) }\end{array}$ \\
\hline $\begin{array}{l}\text { Piperacilina/Tazobactam x } \\
\text { Polimixina B }\end{array}$ & $128(32)$ & $1(0,5)$ & 0,25 & 0,50 & 0,75 & $\begin{array}{l}\text { Indiferente } \\
\text { (PS) }\end{array}$ & $512(64)$ & $1(1)$ & 0,12 & 1,00 & 1,13 & Indiferente \\
\hline Amicacina x Polimixina B & $\begin{array}{l}1024 \\
(0,5)\end{array}$ & $2(1)$ & 0,0004 & 0,50 & 0,50 & Sinergismo & $1024(0,5)$ & $2(1)$ & 0,0004 & 0,50 & 0,50 & Sinergismo \\
\hline $\begin{array}{l}\text { Imipenem } \mathrm{x} \\
\text { Piperacilina/Tazobactam }\end{array}$ & $\begin{array}{c}128 \\
(128)\end{array}$ & $64(0,5)$ & 1 & 0,007 & 1,00 & $\begin{array}{l}\text { Indiferente } \\
\text { (A) }\end{array}$ & $256(4)$ & $128(64)$ & 0,01 & 0,50 & 0,51 & Sinergismo \\
\hline Levofloxacina x Imipenem & $64(32)$ & $\begin{array}{c}512 \\
(128)\end{array}$ & 0,50 & 0,25 & 0,75 & $\begin{array}{l}\text { Indiferente } \\
\text { (PS) }\end{array}$ & $64(32)$ & $512(256)$ & 0,50 & 0,50 & 1,00 & $\begin{array}{l}\text { Indiferente } \\
\text { (A) }\end{array}$ \\
\hline Levofloxacina x Polimixina B & $64(16)$ & $1(0,5)$ & 0,25 & 0,50 & 0,75 & $\begin{array}{l}\text { Indiferente } \\
\text { (PS) }\end{array}$ & $64(8)$ & $0,5(0,5)$ & 0,12 & 1,00 & 1,12 & Indiferente \\
\hline Aztreonam x Levofloxacina & $16(8)$ & $64(8)$ & 0,50 & 0,12 & 0,63 & $\begin{array}{l}\text { Indiferente } \\
\text { (PS) }\end{array}$ & $8(4)$ & $64(4)$ & 0,50 & 0,06 & 0,56 & $\begin{array}{l}\text { Indiferente } \\
\text { (PS) }\end{array}$ \\
\hline $\begin{array}{l}\text { Levofloxacina } x \\
\text { Piperacilina/Tazobactam }\end{array}$ & $64(16)$ & $\begin{array}{c}512 \\
(128)\end{array}$ & 0,25 & 0,25 & 0,50 & Sinergismo & $64(32)$ & $512(64)$ & 0,50 & 0,12 & 0,61 & $\begin{array}{l}\text { Indiferente } \\
\text { (PS) }\end{array}$ \\
\hline Levofloxacina x DDA & $64(1)$ & $32(8)$ & 0,01 & 0,25 & 0,26 & Sinergismo & $64(32)$ & $16(1)$ & 0,50 & 0,06 & 0,56 & $\begin{array}{l}\text { Indiferente } \\
\text { (PS) }\end{array}$ \\
\hline Amicacina $\times$ DDA & $\begin{array}{l}2048 \\
(128)\end{array}$ & $32(8)$ & 0,06 & 0,25 & 0,31 & Sinergismo & $2048(512)$ & $32(16)$ & 0,25 & 0,50 & 0,75 & $\begin{array}{l}\text { Indiferente } \\
\text { (PS) }\end{array}$ \\
\hline Tigeciclina $\times$ DDA & $16(2)$ & $32(4)$ & 0,125 & 0,125 & 0,25 & Sinergismo & $16(1)$ & $16(4)$ & 0,06 & 0,25 & 0,31 & Sinergismo \\
\hline
\end{tabular}

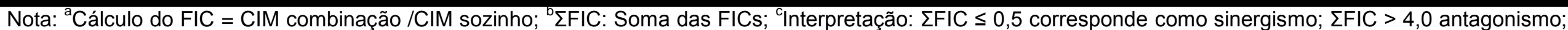

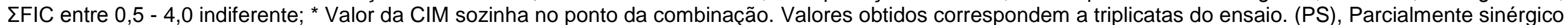
$=(\Sigma \mathrm{FIC},>0,5 \leq 1) ;(\mathrm{A})$, Aditivo $=\left(\sum \mathrm{FIC}=1\right)$.

Fonte: Sader e Jones (2005), CLSI (2011). 
Tabela 2 - Valores da concentração bactericida mínima (CBM), concentração bactericida fracional (FBC) e somatório das FBC $(\Sigma F B C)$ para cepas de $P$. aeruginosa na combinação [Tigeciclina e DDA].

\begin{tabular}{|c|c|c|c|c|c|c|}
\hline \multirow{3}{*}{ Cepas } & \multicolumn{6}{|c|}{ Combinação (A x B) } \\
\hline & \multicolumn{6}{|c|}{ Tigeciclina x DDA $(\mu \mathrm{g} / \mathrm{mL})$} \\
\hline & CBM A $\left(^{*}\right)$ & CBM B $\left(^{*}\right)$ & ${ }^{\mathrm{a}} \mathrm{FBC} A$ & ${ }^{\mathrm{a}} \mathrm{FBC} B$ & $\begin{array}{l}{ }^{\mathrm{D}} \sum \mathrm{FBC}= \\
F B C A+ \\
F B C B\end{array}$ & ${ }^{c}$ Interpretação \\
\hline PA01 & $16(0,5)$ & $8(1)$ & 0,03 & 0,12 & 0,15 & Sinergismo \\
\hline 48-1997A (SPM-1) & $32(2)$ & $16(1)$ & 0,06 & 0,06 & 0,12 & Sinergismo \\
\hline 111ER (SPM-1) & $16(2)$ & $32(4)$ & 0,125 & 0,125 & 0,25 & Sinergismo \\
\hline 44CIB (SPM-1) & $16(1)$ & $16(4)$ & 0,06 & 0,25 & 0,31 & Sinergismo \\
\hline $36 \mathrm{C}(\mathrm{SPM}-1)$ & $16(4)$ & $16(4)$ & 0,25 & 0,25 & 0,50 & Sinergismo \\
\hline $31 \mathrm{C}(\mathrm{SPM}-1)$ & $32(2)$ & $4(0,5)$ & 0,06 & 0,12 & 0,18 & Sinergismo \\
\hline 10C (SPM-1) & $32(2)$ & $32(1)$ & 0,06 & 0,03 & 0,09 & Sinergismo \\
\hline PA0905 (SPM-1) & $32(4)$ & $8(2)$ & 0,12 & 0,25 & 0,37 & Sinergismo \\
\hline $\mathrm{Pa}$ 247B (VIM-1) & $32(4)$ & $16(1)$ & 0,12 & 0,06 & 0,18 & Sinergismo \\
\hline $\mathrm{Pa}$ GIM-1 & $16(1)$ & $4(0,5)$ & 0,06 & 0,12 & 0,18 & Sinergismo \\
\hline
\end{tabular}

Nota: ${ }^{a}$ Cálculo do FBC = CBM combinação/CBM sozinho; ${ }^{0} \Sigma F B C$ : Soma das FBCs; ${ }^{c}$ Interpretação: $\Sigma F B C \leq 0,5$ corresponde como sinergismo; $\Sigma F B C>4,0$ antagonismo; $\Sigma F B C$ entre $0,5-4,0$ indiferente; * Valor da CBM sozinha no ponto da combinação; Valores obtidos correspondem a triplicatas do ensaio.

Fonte: Adaptado do EUCAST (2012a). 
Tabela 3 - Valores da concentração inibitória mínima (CIM), concentração inibitória fracional (FIC), somatório das FIC ( $\Sigma F I C)$ para cepas de $P$. aeruginosa na combinação [Piperacilina/Tazobactam e Aztreonam].

\begin{tabular}{|c|c|c|c|c|c|c|}
\hline \multirow{3}{*}{ Cepas } & \multicolumn{6}{|c|}{ Combinação (A x B) } \\
\hline & \multicolumn{6}{|c|}{ Piperacilina/Tazobactam x Aztreonam $(\mu \mathrm{g} / \mathrm{mL})$} \\
\hline & $\operatorname{CIM} \mathbf{A}\left({ }^{*}\right)$ & CIM B (*) & ${ }^{a}$ FIC A & ${ }^{a}$ FIC B & $\begin{array}{l}{ }^{\mathrm{b}} \sum_{\mathrm{FIC}=}= \\
\text { FIC A + } \\
\text { FIC B }\end{array}$ & $\begin{array}{c}\text { c } \\
\text { Interpretação }\end{array}$ \\
\hline PA01 & $4(0,5)$ & $8(2)$ & 0,12 & 0,25 & 0,37 & Sinergismo \\
\hline 48-1997A (SPM-1) & $256(4)$ & $8(2)$ & 0,01 & 0,25 & 0,26 & Sinergismo \\
\hline 111ER (SPM-1) & $128(64)$ & $8(0,25)$ & 0,50 & 0,03 & 0,53 & Sinergismo \\
\hline 44CIB (SPM-1) & $128(0,06)$ & $8(4)$ & 0,0004 & 0,50 & 0,50 & Sinergismo \\
\hline 36C (SPM-1) & $1024(32)$ & $8(2)$ & 0,03 & 0,25 & 0,53 & Sinergismo \\
\hline $31 \mathrm{C}(\mathrm{SPM}-1)$ & $512(128)$ & $8(2)$ & 0,25 & 0,25 & 0,50 & Sinergismo \\
\hline 10C (SPM-1) & $128(32)$ & $8(1)$ & 0,25 & 0,12 & 0,37 & Sinergismo \\
\hline PA0905 (SPM-1) & $128(32)$ & $8(4)$ & 0,25 & 0,50 & 0,75 & Indiferente (PS) \\
\hline $\mathrm{Pa}$ 247B (VIM-1) & $128(32)$ & $8(2)$ & 0,25 & 0,25 & 0,50 & Sinergismo \\
\hline Pa GIM-1 & $1024(256)$ & $8(2)$ & 0,25 & 0,25 & 0,50 & Sinergismo \\
\hline $\begin{array}{l}\text { Nota: }{ }^{a} \text { Cálculo do FI } \\
0,5 \text { corresponde con } \\
\text { da CIM sozinha no } p \\
\text { Parcialmente sinérgi } \\
\text { Fonte: Sader e Jone }\end{array}$ & $\begin{array}{l}=\left(\sum \mathrm{FIC},>0\right. \\
005), \mathrm{CLSI}\end{array}$ & $\begin{array}{l}\text { ão/CIM sc } \\
\text { IC > } 4,0 \text { a } \\
\text { ão; Valore } \\
\leq 1) \text {. } \\
11 \text { ). }\end{array}$ & go; ${ }^{0} \Sigma$ & $\begin{array}{l}\text { ioma d } \\
\text { IC ent }\end{array}$ & $\begin{array}{l}\text { ICs; }{ }^{\circ} \text { Inte } \\
5-4,0 \text { i } \\
\text { triplicata }\end{array}$ & $\begin{array}{l}\text { etação: } \Sigma F I C \leq \\
\text { erente; }{ }^{*} \text { Valor } \\
\text { b ensaio. (PS), }\end{array}$ \\
\hline
\end{tabular}


Tabela 4 - Valores da concentração inibitória mínima (CIM), concentração inibitória fracional (FIC), somatório das FIC ( $\Sigma \mathrm{FIC})$ para cepas de $P$. aeruginosa na combinação [Amicacina $x$ Polimixina $B$ ].

\begin{tabular}{|c|c|c|c|c|c|c|}
\hline \multirow{3}{*}{ Cepas } & \multicolumn{6}{|c|}{ Combinação (A x B) } \\
\hline & \multicolumn{6}{|c|}{ Amicacina x Polimixina B $(\mu \mathrm{g} / \mathrm{mL})$} \\
\hline & $\operatorname{CIM} A\left(^{*}\right)$ & CIM B (*) & ${ }^{a}$ FIC A & ${ }^{a}$ FIC B & $\begin{array}{l}{ }^{b} \sum F I C= \\
\text { FIC A+ } \\
\text { FIC B }\end{array}$ & $\begin{array}{c}\text { c } \\
\text { Interpretação }\end{array}$ \\
\hline PA01 & $8(0,5)$ & $1(1)$ & 0,06 & 1,00 & 1,06 & Indiferente \\
\hline 48-1997A (SPM-1) & $64(32)$ & $2(2)$ & 0,5 & 1,00 & 1,50 & Indiferente \\
\hline 111ER (SPM-1) & $1024(0,5)$ & $2(1)$ & 0,0004 & 0,50 & 0,50 & Sinergismo \\
\hline 44CIB (SPM-1) & $1024(0,5)$ & $2(1)$ & 0,0004 & 0,50 & 0,50 & Sinergismo \\
\hline 36C (SPM-1) & $64(32)$ & $2(2)$ & 0,50 & 1,00 & 1,50 & Indiferente \\
\hline $31 \mathrm{C}(\mathrm{SPM}-1)$ & $64(16)$ & $2(2)$ & 0,25 & 1,00 & 1,25 & Indiferente \\
\hline 10C (SPM-1) & $64(8)$ & $2(2)$ & 0,125 & 1,00 & 1,12 & Indiferente \\
\hline PA0905 (SPM-1) & $256(128)$ & $2(2)$ & 0,50 & 1,00 & 1,50 & Indiferente \\
\hline $\mathrm{Pa}$ 247B (VIM-1) & $8(0,5)$ & $1(1)$ & 0,06 & 1,00 & 1,06 & Indiferente \\
\hline Pa GIM-1 & $32(8)$ & $1(1)$ & 0,25 & 1,00 & 1,25 & Indiferente \\
\hline $\begin{array}{l}\text { Nota: }{ }^{\mathrm{a} C a ́ l c u l o ~ d o ~ F} \\
0,5 \text { corresponde co } \\
\text { da CIM sozinha no } \\
\text { Fonte: CLSI (2011) }\end{array}$ & $0 \mathrm{~d}$ & $y$ & ${ }^{b_{\Sigma}}$ & ol & $\begin{array}{l}\mathrm{Cs} ;{ }^{c} / 1 \\
5-4,\end{array}$ & $\begin{array}{l}\text { etação: } \Sigma F I C \leq \\
\text { erente; }{ }^{*} \text { Valor } \\
\text { as do ensaio. }\end{array}$ \\
\hline
\end{tabular}

\section{3 "Time-Kill" da Combinação [Tigeciclina x DDA]}

Foi realizado o teste de "Time-Kill" da combinação [Tigeciclina x DDA], uma vez que foi demonstrada sua atividade sinérgica através do teste de "Checkerboard".

Inicialmente o teste foi feito para a cepa 111ER (Figura 4). As concentrações utilizadas no teste foram de acordo com os resultados da Tabela 2.

Na Figura 4 podemos observar que a Tigeciclina na concentração da CIM (16 $\mu \mathrm{g} / \mathrm{mL}$ ) levou a morte bacteriana na sexta hora, o mesmo acontece para o DDA na concentração (CIM $32 \mu \mathrm{g} / \mathrm{mL}$ ). Enquanto que a combinação sinérgica de Tigeciclina $(2 \mu \mathrm{g} / \mathrm{mL})$ e DDA $(4 \mu \mathrm{g} / \mathrm{mL})$ ocasionou a morte bacteriana já na primeira hora. 
Figura 4 - Curva de morte (gráfico "Time-Kill") da cepa de $P$. aeruginosa 111ER para a combinação [Tigeciclina x DDA].

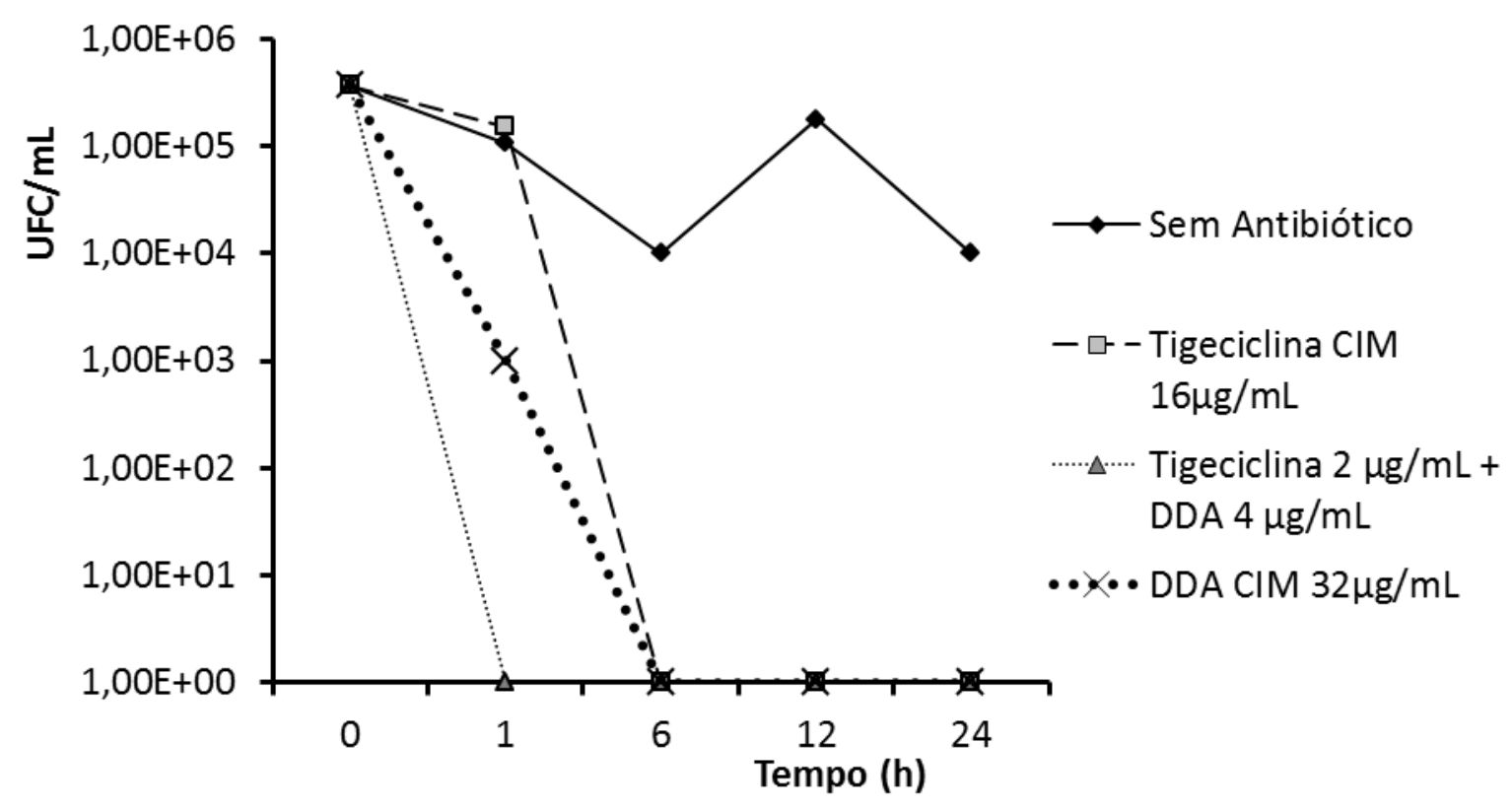

Posteriormente o "Time-Kill" da combinação [Tigeciclina $x$ DDA] foi realizado para as cepas 48-1997A SPM-1 (Figura 5), 247B VIM-1 (Figura 6) e PA GIM-1 (Figura 7). As concentrações de antimicrobianos selecionadas foram de acordo com os maiores valores obtidos em triplicata da atividade bactericida, realizadas após os testes de "Checkerboard".

Para a cepa 48-1997A SPM-1 (Figura 5), tanto para Tigeciclina (CIM 32 $\mu \mathrm{g} / \mathrm{mL}$ ), quanto o DDA (CIM $16 \mu \mathrm{g} / \mathrm{mL}$ ) ocasionaram a morte das bactérias na sexta hora, já a combinação sinérgica de Tigeciclina e DDA (2 $\mu \mathrm{g} / \mathrm{mL}$ e $0,5 \mu \mathrm{g} / \mathrm{mL}$, respectivamente) levaram a morte bacteriana na primeira hora.

A cepa 247B VIM-1 (Figura 6) a morte bacteriana ocorreu na primeira hora para o DDA (CIM $16 \mu \mathrm{g} / \mathrm{mL}$ ), na sexta hora para Tigeciclina (CIM $32 \mu \mathrm{g} / \mathrm{mL}$ ) e em 24 horas para a combinação dos dois antimicrobianos [Tigeciclina $4 \mu \mathrm{g} / \mathrm{mL} \times$ DDA 1 $\mu \mathrm{g} / \mathrm{mL}]$. 
Figura 5 - Curva de morte (gráfico "Time-Kill") da cepa de P. aeruginosa 48-1997A SPM-1 para a combinação [Tigeciclina x DDA].

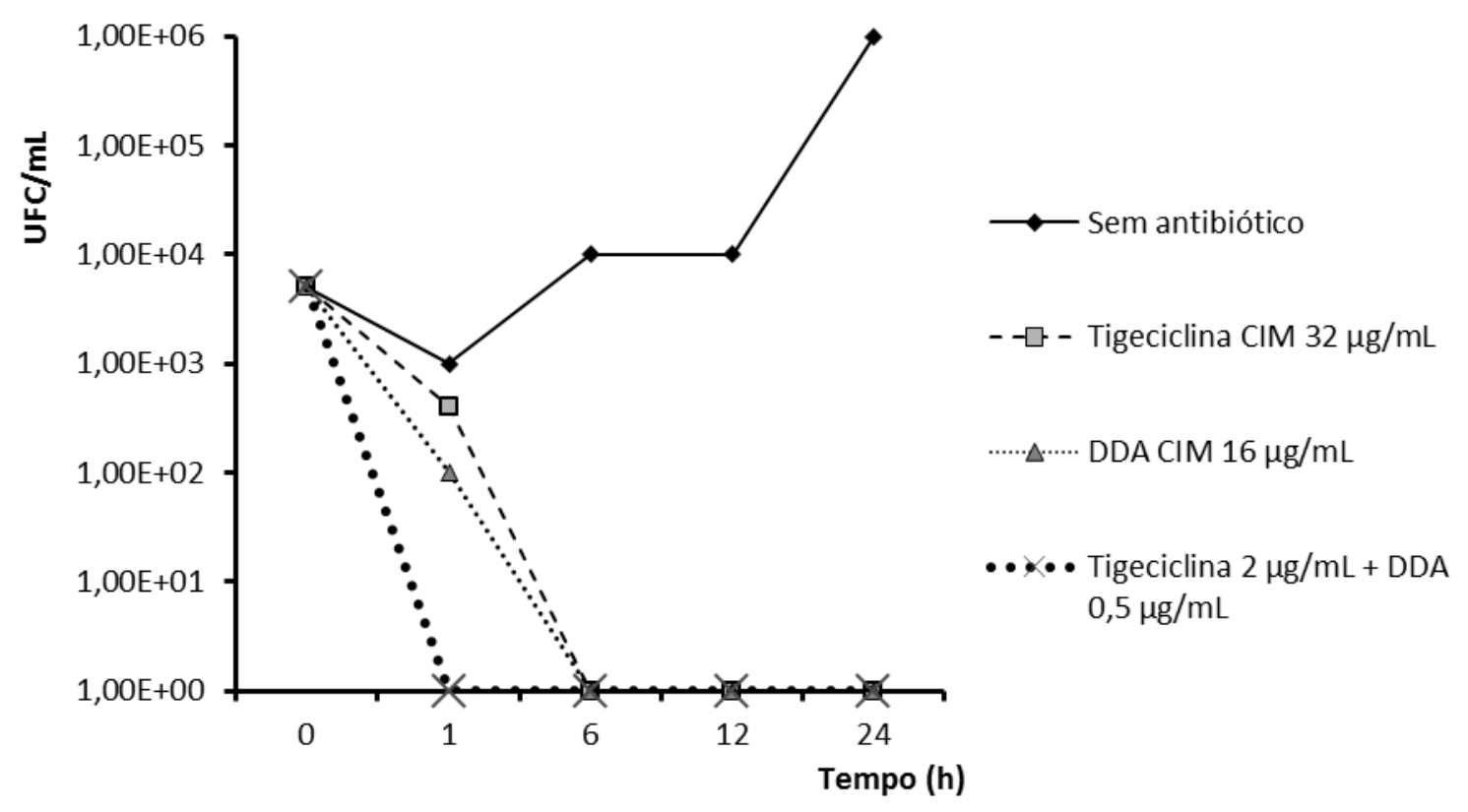

Para a cepa PA GIM-1 (Figura 7) possuía a CIM de Tigeciclina $16 \mu \mathrm{g} / \mathrm{mL}$ e de DDA, $4 \mu \mathrm{g} / \mathrm{mL}$, já as concentrações para o ponto sinérgico foram (Tigeciclina 1 $\mu \mathrm{g} / \mathrm{mL}$ e DDA $0,5 \mu \mathrm{g} / \mathrm{mL}$ ). A Tigeciclina sozinha ocasionou a morte em 12 horas, o DDA sozinho na sexta hora e a combinação já na primeira hora.

Após a realização do "Time-Kill" foi obtido o espectro UV visível de Tigeciclina e sua associação com DDA, posteriormente as interações entre bactéria e os antimicrobianos [Tigeciclina $\times$ DDA] foram estudadas por "Light Scattering", para obter dados físico-químicos associados com o possível efeito sinérgico (Figura 9) e (Figura 10). 
Figura 6 - Curva de morte (gráfico “Time-Kill") da cepa de P. aeruginosa 247B VIM-1 para a combinação [Tigeciclina x DDA].

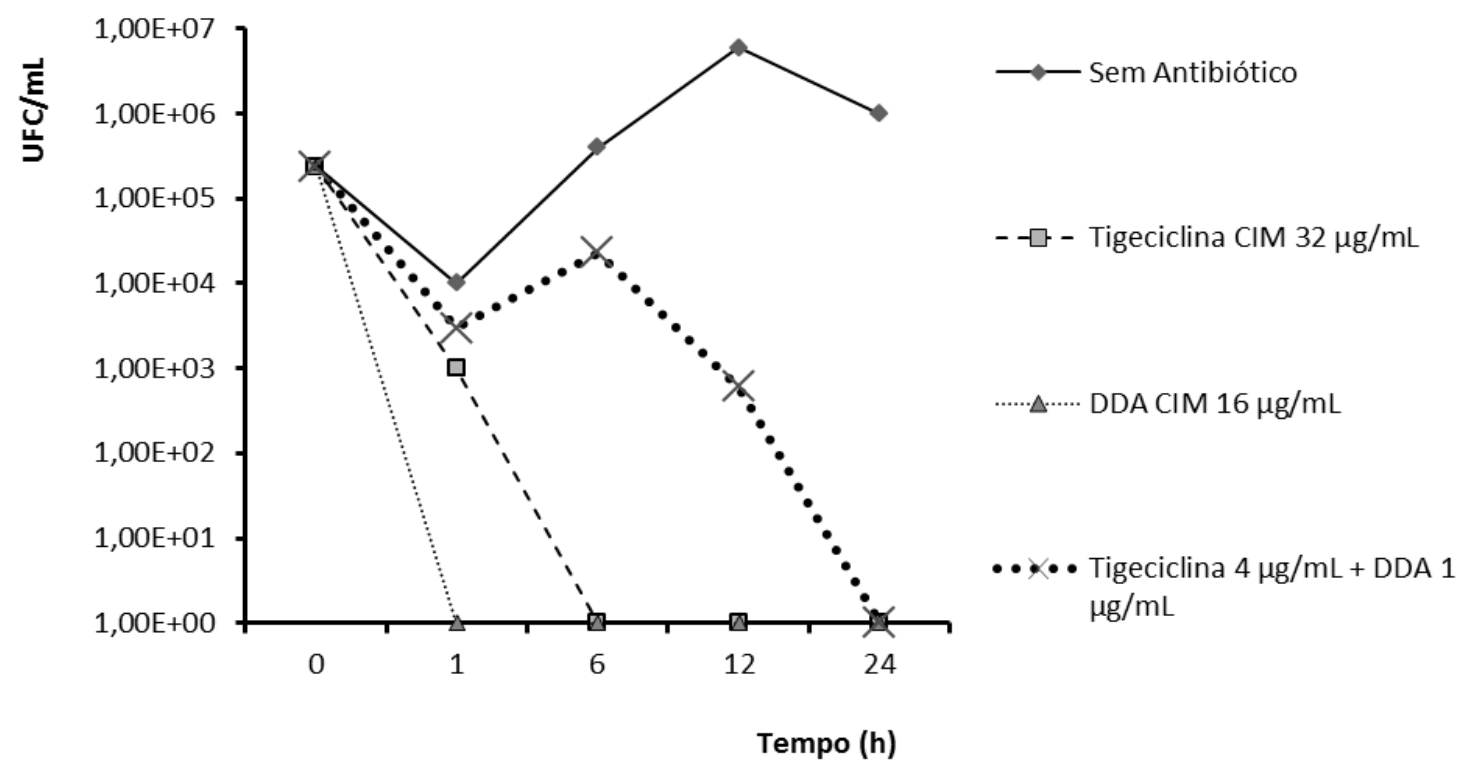

Figura 7 - Curva de morte (gráfico "Time-Kill") da cepa de P. aeruginosa PA GIM-1 para a combinação [Tigeciclina x DDA].

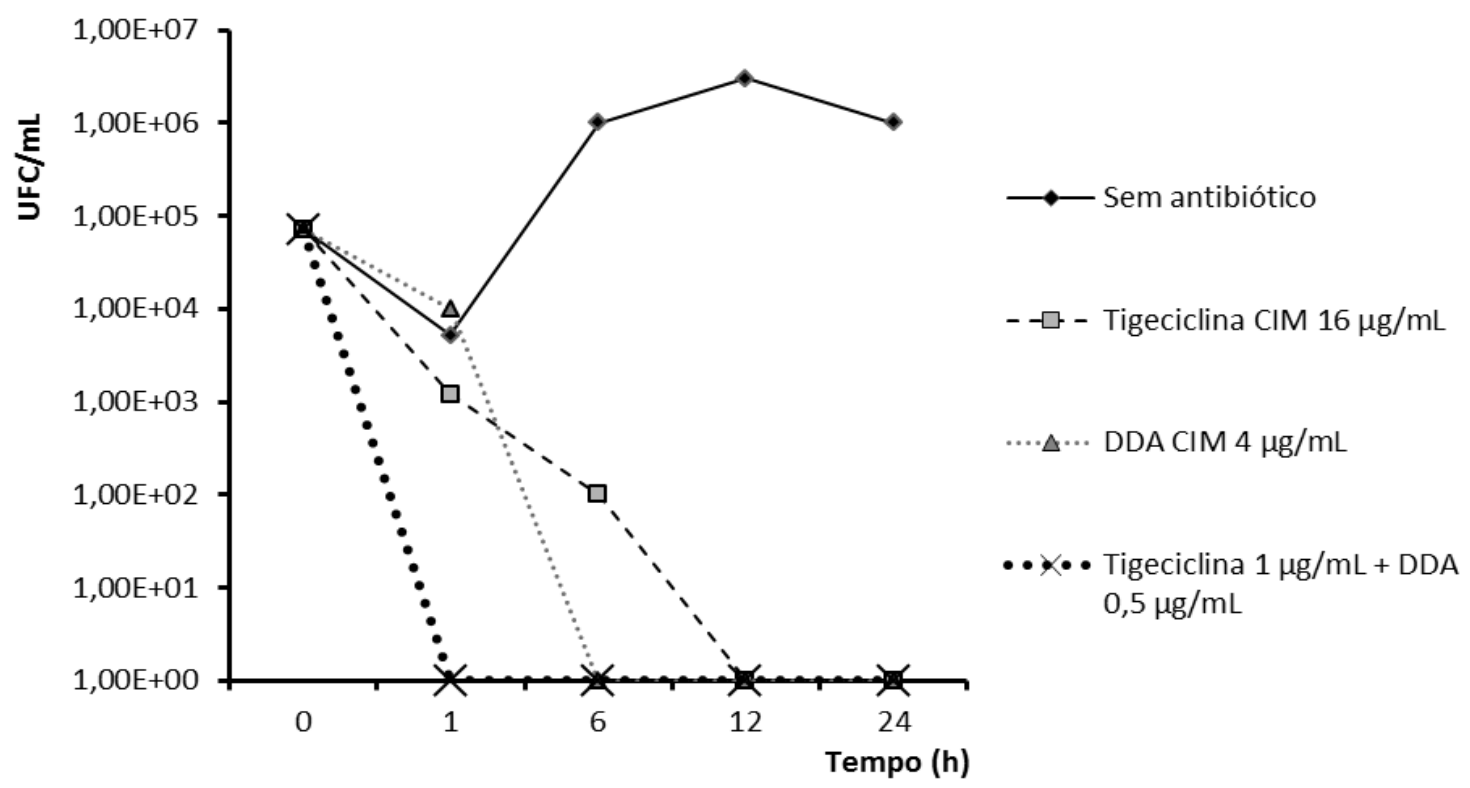




\subsection{Espectrofotometria UV Visível}

Foi obtido o espectro UV visível de Tigeciclina e sua associação com DDA (Figura 8), o que resultou na formação do espectro típico da Tigeciclina no seu estado monomérico referente à sua total solubilização. Nesta condição foi confirmada a presença do máximo de absorção no comprimento de onda de $\lambda 246 \mathrm{e}$ $\lambda 350$ (Molina-Garcia et al., 2011). As concentrações escolhidas para esse teste foram baseadas nas CIMs de Tigeciclina e DDA para a cepa 111ER (Tabela 2).

Figura 8 - Espectro de absorção UV visível de Tigeciclina $(16 \mu \mathrm{g} / \mathrm{mL})$ e da combinação [Tigeciclina/DDA] [16/32 $\mu \mathrm{g} / \mathrm{mL}]$.

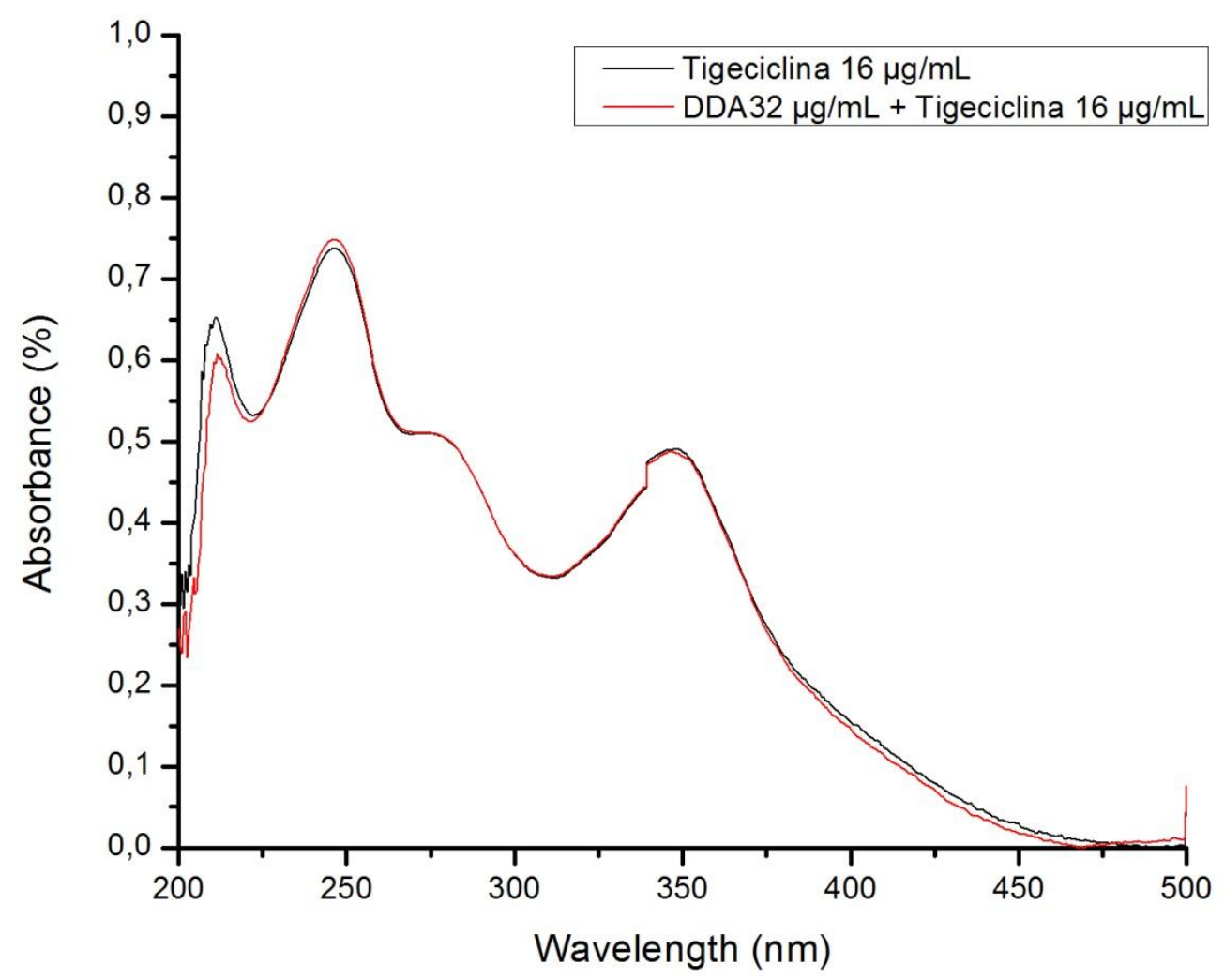

Nota: As leituras foram feitas em solução aquosa, após 1 hora de interação. As concentrações utilizadas foram baseadas no conceito da lei de Lambert-Beer (relação linear entre absorbância e concentração entre 0,1 a 1,0). 


\section{5 “Light Scattering” e Potencial Zeta}

Figura 9 - Distribuição de tamanhos (diâmetro médio) e potencial zeta ( $\zeta$ ) resultante da interação $P$. aeruginosa e DDA.

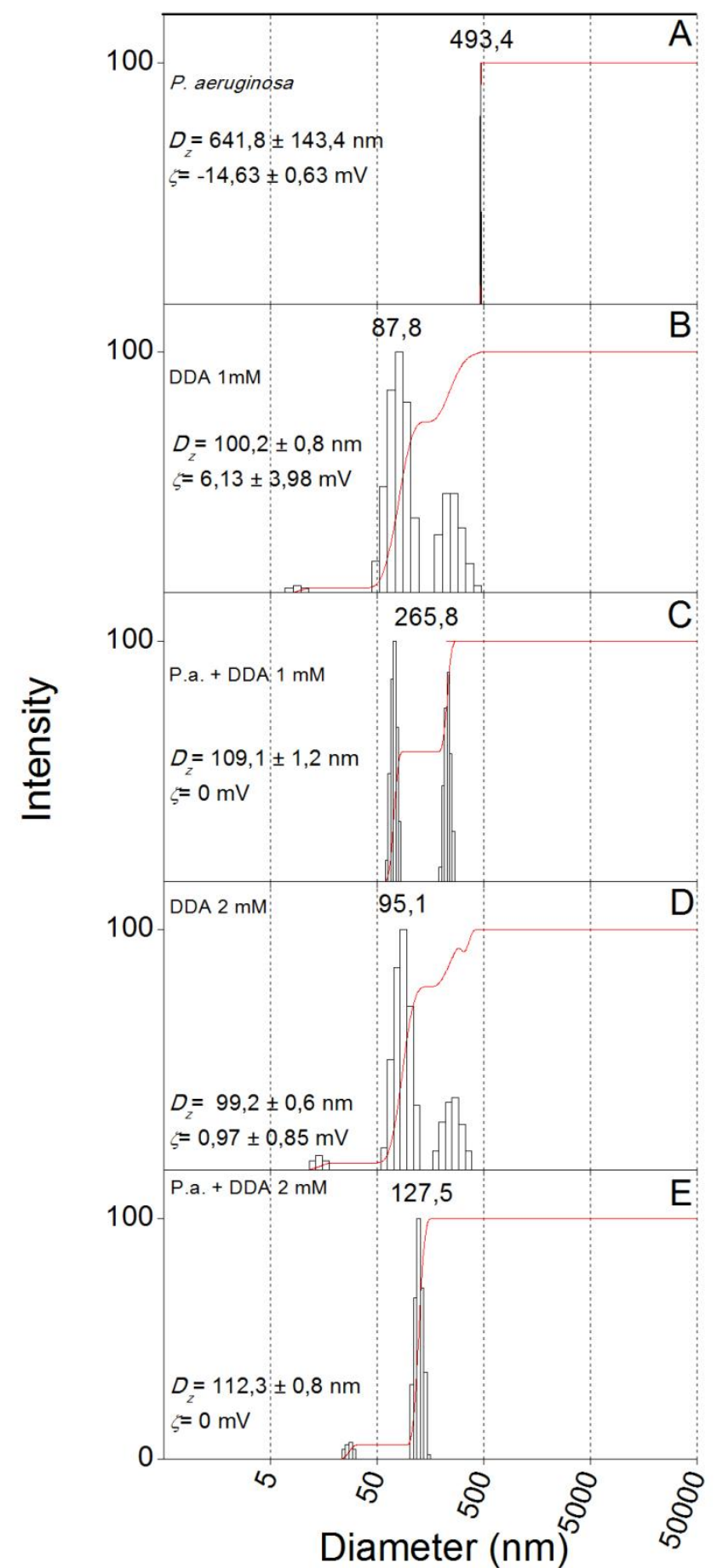

Nota: $\mathrm{Pa}=P$. aeruginosa; $\mathrm{d}=$ diâmetro médio em nanômetros; $\zeta=$ potencial zeta em milivolts; No quadro $A$ encontra-se $P$. aeruginosa 111ER sozinha; no quadro $B$ apenas DDA na concentração de 1 $\mathrm{mM}$; no quadro $C$ encontra-se $P$. aeruginosa acrescido de DDA na concentração de $1 \mathrm{mM}$; no quadro $\mathrm{D}$ apenas DDA na concentração de $2 \mathrm{mM}$; já no quadro $E$ encontra-se $P$. aeruginosa acrescido de DDA na concentração de $2 \mathrm{mM}$. 
Figura 10 - Distribuição de tamanhos (diâmetro médio) e potencial zeta ( $\zeta$ ) resultante da interação $P$. aeruginosa, DDA e Tigeciclina.

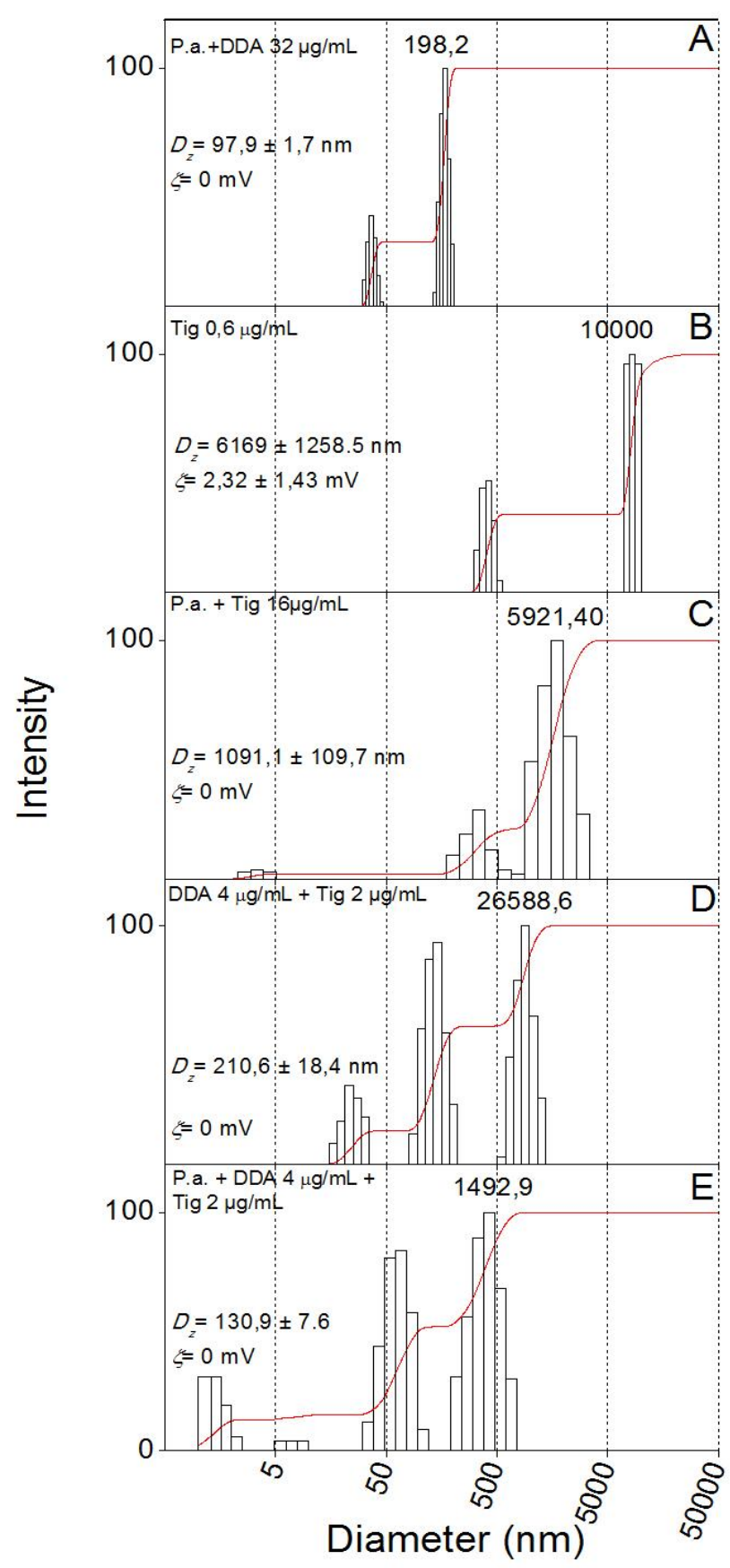

Nota: $\mathrm{Pa}=P$. aeruginosa; $\mathrm{d}=$ diâmetro médio em nanômetros; $\zeta=$ potencial zeta em milivolts; $\mathrm{TGC}=$ Tigeciclina. No quadro A encontra-se $P$. aeruginosa acrescido de DDA na concentração de $32 \mu \mathrm{g} / \mathrm{mL}$; no quadro $B$ está Tigeciclina na concentração de $0,6 \mathrm{mg} / \mathrm{mL}$; no quadro $C$ está $P$. aeruginosa interagindo com Tigeciclina na concentração de $16 \mu \mathrm{g} / \mathrm{mL}$; no quadro $D$ encontram-se combinados a Tigeciclina na concentração de $2 \mu \mathrm{g} / \mathrm{mL}$ e DDA na concentração de $4 \mu \mathrm{g} / \mathrm{mL}$; no quadro E encontramse combinados $P$. aeruginosa, com Tigeciclina na concentração de $2 \mu \mathrm{g} / \mathrm{mL}$ e DDA na concentração de $4 \mu \mathrm{g} / \mathrm{mL}$. 
Na figura 9A é apresentado o diâmetro médio da cepa de $P$. aeruginosa 111ER $(d=641,8 \mathrm{~nm})$ e sua carga superficial negativa $(\zeta=-14,63 \mathrm{mV})$. Na Figura 9B e 9D podemos observar o DDA em diferentes concentrações, de $1 \mathrm{mM}$ e $2 \mathrm{mM}$, seus diâmetros médios variaram pouco ( $d=100,2 \mathrm{~nm})$ e $(d=99,2 \mathrm{~nm})$, enquanto que suas cargas superficiais apresentaram respectivamente $(\zeta=+6,13 \mathrm{mV})$ e $(\zeta=+0,97 \mathrm{mV})$.

Quando Pseudomonas aeruginosa é combinada com DDA $1 \mathrm{mM}$ obtemos um diâmetro médio de ( $d=109,1 \mathrm{~nm}$ ) e, uma carga superficial de ( $\zeta=0 \mathrm{mV}$ ) (Figura $9 \mathrm{C}$ ). Já quando a $P$. aeruginosa é associada ao DDA 2 mM o diâmetro médio ( $d=112,3$ $\mathrm{nm}$ ) e sua carga superficial também é ( $\zeta=0 \mathrm{mV}$ ) (Figura 9E).

$\mathrm{Na}$ Figura 10A Pseudomonas aeruginosa foi associada ao DDA na concentração da CIM (32 $\mathrm{\mu g} / \mathrm{mL})$, obtendo uma carga superficial de $(\zeta=0 \mathrm{mV})$. A Tigeciclina pode ser observada sozinha na concentração de $0,6 \mathrm{mg} / \mathrm{mL}$ na Figura 10B, onde apresenta um diâmetro médio de $\left(d_{=} 6169 \mathrm{~nm}\right)$ e uma carga superficial positiva de $(\zeta=2,32 \mathrm{mV})$.

A Tigeciclina na concentração CIM de $16 \mu \mathrm{g} / \mathrm{mL}$, em associação com $P$. aeruginosa (Figura 10C) resultou na modificação da carga superficial da bactéria, de um valor negativo para a neutralização $(\zeta=0 \mathrm{mV})$ e um diâmetro médio de $(d=$ 1091,1 nm).

A interação da Tigeciclina (na concentração de $2 \mu \mathrm{g} / \mathrm{mL}$ ) com DDA (na concentração de $4 \mu \mathrm{g} / \mathrm{mL}$ ) pode ser observada na Figura 10D, na qual o diâmetro médio do complexo é ( $d=210,6 \mathrm{~nm}$ ) e a carga superficial é ( $\zeta=0 \mathrm{mV}$ ).

$\mathrm{Na}$ Figura 10E temos a combinação da Tigeciclina (na concentração de 2 $\mu \mathrm{g} / \mathrm{mL}$ ), com DDA (na concentração de $4 \mu \mathrm{g} / \mathrm{mL}$ ) e com Pseudomonas aeruginosa. Esse complexo apresenta um diâmetro médio de $(d=130,9 \mathrm{~nm})$ e uma carga superficial de $(\zeta=0 \mathrm{mV})$.

\subsection{Sinergismo de Piperacilina/Tazobactam e Aztreonam}

Além da combinação [Tigeciclina $x$ DDA] a combinação que também demonstrou efeito sinérgico para 9 cepas foi Piperacilina/Tazobactam com Aztreonam (Tabela 3).

Após a confirmação do sinergismo pelo teste de "Checkerboard" foi realizada a atividade bactericida com Alamar Blue (Materiais e Métodos, seção 3.6), a qual 
pode ser observada na Figura 11 para a cepa 247B VIM-1, Figura 12 para a cepa PA GIM-1 e Figura 13 para a cepa 48-1997A SPM-1.

Para a cepa 247B VIM-1 (Figura 11) a concentração bactericida mínima (CBM) de Aztreonam foi $16 \mu \mathrm{g} / \mathrm{mL}$, já a de Piperacilina/Tazobactam foi de $128 \mu \mathrm{g} / \mathrm{mL}$ e, o Ponto do sinergismo teve como concentrações [Aztreonam $4 \mu \mathrm{g} / \mathrm{mL}$ ] e [Piperacilina/Tazobactam $32 \mu \mathrm{g} / \mathrm{mL}$ ].

A Figura 12 apresenta a CBM de PA GIM-1, que para Aztreonam foi de 16 $\mu \mathrm{g} / \mathrm{mL}$, de Piperacilina/Tazobactam foi de $1024 \mu \mathrm{g} / \mathrm{mL}$ e, o ponto sinérgico obteve as concentrações [Aztreonam $4 \mu \mathrm{g} / \mathrm{mL}$ ] e [Piperacilina/Tazobactam $256 \mu \mathrm{g} / \mathrm{mL}$ ].

Já a CBM para a cepa 48-1997A SPM-1 (Figura 13), o ponto onde ocorreu o sinergismo tinha $2 \mu \mathrm{g} / \mathrm{mL}$ de Aztreonam e $8 \mu \mathrm{g} / \mathrm{mL}$ de Piperacilina/Tazobactam, enquanto que o Aztreonam sozinho teve a CBM de $16 \mu \mathrm{g} / \mathrm{mL}$ e a Piperacilina/Tazobactam $512 \mu \mathrm{g} / \mathrm{mL}$.

Figura 11 - Atividade bactericida da combinação [Piperacilina/Tazobactam x Aztreonam] para a cepa 247B VIM-1.

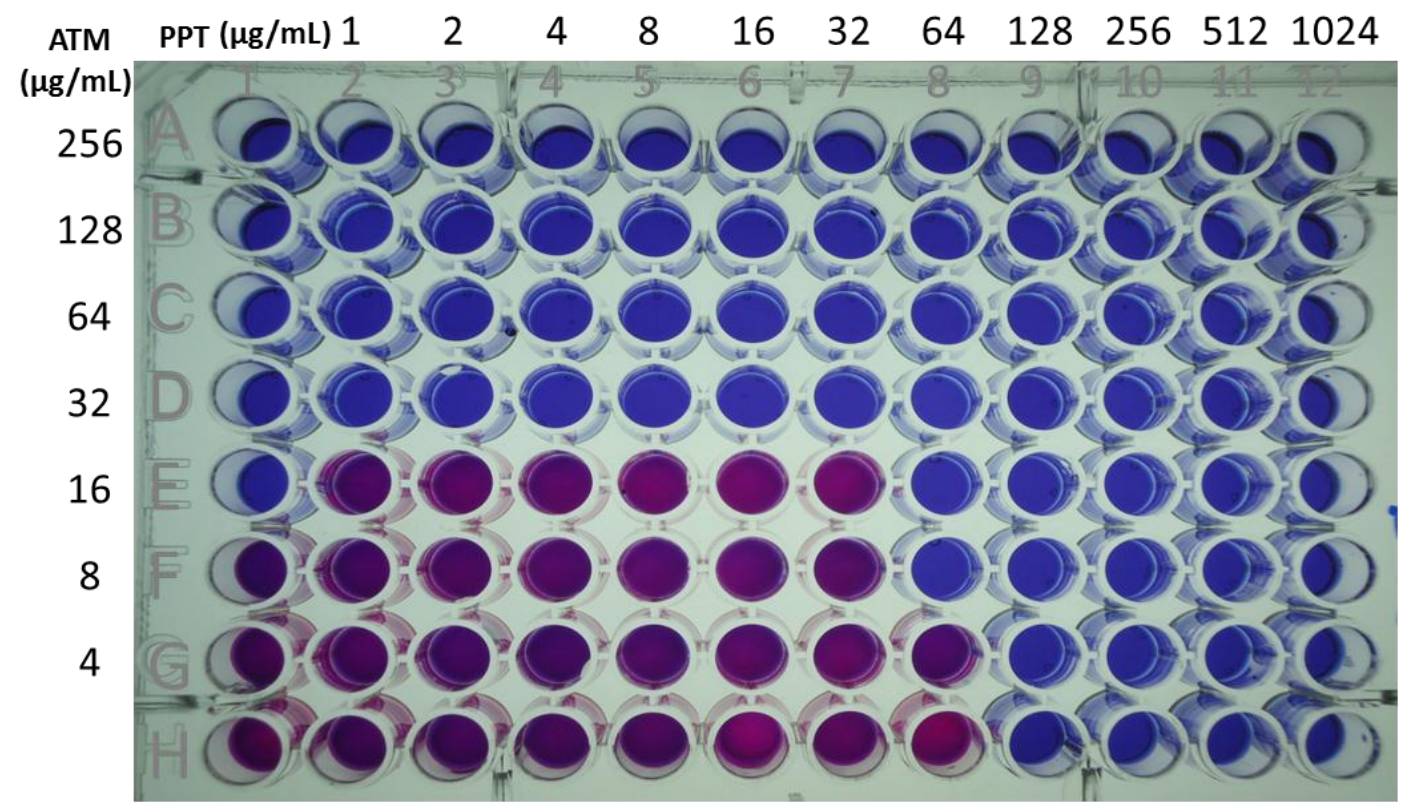

Nota: Poços em azul = sem crescimento bacteriano; Poços em rosa $=$ com crescimento bacteriano. ATM = Aztreonam; PPT = Piperacilina/Tazobactam. Horizontal: concentrações de PPT; Vertical: concentrações de ATM. $\Sigma F I C=0,5$. ATM CBM $16 \mu \mathrm{g} / \mathrm{mL}$ (E1); PPT CBM $128 \mu \mathrm{g} / \mathrm{mL}$ (H9); Ponto do sinergismo F8 [Aztreonam $4 \mu \mathrm{g} / \mathrm{mL}$ ] e [Piperacilina/Tazobactam $32 \mu \mathrm{g} / \mathrm{mL}$ ]. 
Figura 12 - Atividade bactericida da combinação [Piperacilina/Tazobactam x Aztreonam] para a cepa PA GIM-1.

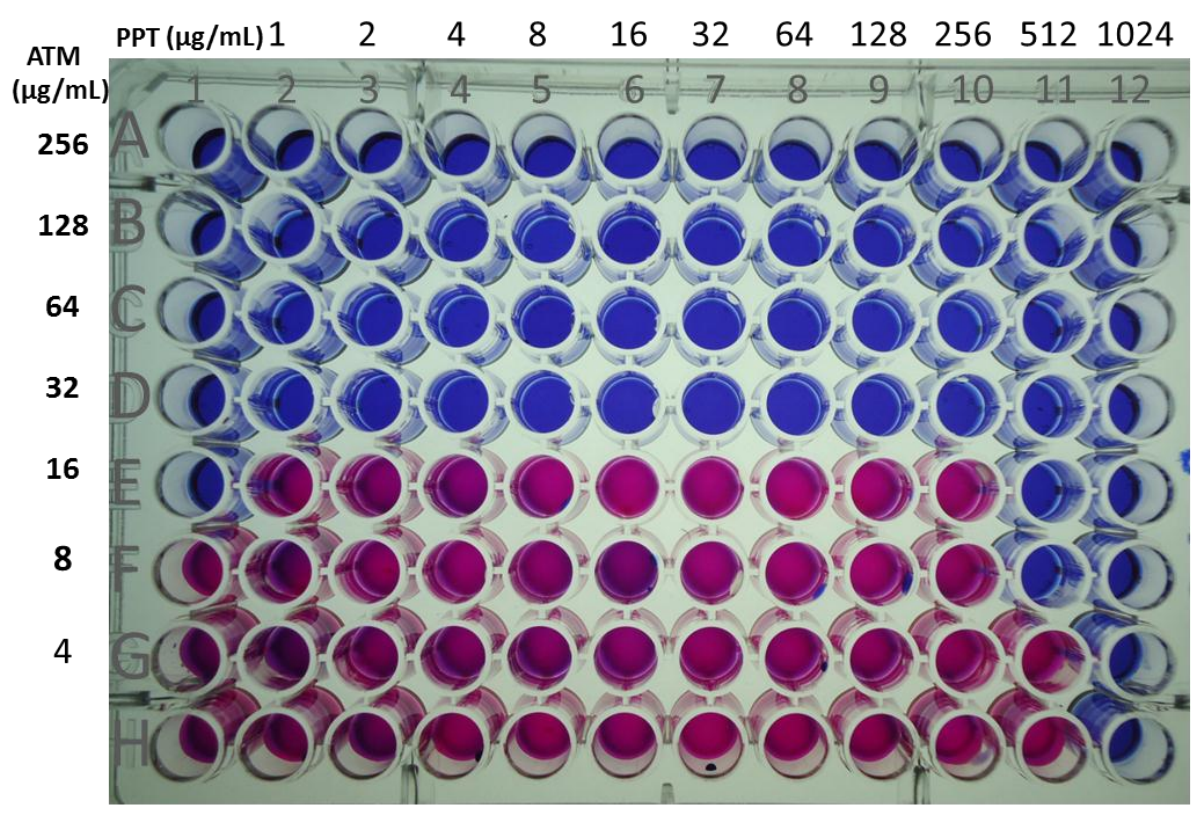

Nota: Poços em azul = sem crescimento bacteriano; Poços em rosa = com crescimento bacteriano. ATM = Aztreonam; PPT = Piperacilina/Tazobactam. Horizontal: concentrações de PPT; Vertical: concentrações de ATM. $\Sigma F I C=0,5$. ATM CBM $16 \mu \mathrm{g} / \mathrm{mL}$ (E1); PPT CBM $1024 \mu \mathrm{g} / \mathrm{mL}$ (H12); Ponto do sinergismo F11 [Aztreonam $4 \mu \mathrm{g} / \mathrm{mL}$ ] e [Piperacilina/Tazobactam $256 \mu \mathrm{g} / \mathrm{mL}$ ].

Figura 13 - Atividade bactericida da combinação [Piperacilina/Tazobactam $x$ Aztreonam] para a cepa 48-1997A SPM-1.

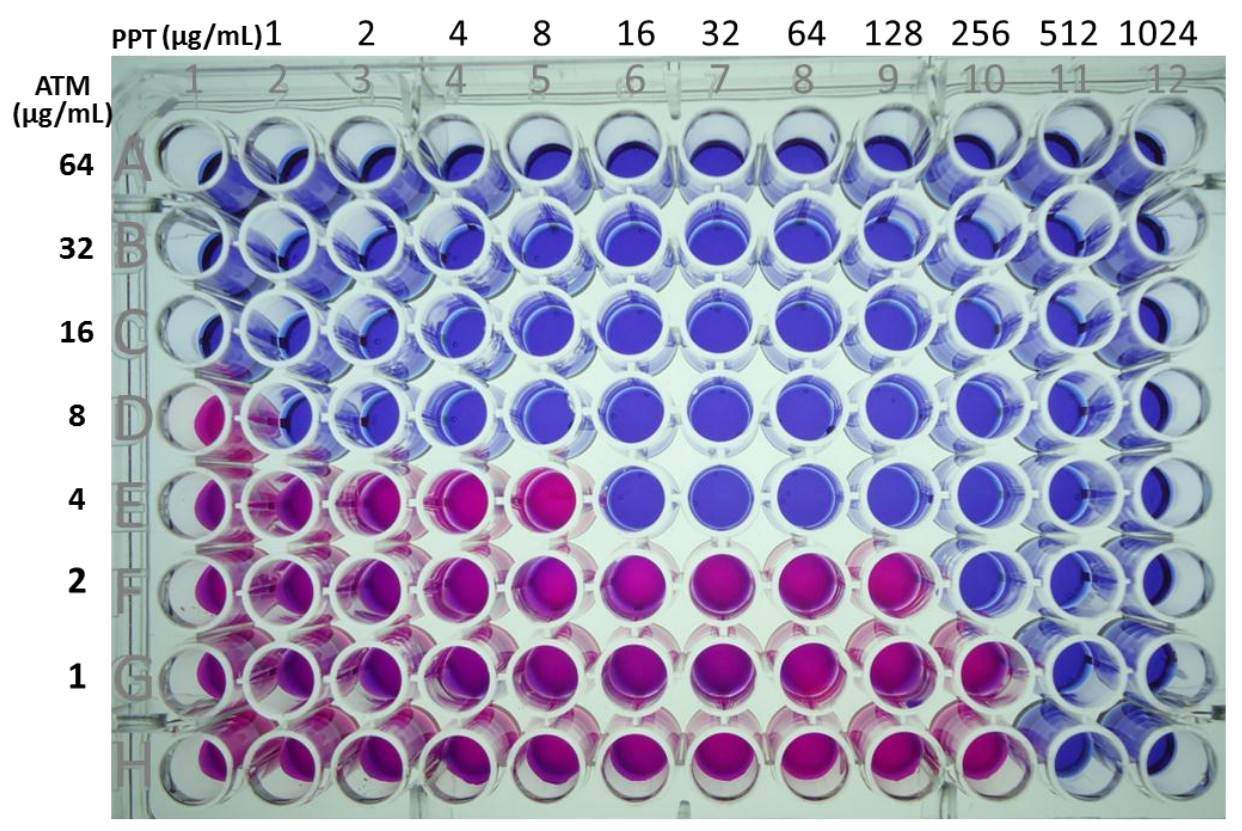

Nota: Poços em azul = sem crescimento bacteriano; Poços em rosa = com crescimento bacteriano. ATM = Aztreonam; PPT = Piperacilina/Tazobactam. Horizontal: concentrações de PPT; Vertical: concentrações de ATM. $\Sigma F I C=0,14$. ATM CBM $16 \mu \mathrm{g} / \mathrm{mL}(\mathrm{C} 1)$; PPT CBM $512 \mu \mathrm{g} / \mathrm{mL}$ (H11); Ponto do sinergismo E6 [Aztreonam $2 \mu \mathrm{g} / \mathrm{mL}$ ] e [Piperacilina/Tazobactam $8 \mu \mathrm{g} / \mathrm{mL}$ ]. 


\subsection{Teste Confirmatório de Sinergismo de [Piperacilina/Tazobactam $x$ Aztreonam]}

O teste confirmatório de sinergismo (Materiais e Métodos, seção 3.11) foi realizado para a cepa 247B VIM-1 (Figura 14), para a cepa PA GIM-1 (Figura 15) e para a cepa 48-1997A SPM-1 (Figura 16). Os valores das concentrações de Aztreonam adicionadas ao ágar Mueller-Hinton e os valores dos halos de inibição podem ser observados na Tabela 5.

Podemos observar o aumento dos halos (Figura 14B, 14C e 14D) nas placas com concentrações crescentes de Aztreonam no ágar Mueller-Hinton (4, 8 e 16 $\mu \mathrm{g} / \mathrm{mL}$ ) quando comparadas com a Figura 14A, a qual não possui Aztreonam. A maior concentração de Aztreonam (adicionado ao ágar) que permitiu a formação de halos foi utilizada para a adição da fita de E-test de Piperacilina/Tazobactam.

Tabela 5 - Valores dos diâmetros dos halos de inibição do teste confirmatório de sinergismo.

\begin{tabular}{|c|c|c|c|c|c|c|c|}
\hline \multirow[b]{2}{*}{ CEPAS } & \multirow[b]{2}{*}{ Figuras* } & \multirow{2}{*}{$\begin{array}{c}\mu \mathrm{g} / \mathrm{mL} \\
\mathrm{de} \\
\text { ATM } \\
\text { no } \\
\text { ágar }\end{array}$} & \multicolumn{5}{|c|}{ (\#) Diâmetro do Halo de inibição (mm) } \\
\hline & & & $\begin{array}{c}\text { LVX } \\
S \geq 17 ; R \leq 13\end{array}$ & $\begin{array}{c}P O L \\
S \geq 12 ; R \leq 11\end{array}$ & $\begin{array}{c}\text { AMI } \\
S \geq 17 ; R \leq 14\end{array}$ & $\begin{array}{c}P P T \\
S \geq 18 ; R \leq 17\end{array}$ & $\begin{array}{c}\text { ATM } \\
S \geq 22 ; R \leq 15\end{array}$ \\
\hline \multirow[t]{4}{*}{ 247B VIM-1 } & $14 \mathrm{~A}$ & - & 6 & 16 & 20 & 17 & 22 \\
\hline & 14B & 4 & 6 & 16 & 24 & 20 & - \\
\hline & $14 \mathrm{C}$ & 8 & 6 & 17 & 28 & 22 & - \\
\hline & 14D & 16 & 6 & 18 & 35 & 27 & - \\
\hline \multirow[t]{4}{*}{ PA GIM-1 } & $15 \mathrm{~A}$ & - & 6 & 17 & 21 & 12 & 24 \\
\hline & 15B & 4 & 6 & 18 & 24 & 15 & - \\
\hline & $15 \mathrm{C}$ & 8 & 6 & 19 & 26 & 18 & - \\
\hline & $15 \mathrm{D}$ & 16 & 8 & 20 & 32 & 22 & - \\
\hline \multirow[t]{4}{*}{ 48-1997A SPM-1 } & $16 \mathrm{~A}$ & - & 6 & 12 & 16 & 14 & 22 \\
\hline & $16 \mathrm{~B}$ & 8 & 6 & 15 & 23 & 19 & - \\
\hline & $16 \mathrm{C}$ & 16 & 6 & 17 & 27 & 21 & - \\
\hline & $16 \mathrm{D}$ & 32 & 8 & 20 & 34 & 24 & - \\
\hline
\end{tabular}

Nota: Antibióticos usados em combinação com diferentes concentrações de Aztreonam, adicionadas ao ágar Mueller-Hinton. * Figuras encontradas no texto. AMI (Amicacina), LVX (Levofloxacina), ATM (Aztreonam), PPT (Piperacilina/Tazobactam), POL (Polimixina B). R, resistente; S, sensível. Fonte: (\#) Adaptado do CLSI (2011). 
A Figura 14F mostra uma CIM de Piperacilina/Tazobactam (com Aztreonam na concentração de $16 \mu \mathrm{g} / \mathrm{mL}$ adicionado ao ágar) de $12 \mu \mathrm{g} / \mathrm{mL}$, já a CIM sem a adição de Aztreonam é de $128 \mu \mathrm{g} / \mathrm{mL}$ (Figura 14E).

Houve um aumento nos halos (Figura 15B, 15C e 15D) nas placas de MuellerHinton com concentrações crescentes de Aztreonam (4, 8 e $16 \mu \mathrm{g} / \mathrm{mL}$ ), quando comparadas com a Figura 15A, a qual não possui o Aztreonam adicionado no ágar. A maior concentração de Aztreonam (16 $\mu \mathrm{g} / \mathrm{mL}$ ) foi acrescentada ao ágar para a colocação da fita de E-test de Piperacilina/Tazobactam (Figura 15F) e comparada com outra fita sem a adição do Aztreonam (Figura 15E). A CIM no E-test sem Aztreonam incluído ao ágar, foi maior do que $256 \mu \mathrm{g} / \mathrm{mL}$, enquanto que na placa com a adição de ATM ao ágar foi de $48 \mu \mathrm{g} / \mathrm{mL}$.

O mesmo efeito pode ser observado na Figura 16B, 16C E 16D, onde as concentrações crescentes de Aztreonam (8, 16 e $32 \mu \mathrm{g} / \mathrm{mL}$ ) tiveram um aumento nos halos de inibição, quando comparados com a Figura 16A. A concentração de 32 $\mu \mathrm{g} / \mathrm{mL}$ de Aztreonam adicionado ao ágar foi utilizada para o acréscimo da fita de $\mathrm{E}$ test de Piperacilina/Tazobactam (Figura 16F), a qual teve uma CIM de $4 \mu \mathrm{g} / \mathrm{mL}$, já a CIM da placa sem o acréscimo de Aztreonam ao ágar foi acima de $256 \mu \mathrm{g} / \mathrm{mL}$ (Figura 16E).

Figura 14 - Teste confirmatório de sinergismo para a combinação de [Piperacilina/Tazobactam x Aztreonam] para a cepa 247B VIM-1.
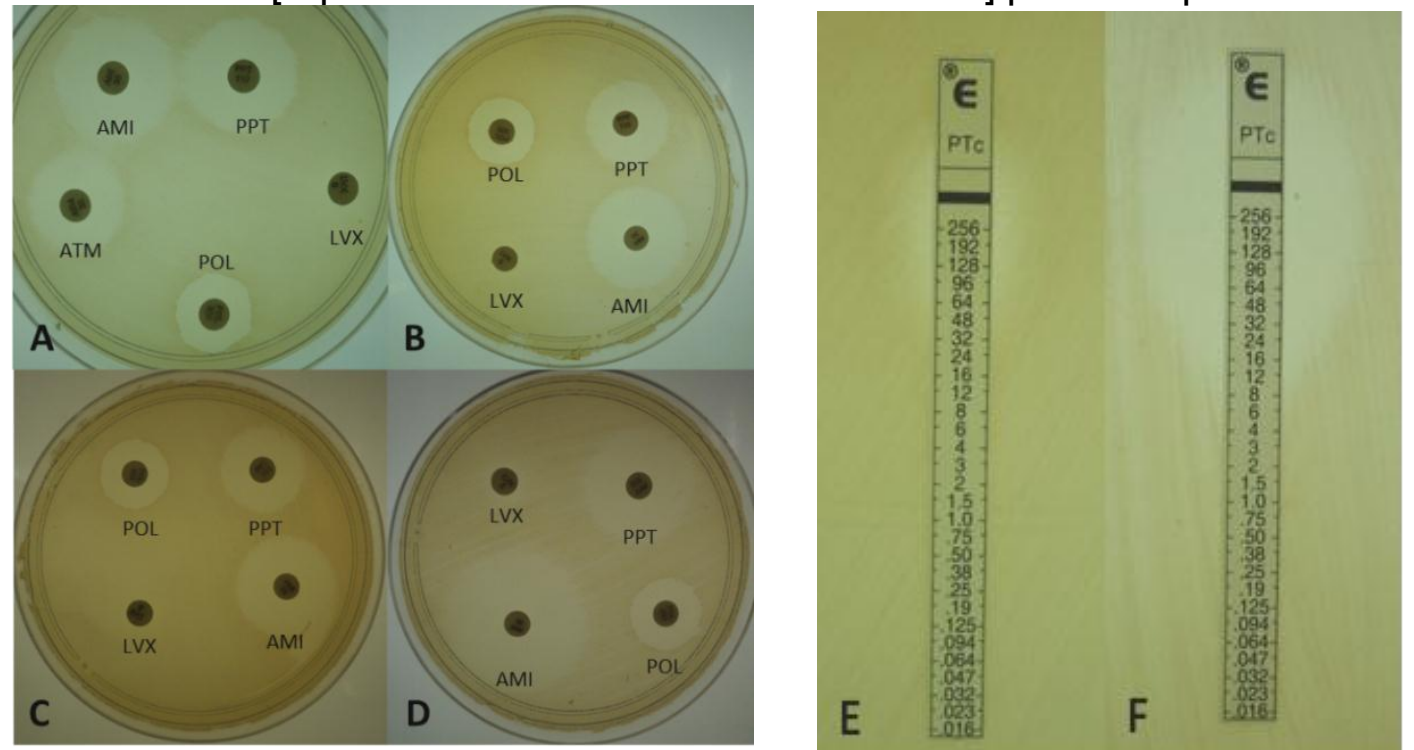

Nota: AMI (Amicacina), LVX (Levofloxacina), ATM (Aztreonam), PPT (Piperacilina/Tazobactam), POL (Polimixina B). A, placa sem Aztreonam adicionado ao ágar Mueller-Hinton; B, placa com Aztreonam adicionado ao ágar $4 \mu \mathrm{g} / \mathrm{mL}$; C, placa com Aztreonam adicionado ao ágar $8 \mu \mathrm{g} / \mathrm{mL}$; D, placa com Aztreonam adicionado ao ágar $16 \mu \mathrm{g} / \mathrm{mL} ; \mathrm{E}$, E-test Piperacilina/Tazobactam sem Aztreonam adicionado ao ágar; F, E-test Piperacilina/Tazobactam com Aztreonam $16 \mu \mathrm{g} / \mathrm{mL}$ adicionado ao ágar. 
Figura 15 - Teste confirmatório de sinergismo para a combinação de [Piperacilina/Tazobactam x Aztreonam] para a cepa PA GIM-1.
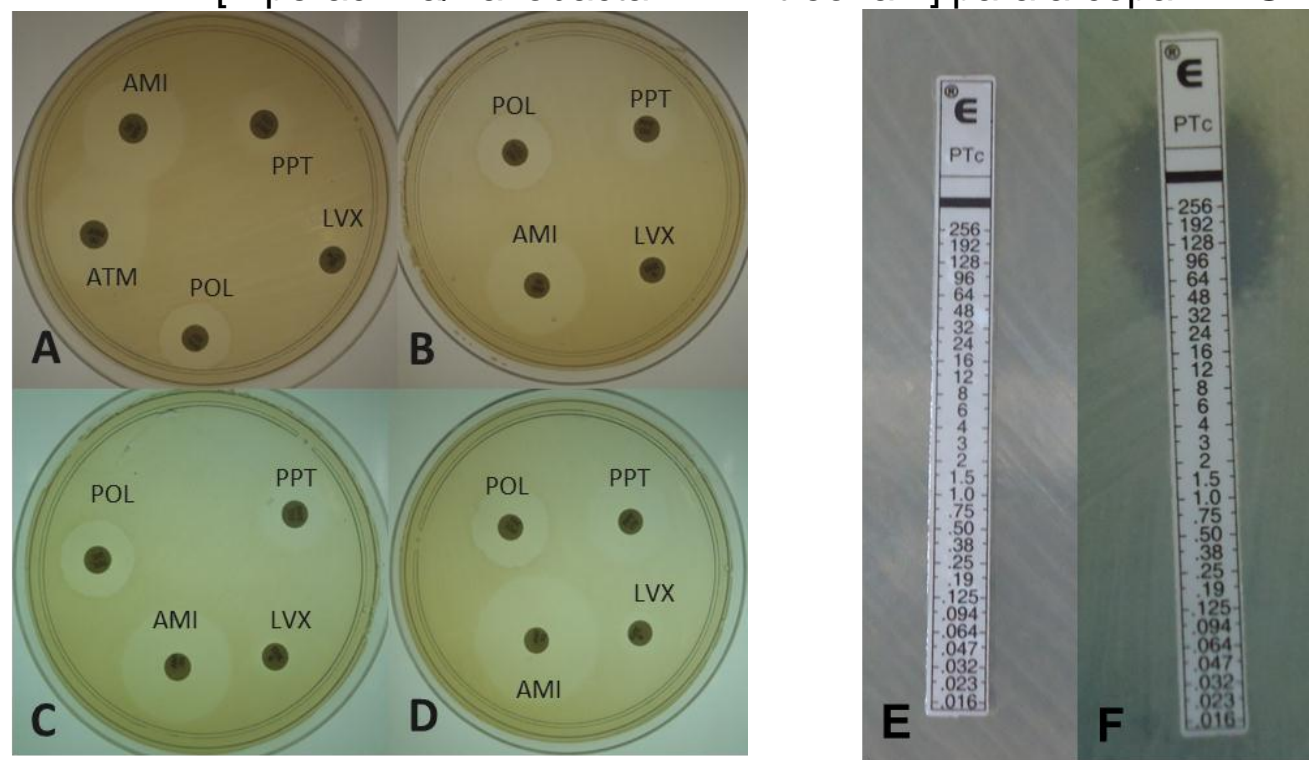

Nota: AMI (Amicacina), LVX (Levofloxacina), ATM (Aztreonam), PPT (Piperacilina/Tazobactam), POL (Polimixina B). A, placa sem Aztreonam adicionado ao ágar Mueller-Hinton; B, placa com Aztreonam adicionado ao ágar $4 \mu \mathrm{g} / \mathrm{mL}$; C, placa com Aztreonam adicionado ao ágar $8 \mu \mathrm{g} / \mathrm{mL}$; D, placa com Aztreonam adicionado ao ágar $16 \mu \mathrm{g} / \mathrm{mL} ; \mathrm{E}$, E-test Piperacilina/Tazobactam sem Aztreonam adicionado ao ágar; F, E-test Piperacilina/Tazobactam com Aztreonam $16 \mu \mathrm{g} / \mathrm{mL}$ adicionado ao ágar.

Figura 16 - Teste confirmatório de sinergismo para a combinação de [Piperacilina/Tazobactam x Aztreonam] para a cepa 48-1997A SPM-1.
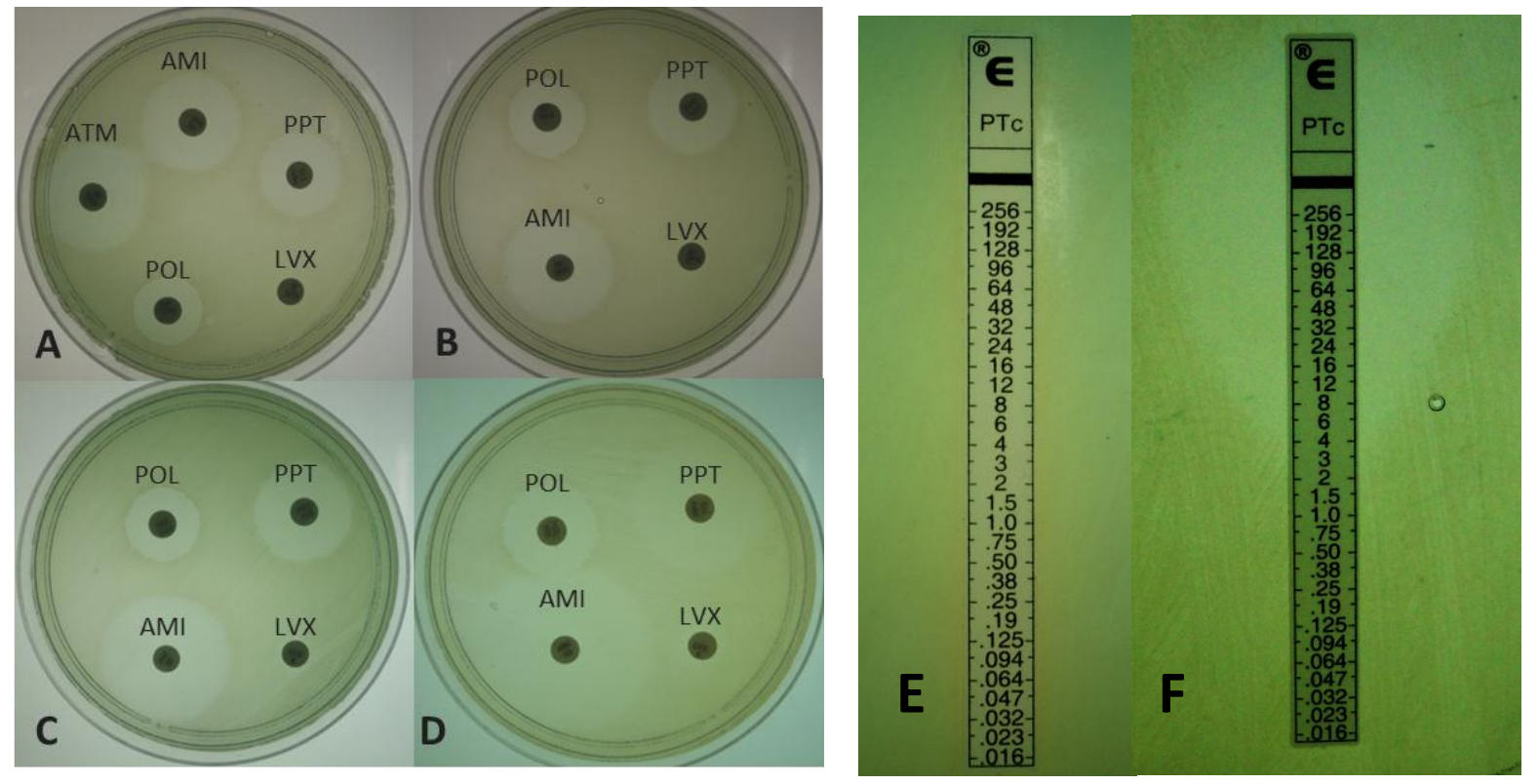

Nota: AMI (Amicacina), LVX (Levofloxacina), ATM (Aztreonam), PPT (Piperacilina/Tazobactam), POL (Polimixina B). A, placa sem Aztreonam adicionado ao ágar Mueller-Hinton; B, placa com Aztreonam adicionado ao ágar $8 \mu \mathrm{g} / \mathrm{mL}$; C, placa com Aztreonam adicionado ao ágar $16 \mu \mathrm{g} / \mathrm{mL}$; D, placa com Aztreonam adicionado ao ágar $32 \mu \mathrm{g} / \mathrm{mL}$; E, E-test Piperacilina/Tazobactam sem Aztreonam no ágar; F, E-test Piperacilina/Tazobactam com Aztreonam $32 \mu \mathrm{g} / \mathrm{mL}$ adicionado ao ágar. 


\section{8 "Time-Kill” da combinação [Piperacilina/Tazobactam x Aztreonam]}

Após a realização dos testes confirmatórios de sinergismo foi realizado o "Time-Kill" para as cepas 247B VIM-1, PA GIM-1 e 48-1997A SPM-1. As concentrações dos antibióticos usados para o teste foram selecionadas de acordo com os maiores valores resultantes da atividade bactericida, em triplicata (realizadas após os testes de "Checkerboard").

Para a cepa 247B VIM-1 tanto o Aztreonam na concentração de $16 \mu \mathrm{g} / \mathrm{mL}$, como a Piperacilina/Tazobactam na concentração de $128 \mu \mathrm{g} / \mathrm{mL}$ levaram a morte bacteriana em 12 horas. Já a combinação sinérgica dos dois antibióticos [Aztreonam $4 \mu \mathrm{g} / \mathrm{mL}$ ] e [Piperacilina/Tazobactam $32 \mu \mathrm{g} / \mathrm{mL}$ ] levaram a morte das bactérias na sexta hora (Figura 17).

A morte bacteriana para Aztreonam (16 $\mu \mathrm{g} / \mathrm{mL}$ ), para a cepa PA GIM-1 (Figura 18) ocorreu na sexta hora. Já a Piperacilina/Tazobactam não levou a morte as bactérias nem em 24 horas. No entanto, a combinação dos dois antibióticos [Aztreonam $4 \mu \mathrm{g} / \mathrm{mL}$ ] e [Piperacilina/Tazobactam $256 \mu \mathrm{g} / \mathrm{mL}$ ] ocasionou a morte das bactérias na sexta hora.

Já para a cepa 48-1997A SPM-1 (Figura 19), o Aztreonam (32 $\mu \mathrm{g} / \mathrm{mL}$ ) ocasionou a morte das bactérias na hora 24 , enquanto que a Piperacilina/Tazobactam $(512 \mu \mathrm{g} / \mathrm{mL})$ matou em 12 horas e, a combinação dos dois antibióticos [Aztreonam $4 \mu \mathrm{g} / \mathrm{mL}$ ] e [Piperacilina/Tazobactam $8 \mu \mathrm{g} / \mathrm{mL}$ ] levou a morte bacteriana na sexta hora. 
Figura 17 - Curva de morte (gráfico "Time-Kill") da cepa de P. aeruginosa 247B VIM-1 para a combinação [Piperacilina/Tazobactam x Aztreonam].

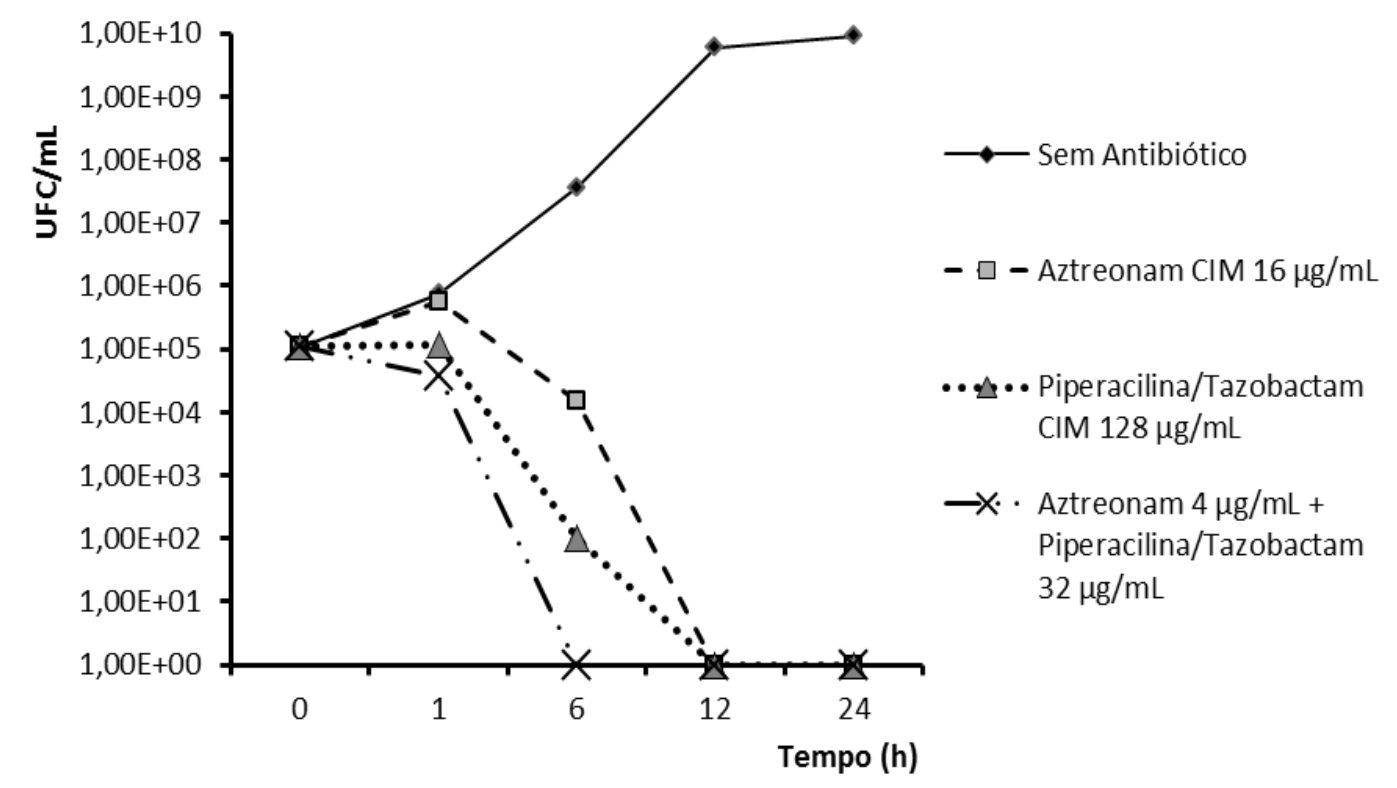

Figura 18 - Curva de morte (gráfico "Time-Kill") da cepa de P. aeruginosa PA GIM-1 para a combinação [Piperacilina/Tazobactam x Aztreonam].

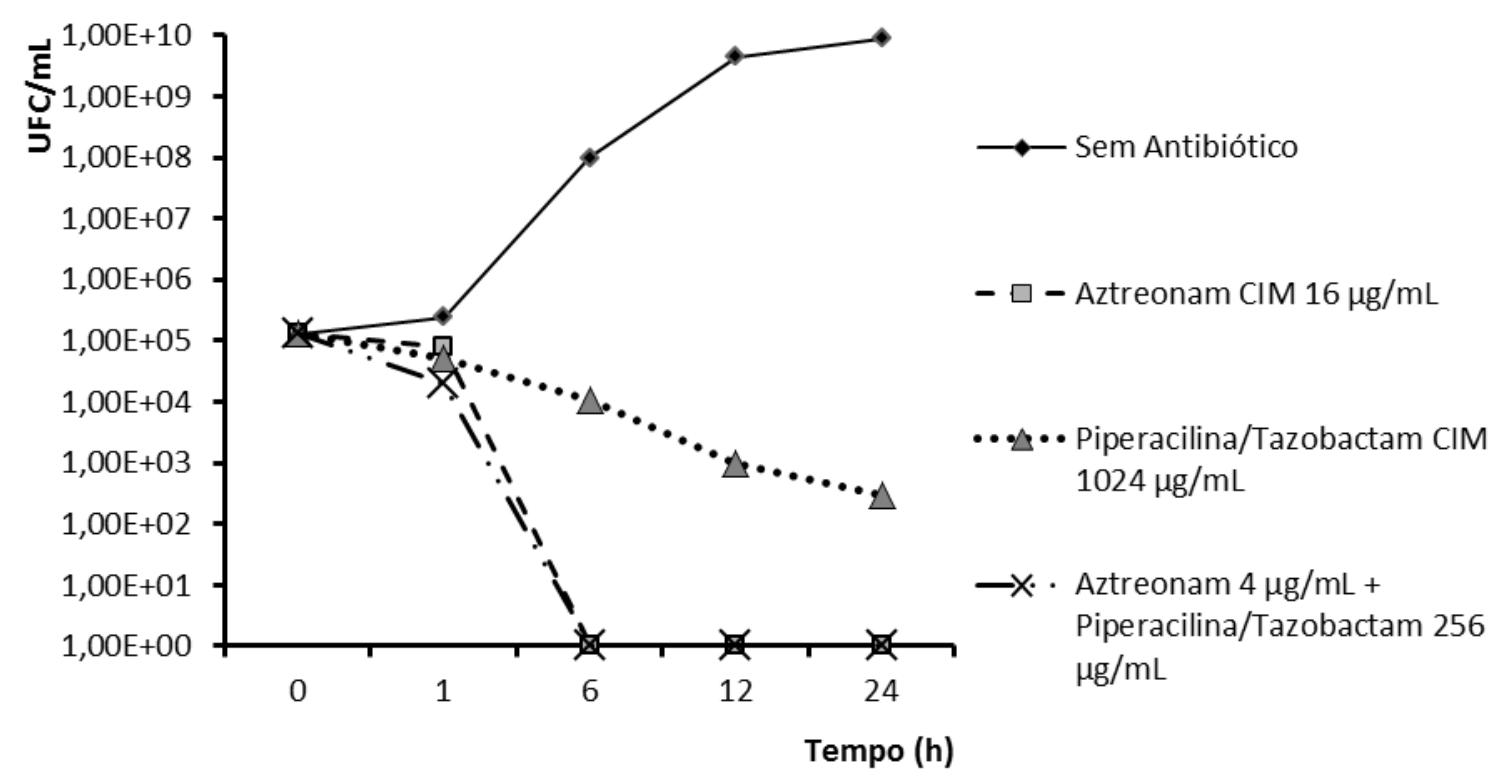


Figura 19 - Curva de morte (gráfico “Time-Kill”) da cepa de $P$. aeruginosa 48-1997A SPM-1 para a combinação [Piperacilina/Tazobactam x Aztreonam].

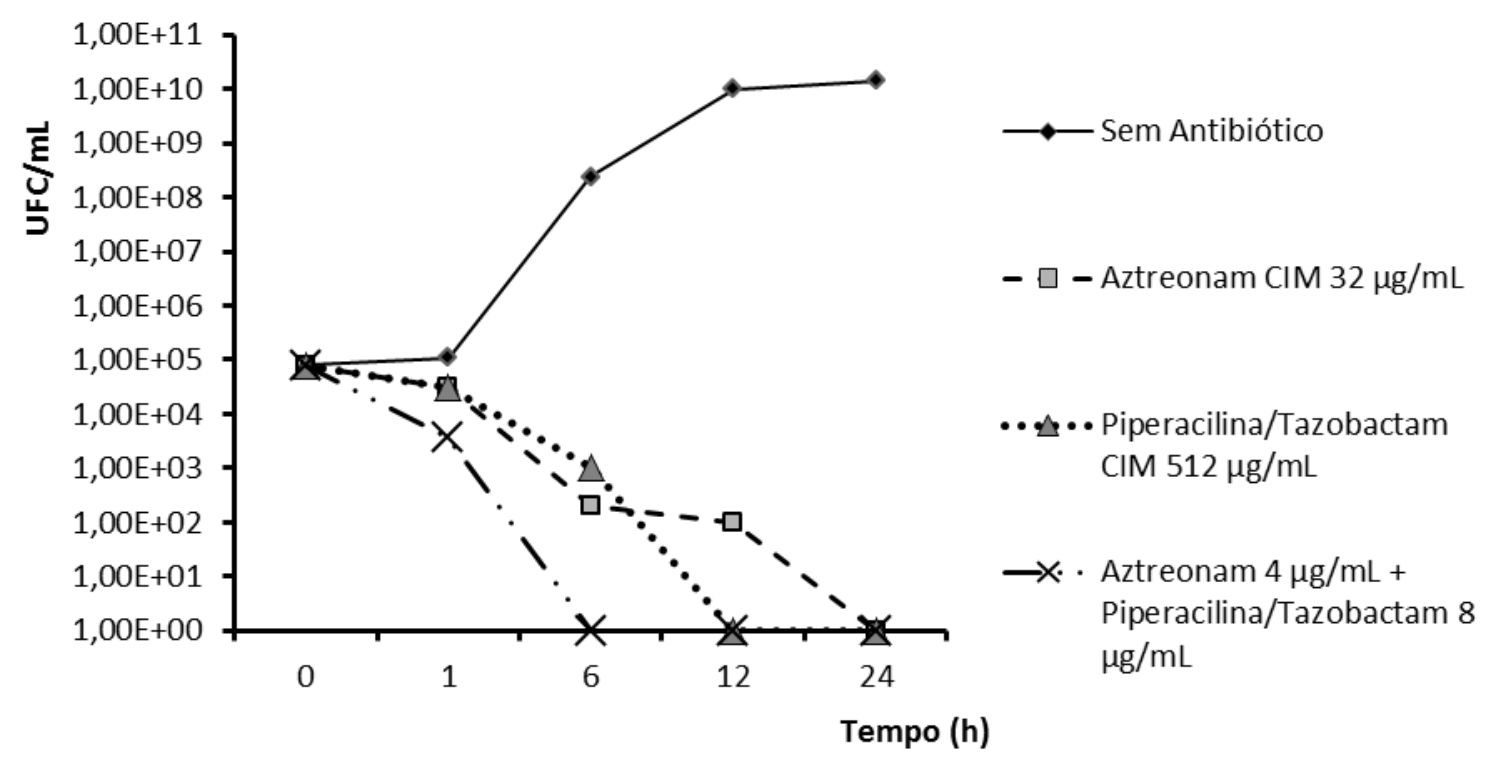




\section{DISCUSSÃO}

O desenvolvimento da resistência é um evento biológico natural, que se seguiu à introdução dos agentes antimicrobianos, porém o uso excessivo, assim como subutilização através de dosagem inadequada e baixa qualidade de antimicrobianos também pode contribuir para o seu aumento (Davies, Davies, 2010; Moura, 2007; Rossi, 2011). A resistência bacteriana é uma preocupação mundial, sendo objeto de estudo das mais diversas pesquisas (Sader et al., 2001; Kiffer et al., 2005; Theuretzbacher, 2012).

Vários fatores podem levar a seleção de cepas resistentes e à endemicidade, as quais são associadas às infecções hospitalares, como o uso de técnicas inadequadas de controle de infecção por profissionais da saúde, o contato direto e indireto com reservatórios das cepas, além de procedimentos não apropriados de assepsia, limpeza, desinfecção do ambiente e de equipamentos (Moura, 2007; Pellegrino et al., 2002).

O aumento da resistência aos carbapenêmicos é preocupante, uma vez que eles são considerados como último recurso no tratamento de infecções hospitalares. A dificuldade no desenvolvimento de novas drogas tem limitado as alternativas terapêuticas para as infecções ocasionadas por bactérias MR (Tillotson, 2008).

Pseudomonas aeruginosa é um patógeno oportunista que acomete especialmente pacientes imunocomprometidos, sob ventilação mecânica, queimados, portadores de fibrose cística e os que estão em unidades de terapia intensiva, e é um dos mais frequentes patógenos em pneumonia nosocomial (Azzopardi et al., 2011; Carvalho et al., 2008; Goossens, 2003; Høiby, 2011; Sader et al., 2001).

Infecções ocasionadas por $P$. aeruginosa são de grande importância devido a expressão de múltiplos mecanismos de resistência, dificultando a ação de antibacterianos, ocasionando elevados índices de morbidade e mortalidade (Gales et al., 2004; Pellegrino et al., 2002; Poole, 2011; Sader et al., 2001).

Dentre os diversos mecanismos de resistência ressaltam-se: inativação ou degradação enzimática dos antimicrobianos por enzimas, super expressão de bombas de efluxo, perda de porina, alterações no sítio alvo (Kanj, Kanafani, 2011; Muller et al., 2011; Zavascki et al., 2010). 
Quase todos os mecanismos de resistência intrínseca ou adquirida, conhecidos em bactérias gram-negativas podem ser encontrados em $P$. aeruginosa e essa sua capacidade de utilizar e combinar esses mecanismos faz com que ela seja um patógeno altamente resistente a agentes tóxicos e que sobreviva em ambientes com alta pressão seletiva pelo uso corrente de antimicrobianos (Davies, Davies, 2010; Hancock, Speert, 2000; Livermore, 2002; Perez et al., 2012; Poole, 2011).

Pseudomonas aeruginosa pode apresentar resistência a um grande número de antibióticos normalmente utilizados na prática clínica, como cefalosporinas de primeira e segunda geração, tetraciclinas, cloranfenicol e macrolídeos (Livermore, 2002; Strateva, Yordanov, 2009; Yoneda et al., 2005).

Dentre os mecanismos de resistência bacteriana, a produção de enzimas é considerada a de maior relevância. Metalo- $\beta$-lactamases pertencem à classe molecular B, de acordo com a classificação de Ambler (1980) e as subclasses conhecidas IMP, VIM-1, GIM-1, SIM, SPM-1, NDM-1.

Esta classe de $\beta$-lactamases é caracterizada pela capacidade de hidrolisar carbapenêmicos e por sua resistência aos inibidores comercialmente disponíveis, como o ácido clavulânico, mas são consideradas zinco-dependentes e necessitam deste metal para realizar a sua atividade. Sendo assim estas enzimas são inibidas por agentes quelantes como o ácido etilenodiamino tetracético (EDTA) e o ácido 2mercapto-propiônico (MPA) (Queenan, Bush, 2007).

No Brasil há relatos de disseminação Pseudomonas aeruginosa SPM-1 (Gales et al., 2003a; Lincopan et al., 2010) que, desde seu primeiro relato ocorreu elevada mortalidade entre os pacientes hospitalizados (Furtado et al., 2011; Gales et al., 2003a; Queenan, Bush, 2007; Santos Filho et al., 2002; Zavascki et al., 2006).

Além disso, há estudos comprovando a co-produção de SPM-1 e a proteína RmtD, uma metilase 16S RNAr, que confere um nível elevado de resistência a aminoglicosídeos usados clinicamente (Doi et al., 2007, Lincopan et al., 2010).

Diante desse panorama desfavorável existe uma urgência pela procura de opções terapêuticas para esses isolados. Uma opção para esse quadro seria o uso combinado de antimicrobianos para obtenção de um efeito sinérgico (Rodloff et al., 2006; Tripodi et al., 2007; Zhanel et al., 2006). 
Em uma primeira etapa, realizamos os antibiogramas das 10 cepas clonalmente não relacionados (PA01, 48-1997A SPM-1, 111ER, 44CIB, 36C, 31C, 10C, PA0905, VIM-1 247B, PA GIM-1) para a determinação das CIMs (Quadro 4).

A seguir, foi realizado o teste de sinergismo para as cepas [111ER e 44CIB] com quatorze combinações de antimicrobianos (Tabela 1).

Posteriormente, as combinações que se mostraram sinérgicas para ambas as cepas foram então testadas para as demais cepas (PA01, 48-1997A SPM-1, 36C, 31C, 10C, PA0905, VIM-1 247B e PA GIM-1) (Tabelas 3, 4 e 5).

Após a obtenção dos resultados sinérgicos foi realizado o teste de "Time-Kill" para as cepas 48-1997A SPM-1, 247B VIM-1 e PA GIM-1.

Finalmente, ensaios adicionais foram feitos para melhor visualização dos efeitos sinérgicos, como o Teste Confirmatório de Sinergismo, Espectrofotometria de UV visível, Potencial Zeta e "Light Scattering".

\subsection{Antibiogramas}

Segundo Magiorakos et al. (2012) os microrganismos multirresistentes são aqueles que apresentam resistência a pelo menos três antibióticos de classes diferentes, os antibiogramas das nove cepas, já caracterizadas em pesquisas prévias como produtoras de Metalo- $\beta$-lactamase, revelaram um fenótipo de multirresistência. PA01 foi sensível a todos os antibióticos avaliados, exceto a Tigeciclina, como pode ser observado no Quadro 4.

As cepas demonstraram serem resistentes aos principais antimicrobianos usados na prática clínica, sendo eles Ceftazidima, Ciprofloxacina, Levofloxacina, Gentamicina, incluindo os carbapenêmicos, considerados de última escolha terapêutica (Meropenem e Imipenem). Foi observado o perfil de resistência para Piperacilina/Tazobactam em nove cepas, sete para Amicacina e sete para Cefepime. Como era de esperar, todas as cepas foram resistentes a Tigeciclina, de acordo com a interpretação dada as Enterobacteriaceae pelo EUCAST (2012a).

Por outro lado, não foram detectadas cepas resistentes ao Aztreonam, Polimixina B e Colistina. Esse resultado é compatível com vários estudos, os quais mostram que Aztreonam é mais estável frente as cepas produtoras de $\mathrm{M} \beta \mathrm{L}$, como a SPM-1 ( Toleman et al., 2002). Já o perfil de sensibilidade obtido para Polimixina B e 
Colistina também são condizentes de acordo com Castanheira et al. (2004) e Schurek et al. (2009).

\section{2 "Checkerboard"}

\subsubsection{Resultados Sinérgicos}

Devido a dificuldade de tratamento e falta de opções terapêuticas para Pseudomonas aeruginosa, uma opção a se apresentar diante dessa problemática, é o estudo de combinações de antimicrobianos em busca de efeitos sinérgicos (Bouza, Muñoz, 2000; Choi et al., 2004; Davies, Davies, 2010; Lyczak et al., 2002; Tripodi et al., 2007; Zhanel et al., 2006).

Após a obtenção dos fenótipos de multirresistência através do método de "Kirby-Bauer" foram determinadas as CIMs, através do teste de "Checkerboard". Duas cepas resistentes a todos os antimicrobianos (exceto Polimixina B, Colistina e Aztreonam) foram selecionadas [111ER e 44CIB]. As combinações que demonstrassem serem sinérgicas para ambas as cepas seriam testadas para as demais.

Foram testadas quatorze combinações de antimicrobianos contra as cepas [111ER e 44CIB], dentre essas, sete combinações obtiveram o efeito sinérgico para a cepa 111ER e quatro combinações foram sinérgicas contra a cepa 44CIB (Tabela 1). Com relação aos valores da CIM, as interpretações foram baseadas no CLSI (2011).

Analisando separadamente os resultados dos sinergismos obtidos para a cepa 111ER, a combinação [Polimixina B/Amicacina] que resultou na queda da CIM da Amicacina de $1024 \mu \mathrm{g} / \mathrm{mL}$ para $0,5 \mu \mathrm{g} / \mathrm{mL}$ (diminuição de 2048 vezes).

A Polimixina B também favoreceu a queda da CIM do Imipenem de 256 para $0,005 \mu \mathrm{g} / \mathrm{mL}$ (diminuição de 51200 vezes). A Piperacilina/Tazobactam favoreceu a queda da CIM do Aztreonam de 8 para $0,25 \mu \mathrm{g} / \mathrm{mL}$ (diminuição de 32 vezes).

Tanto a Piperacilina/Tazobactam quanto a Levofloxacina tiveram sua CIM diminuída de 512 para $128 \mu \mathrm{g} / \mathrm{mL}$ e de 64 para $16 \mu \mathrm{g} / \mathrm{mL}$, respectivamente (queda de 4 vezes) quando em combinação. Por outro lado, Levofloxacina quando em 
combinação com o DDA teve sua CIM reduzida de 64 para $1 \mu \mathrm{g} / \mathrm{mL}$ (diminuição de 64 vezes).

A Amicacina em combinação com o DDA teve a queda da CIM de 2048 para $128 \mu \mathrm{g} / \mathrm{mL}$ (diminuição de 16 vezes). Também a Tigeciclina combinada com o DDA teve queda da CIM de 16 para $2 \mu \mathrm{g} / \mathrm{mL}$ (diminuição de 8 vezes).

Já para a cepa 44CIB, a combinação sinérgica [Piperacilina/Tazobactam e Aztreonam] resultou na diminuição da CIM de Piperacilina/Tazobactam de 128 para $0,06 \mu \mathrm{g} / \mathrm{mL}$ (diminuição de 2133 vezes). A Piperacilina/Tazobactam também permitiu a queda da CIM do Imipenem de 256 para $4 \mu \mathrm{g} / \mathrm{mL}$ (diminuição de 64 vezes).

A Polimixina B quando combinada com a Amicacina resultou na queda da CIM de 1024 para 0,5 $\mathrm{mg} / \mathrm{mL}$ (diminuição de 2048 vezes). E a combinação [Tigeciclina/DDA] permitiu a diminuição da CIM da Tigeciclina de 16 para $1 \mu \mathrm{g} / \mathrm{mL}$ (queda de 16 vezes).

Evidenciando-se as combinações de antimicrobianos promissoras [Tigeciclina $x$ DDA], [Piperacilina/Tazobactam x Aztreonam] e [Amicacina x Polimixina B] foram realizados novos testes de "Checkerboard" para as cepas (PA01, 48-1997A SPM-1, 36C, 31C, 10C, PA0905, VIM-1 247B e PA GIM-1).

Os resultados obtidos para [Tigeciclina $x$ DDA] podem ser observados na Tabela 2. Metade das cepas apresentaram uma CBM de $32 \mu \mathrm{g} / \mathrm{mL}$ para Tigeciclina e a outra metade $16 \mu \mathrm{g} / \mathrm{mL}$. Já para o DDA as cepas apresentaram valores da CBM mais diversificados, variando de 4 para $32 \mu \mathrm{g} / \mathrm{mL}$. A CBM das cepas para o DDA foram 20\% (4 $\mu \mathrm{g} / \mathrm{mL}), 20 \%$ (8 $\mu \mathrm{g} / \mathrm{mL}$ ), 40\% (16 $\mu \mathrm{g} / \mathrm{mL})$ e $20 \%(32 \mu \mathrm{g} / \mathrm{mL})$.

A CBM da Tigeciclina teve queda de 16 vezes quando em combinação com o DDA (diminuição de 16 para $1 \mu \mathrm{g} / \mathrm{mL}$ ), a queda para o DDA foi de 8 vezes (de 4 para $0.5 \mu \mathrm{g} / \mathrm{mL})$.

Para a combinação [Piperacilina/Tazobactam x Aztreonam], as CIMs de Piperacilina/Tazobactam variaram de $128 \mu \mathrm{g} / \mathrm{mL}$ (exceto para a cepa sensível PA01) até $1024 \mu \mathrm{g} / \mathrm{mL}$. Já o Aztreonam se mostrou sensível para todas as cepas. A queda da CIM de Piperacilina/Tazobactam variou de 0,06 até $256 \mu \mathrm{g} / \mathrm{mL}$ quando combinada com Aztreonam. Por sua vez, o Aztreonam combinado com Piperacilina/Tazobactam variou de 0,25 até $4 \mu \mathrm{g} / \mathrm{mL}$ no valor da CIM. Os resultados podem ser observados na Tabela 3. Para uma melhor visualização dos sinergismos, 
as Figuras 11, 12 e 13 apresentam as atividades bactericidas com Alamar Blue, de três cepas (VIM-1 247B, PA GIM-1 e 48-1997A SPM-1).

A combinação [Tigeciclina $x$ DDA] apresentou um resultado sinérgico para todas as cepas, já [Piperacilina/Tazobactam x Aztreonam] foi sinérgico para nove cepas e indiferente apenas para a cepa PA0905.

Por sua vez, a combinação [Amicacina x Polimixina B], que apresentou resultados sinérgicos para as cepas $111 \mathrm{ER}$ e $44 \mathrm{CIB}$, foi testada para as demais cepas, porém oito obtiveram um resultado de indiferença (Tabela 4).

Para as cepas [111ER e 44CIB] a Polimixina B apresentou queda de 1 diluição da sua CIM quando combinada com a Amicacina. Já a CIM da Amicacina, analisando todas as cepas, variou de 0,5 a $128 \mu \mathrm{g} / \mathrm{mL}$. Destacando-se as cepas 111ER e 44CIB, as quais a Amicacina apresentou uma diminuição na CIM de 1024 para $0,5 \mu \mathrm{g} / \mathrm{mL}$ (diminuição da CIM de 2048 vezes).

Pseudomonas aeruginosa MR é de difícil tratamento e, aliado a dificuldade no desenvolvimento de novas drogas (o que ocasiona um temor de um possível regresso à era pré-antibiótica), os resultados sinérgicos obtidos apresentam uma opção de tratamento às infecções ocasionadas por esse microrganismo (Levin, Oliveira, 2008; Paterson, Lipman, 2007; Tillotson, 2008).

Para uma discussão prática dos resultados, a Tabela 6 apresenta os picos séricos e as CIMs dos antibióticos testados.

Tabela 6 - Picos séricos e "breakpoints" dos antimicrobianos avaliados.

\begin{tabular}{|c|c|c|c|c|c|}
\hline \multirow[t]{2}{*}{ ANTIBIÓTICO } & \multirow[t]{2}{*}{$\begin{array}{l}\text { DOSE - VIA DE } \\
\text { ADMINISTRAÇÃOO }\end{array}$} & \multirow{2}{*}{$\begin{array}{l}\text { PICO } \\
\text { SÉRICO } \\
\mu \mathrm{g} / \mathrm{mL}\end{array}$} & \multicolumn{3}{|c|}{$\begin{array}{c}\text { PADRÃO DE } \\
\text { INTERPRETAÇÃO DA } \\
\text { CIM }(\mu \mathrm{g} / \mathrm{mL})^{*}\end{array}$} \\
\hline & & & $\mathrm{S}$ & I & $\mathbf{R}$ \\
\hline AMICACINA & $15 \mathrm{mg} / \mathrm{kg}(24 \mathrm{~h})$ & $56-64$ & $\leq 16$ & 32 & $\geq 64$ \\
\hline AZTREONAM & $1000 \mathrm{mg}-\mathrm{IV}$ & 90 & $\leq 8$ & 16 & $\geq 32$ \\
\hline IMIPENEM & $500 \mathrm{mg}-\mathrm{IV}$ & 40 & $\leq 4$ & 8 & $\geq 16$ \\
\hline LEVOFLOXACINA & $750 \mathrm{mg}$ - VO/IV (24h) & $8.6 / 12.1$ & $\leq 2$ & 4 & $\geq 8$ \\
\hline PIPERACILINA/TAZOBACTAM & $3 / 0.375 \mathrm{~g}-\mathrm{IV}$ & $242-24$ & $\leq 64 / 4$ & - & $\geq 128 / 4$ \\
\hline POLIMIXINA B & $2 \mathrm{mg} / \mathrm{kg} / \mathrm{IV}$ & $1-8$ & $\leq 2$ & 4 & $\geq 8$ \\
\hline TIGECICLINA & $50 \mathrm{mg}-\mathrm{IV}(12 \mathrm{~h})$ & 0,63 & $1^{(\#)}$ & - & $2^{(\#)}$ \\
\hline
\end{tabular}

Nota: IV: intravenoso; VO: via oral; S: sensível; I: intermediário; R: resistente. ${ }^{(\#)}$ Valores para Enterobacteriaceae.

Fonte: Adaptado de Gilbert et al. (2010). *Adaptado de CLSI, 2011. ${ }^{(\#)}$ Adaptado de EUCAST, 2012a. 
Analisando os resultados sinérgicos da Tabela 3, podemos observar que as CIMs do Aztreonam quando combinado com a Piperacilina/Tazobactam, desde o menor valor $(0,25 \mu \mathrm{g} / \mathrm{mL})$ até o maior valor obtido $(4 \mu \mathrm{g} / \mathrm{mL})$ estão bem abaixo do seu pico plasmático $(90 \mu \mathrm{g} / \mathrm{mL})$. Para Piperacilina/Tazobactam quando combinada com Aztreonam as CIMs variaram de $(0,06$ até $128 \mu \mathrm{g} / \mathrm{mL})$, tendo, portanto 3 cepas [PA01, 48-1997A SPM-1, 44CIB] com valores 10x inferior ao pico plasmático (242-24 $\mu \mathrm{g} / \mathrm{mL}$ ) (Tabela 6).

Para a combinação sinérgica de [Amicacina x Polimixina B] (Tabela 4), para as cepas (111ER e 44CIB) a CIM de Amicacina foi $(0,5 \mu \mathrm{g} / \mathrm{mL})$ estando bem abaixo do pico sérico (56-64 $\mu \mathrm{g} / \mathrm{mL}$ ). Já a Polimixina $B$ quando combinada com a Amicacina ficou com a CIM em $1 \mu \mathrm{g} / \mathrm{mL}$, sendo o pico plasmático (1-8 $\mu \mathrm{g} / \mathrm{mL}$ ) (Tabela 6).

Assim, estas combinações podem ser efetivas, in vivo, se forem testadas para cada cepa, levando em consideração parâmetros farmacocinéticos necessários de serem contemplados para o sucesso da antibioticoterapia.

Na combinação sinérgica [Tigeciclina x DDA], a Tigeciclina apresentou CIMs variando de (0,5 a $4 \mu \mathrm{g} / \mathrm{mL})$, mas levando em consideração de que o pico sérico da Tigeciclina é $0,63 \mu \mathrm{g} / \mathrm{mL}$ para a família das Enterobacteriaceae, uma vez que a Tigeciclina não é recomendada para Pseudomonas aeruginosa (devido a superexpressão de bombas de efluxo) (Livermore, 2005), os valores das CIMs ultrapassariam esse pico sérico, portanto essa combinação não é indicada para tratamento intravenoso, sendo restrita para uso tópico.

\subsubsection{Resultados Indiferentes}

Analisando todas as combinações testadas, para todas as cepas, realizamos um total de 52 ensaios (excluindo-se triplicatas).

Podemos observar que dos 52 ensaios, obtivemos 26 intitulados como indiferentes (Tabelas 2, 4 e 5), sendo o $\sum$ FIC da maioria $\leq 1$.

Considerando esse fato, outros autores têm utilizado outras formas de interpretação: sinergismo ( $\Sigma \mathrm{FIC}, \leq 0.5)$, parcialmente sinérgico $\left(\sum \mathrm{FIC},>0,5<1\right)$, aditivo $(\Sigma \mathrm{FIC}=1)$, indiferente $(\Sigma \mathrm{FIC},>1 \mathrm{e} \leq 4)$ e antagônico $\left(\sum \mathrm{FIC},>4\right)$ (Sader, Jones, 2005; Song et al., 2003; Timurkaynak et al., 2006). 
De acordo com essa nova interpretação, dos 26 ensaios dados como indiferentes, 12 passariam a ser parcialmente sinérgicos, 4 passariam a ser aditivos e apenas 10 seriam de fato indiferentes.

De acordo com Mitsugui et al. (2011) mesmo com a combinações que não resultarem no efeito sinérgico devem ser consideradas, especialmente se tratando de microrganismo multirresistente. Uma vez que houve redução da CIM, estes antimicrobianos podem ser utilizados e permitir um tratamento efetivo, desde que com doses ajustadas.

$\mathrm{Na}$ maioria dos ensaios dados a princípio como indiferentes, houve redução da CIM para pelo menos um dos antibióticos quando combinados, deixando-os na faixa de sensíveis. De acordo com Sader e Jones (2005) as combinações em que pelo menos um dos antibióticos é dado como sensível, demonstram uma opção terapêutica.

Foram realizados 18 ensaios utilizando Polimixina $B$, porém 15 foram dados como indiferentes, mas de acordo com o outro método de interpretação, 4 seriam parcialmente sinérgicas, 1 aditiva e 10 indiferentes. Conforme Timurkaynak et al. (2006), quando em combinação, as polimixinas podem aumentar a permeabilidade da membrana externa bacteriana e permitir a entrada da outra droga na célula.

Mesmo os resultados dados como indiferentes, em ambas as interpretações, podem vir a serem úteis se os antimicrobianos em combinação puderem ser administrados em doses maiores, ou se a infecção ocorrer onde os antimicrobianos fiquem mais concentrados (Fernández-Cuenca et al., 2003).

Considerando as combinações sinérgicas que foram efetivas para a maioria das cepas [Tigeciclina $x$ DDA] e [Piperacilina/Tazobactam x Aztreonam], outros ensaios foram realizados para confirmar a eficácia da combinação, como Teste Confirmatório de Sinergismo, "Time-Kill", Espectrofotometria de UV visível Potencial Zeta e "Light Scattering".

\subsection{Teste Confirmatório de Sinergismo}

O Teste Confirmatório de Sinergismo foi realizado para a combinação [Piperacilina/Tazobactam $x$ Aztreonam]. As cepas avaliadas foram: 247B VIM-1, PA GIM-1 e 48-1997A SPM-1. As concentrações de Aztreonam adicionadas ao meio de cultura basearam-se nas CIMs obtidas nos testes de microdiluição em caldo (Tabela 
3). Acreditando que pudessem existir diferenças entre os dois métodos (ágar e caldo), diluições com concentrações inferiores e superiores as CIMs também foram testadas. Os discos de antibióticos avaliados seguiram as combinações já avaliadas com Aztreonam, pelo método de "Checkerboard" (Tabela 1).

As concentrações de Aztreonam e os diâmetros dos halos de inibição formados podem ser observados na Tabela 5 .

As três cepas avaliadas demonstraram aumentar consideravelmente os diâmetros dos halos de inibição para todos os antibióticos (exceto Levofloxacina), conforme aumentava a concentração de Aztreonam adicionado ao ágar. O antibiótico de Piperacilina/Tazobactam demonstrou ser resistente para as cepas [PA GIM-1, 48-19987A EPM e VIM-1 247B] quando não havia Aztreonam incluído no ágar, porém após a adição do Aztreonam ao meio Mueller-Hinton as três cepas passaram de resistente para sensível.

Após essa primeira etapa, foi selecionada a CIM de Aztreonam no ágar, para cada cepa. A CIM de Aztreonam foi então utilizada para a adição da fita de E-test de Piperacilina/Tazobactam e comparada a outra placa sem a adição do Aztreonam. Como pode ser observado nas Figuras 14, 15 e 16.

As três cepas tiveram uma diminuição das CIMs de Piperacilina/Tazobactam pelo método de E-test quando combinadas com Aztreonam.

A cepa PA GIM-1 apresentava uma CIM maior do que $256 \mu \mathrm{g} / \mathrm{mL}$, através do E-test, para Piperacilina/Tazobactam, sem a combinação com o Aztreonam, demonstrando resistência. Quando em combinação com o Aztreonam, a CIM de Piperacilina/Tazobactam caiu para $48 \mu \mathrm{g} / \mathrm{mL}$, passando a ser sensível (diminuição da CIM de pelo menos cinco vezes).

A cepa 247B VIM-1, antes da combinação com Aztreonam tinha uma CIM de $128 \mu \mathrm{g} / \mathrm{mL}$, sendo, portanto resistente a Piperacilina/Tazobactam, já quando em combinação com Aztreonam, a cepa apresentou uma CIM de $12 \mu \mathrm{g} / \mathrm{mL}$, passando a ser sensível a Piperacilina/Tazobactam (diminuição da CIM de mais de dez vezes).

A cepa 48-1997A SPM-1, antes da combinação com o Aztreonam, apresentava uma CIM para Piperacilina/Tazobactam acima de $256 \mu \mathrm{g} / \mathrm{mL}$, pelo método de E-test. Quando em combinação com Aztreonam a CIM de Piperacilina/Tazobactam passou a ser $4 \mu \mathrm{g} / \mathrm{mL}$ (diminuição em sessenta e quatro vezes da CIM). 
A variação das CIMs entre as metodologias (Microdiluição e E-test) podem ser explicadas por diferentes fatores. Primeiramente a concentração de inóculo utilizada ( $5 \times 10^{5} \mathrm{UFC} / \mathrm{mL}$ ) para microdiluição e $1 \times 10^{8} \mathrm{UFC} / \mathrm{mL}$ para o E-test, é 200 vezes mais concentrada (Fernández-Cuenca et al., 2008). Ainda segundo este autor, a correlação entre a microdiluição e os métodos baseados em difusão em ágar ( $E$ test e discos) é muito baixa, inclusive, o valor da CIM para Imipenem e Meropenem pelo método de E-test é quatro vezes ou mais quando comparadas com a de microdiluição, para Acinetobacter baumannii.

Masgala et al. (2010) avaliou a discrepância entre vários métodos de suscetibilidade, entre eles, microdiluição e E-test para Stenotrophomonas maltophilia. Nesse estudo, o antibiótico Piperacilina/Tazobactam apresentou 100\% de resistência quando avaliado por microdiluição e $88 \%$ de resistência por E-test.

As referências acima citadas mostram que, realmente, existe a possibilidade de haver discrepâncias entre diferentes metodologias, embora um estudo de Joyce et al. (1992) indique variações menores. No entanto, vale ressaltar que a metodologia apresentada (Materiais e Métodos- seção 3.11) é nova e, deve ainda passar por uma melhor padronização e aperfeiçoamento, diminuindo assim as discrepâncias das CIMs apresentadas entre os diferentes métodos.

\section{4 "Time-Kill” da combinação [Tigeciclina x DDA]}

Para complementar os resultados sinérgicos obtidos, curvas de morte (TimeKil) foram realizadas. A combinação [Tigeciclina $x \mathrm{DDA}$ ] foi testada com as cepas [111ER, 48-1997A SPM-1, 247B VIM-1 e PA GIM-1].

A combinação [Tigeciclina/DDA] demonstrou ser sinérgica contra $P$. aeruginosa $(111 \mathrm{ER})$, interessantemente, já na primeira hora ocorre a morte da população bacteriana, que, comparando separadamente a Tigeciclina e o DDA só vem a obter esse efeito na sexta hora de interação, com uma concentração oito vezes maior (Figura 4).

A mesma situação ocorreu para a cepa 48-1997A SPM-1, onde a morte da população bacteriana ocorre na primeira hora, enquanto a Tigeciclina e o DDA só obtêm esse resultado na sexta hora, porém com uma concentração de Tigeciclina 16 vezes maior e de DDA 32 vezes maior (Figura 5). 
Para a cepa 247B VIM-1 a morte bacteriana ocorreu na primeira hora para 0 DDA, na sexta hora para a Tigeciclina e para a combinação em 24 horas, no entanto, a combinação apresentou uma redução de 16 vezes para o DDA e 8 vezes para a Tigeciclina (Figura 6).

O DDA ocasionou a morte bacteriana na sexta hora para a cepa GIM-1 (Figura 7), a Tigeciclina ocasionou a morte bacteriana em doze horas, porém a combinação já matou na primeira hora com concentrações 16 vezes menores para Tigeciclina e 8 vezes menores para o DDA.

Esses resultados confirmam a eficiência da combinação [Tigeciclina/DDA] para cepas MR de Pseudomonas aeruginosa. Mesmo com todas as reduções significativas das CIMs a combinação levou a morte bacteriana, mostrando ser superior ao tratamento monoterápico.

\section{5 “Time-Kill” da combinação [Piperacilina/Tazobactam x Aztreonam]}

A combinação [Piperacilina/Tazobactam x Aztreonam] foi analisada por "TimeKill”, para as cepas [48-1997A SPM-1, 247B VIM-1 e PA GIM-1]. As concentrações dos antimicrobianos foram selecionadas, para cada cepa, de acordo com os maiores valores obtidos em triplicata da atividade bactericida, após o teste de "Checkerboard” (Tabela 3).

O Aztreonam e a Piperacilina/Tazobactam, separadamente, levaram a morte da cepa 247B VIM-1 bacteriana em 12 horas, já a combinação dos dois antibióticos ocasionou a morte das bactérias na sexta hora e com concentrações 4 vezes menores para Aztreonam e Piperacilina/Tazobactam (Figura 17).

Para a cepa PA GIM-1 (Figura 18), o Aztreonam sozinho levou a morte das bactérias na sexta hora, já Piperacilina/Tazobactam curiosamente não ocasionou a morte dentro do período de $24 \mathrm{hs}$ estudado. No entanto, a combinação dos antibióticos ocasionou a morte da população bacteriana também na sexta hora, porém com a concentração de Aztreonam 4 vezes menor e com a concentração de Piperacilina/Tazobactam em $256 \mu \mathrm{g} / \mathrm{mL}$, sendo que nem com $1024 \mu \mathrm{g} / \mathrm{mL}$ a Piperacilina/Tazobactam sozinha conseguiu a morte bacteriana.

Para a cepa 48-1997A SPM-1 (Figura 19), a Piperacilina/Tazobactam levou a morte da população de bactérias em 12 horas, ao passo que o Aztreonam levou 24 horas. Já a combinação dos antibióticos matou na sexta hora, tendo a CIM do 
Aztreonam diminuído oito vezes, e a da Piperacilina/Tazobactam reduzido em 64 vezes.

Da mesma forma que para [Tigeciclina x DDA], esses resultados corroboram a eficiência da combinação [Piperacilina/Tazobactam x Aztreonam] para cepas MR de Pseudomonas aeruginosa, uma vez que suas CIMs foram diminuídas e mesmo assim demonstraram ser mais eficientes, ocasionando a morte bacteriana com menores doses de antibióticos. Segundo Rahal (2006) menores concentrações de antibióticos reduzem a toxicidade do tratamento.

\subsection{Ensaios Adicionais}

Como citado, dentre as combinações testadas, [Tigeciclina x DDA] foi demonstrada ser promissora pelo fato que houve uma notória queda na CIM da Tigeciclina com uma $\Sigma F B C \leq 0,5$, para as dez cepas de $P$. aeruginosa avaliadas (Tabela 2).

Esta potencialização foi digna de um estudo físico-químico, uma vez que tem sido postulado que $P$. aeruginosa apresenta uma resistência intrínseca a Tigeciclina mediada pela superexpressão de bombas de efluxo (Livermore, 2005).

Os ensaios de espalhamento de luz dinâmico "Light Scattering" (Figura 9) e (Figura 10) sugerem interações entre os compostos que muito provavelmente contribuíram com o efeito sinérgico.

Fica evidente na figura $9 \mathrm{~A}$ a carga negativa $(\zeta=-14,63 \mathrm{mV})$ da cepa $P$. aeruginosa 111ER e seu diâmetro médio $(\mathrm{d}=641,8 \mathrm{~nm})$, com valores similares aos encontrados na literatura (Lincopan, Trabulsi, 2008; Ubbink, Schär-Zammaretti, 2007).

Na Figura 9B e 9D podemos observar o DDA nas concentrações de $1 \mathrm{mM}$ e 2 $\mathrm{mM}$, cujos valores de diâmetro e carga foram próximos, indicando que não há muita discrepância nestas duas concentrações. Essas concentrações foram usadas para poder ver se a força iônica afetaria a leitura do aparelho quando aumentada a concentração. Não houve diferença significativa de leitura.

A Figura 9C mostra a combinação de Pseudomonas aeruginosa com DDA 1 mM obtendo como resultado o diâmetro médio de ( $\mathrm{d}=109,1 \mathrm{~nm})$ e, uma carga superficial de $(\zeta=0 \mathrm{mV})$ (Figura 9C). Já quando a $P$. aeruginosa é associada ao DDA $2 \mathrm{mM}$ o diâmetro médio $(\mathrm{d}=112,3 \mathrm{~nm})$ e sua carga superficial também é $(\zeta=0 \mathrm{mV})$ 
(Figura 9E). O efeito do DDA sobre $P$. aeruginosa sugere que esta interação resultou na neutralização da carga negativa da bactéria, com uma queda no diâmetro médio da mesma, que na prática também resultou em atividade bactericida.

$\mathrm{Na}$ Figura 10A Pseudomonas aeruginosa foi associada ao DDA na concentração da CIM (32 $\mu \mathrm{g} / \mathrm{mL})$. Fica evidente a possível ação bactericida do DDA sobre a bactéria, pois a bactéria sem a combinação com o DDA tem carga superficial negativa e já na presença do DDA essa carga foi neutralizada. Um fato interessante é o surgimento de duas populações, indicando a possível fragmentação da bactéria após o tratamento com DDA.

A Tigeciclina é um composto altamente solúvel em uma ampla faixa de $\mathrm{pH}$ devido a presença de diversos grupos ionizáveis, com diferentes valores de pKa. No interior da molécula, existem três grupamentos básicos e dois ácidicos. Os valores de pKa de cada um desses grupamentos variam de 2.8 à 9.5 (FDA, 2005). As análises dos valores de pKa, dos diferentes grupos ionizáveis indicam que a Tigeciclina apresenta uma carga levemente positiva em $\mathrm{pH} 7$, no qual o tampão foi preparado, condizendo com o valor apresentado pelo potencial zeta. Entretanto, na Figura 10B podemos observar duas populações de Tigeciclina, provavelmente devido à aglomeração das moléculas, devido a presença de radicais hidrofóbicos no interior da estrutura da molécula (Figura 3) (Rose, Ryback, 2006).

$\mathrm{Na}$ Figura 10C, podemos observar a interação da Tigeciclina com a bactéria, que resultou na formação de duas populações, sugerindo a fragmentação da bactéria. A neutralização da carga superficial indica a interação molecular na superfície bacteriana.

$\mathrm{Na}$ figura 10D, podemos observar o surgimento de três populações e a neutralização de cargas. Estes resultados poderiam indicar que existe interação molecular dos dois compostos, provavelmente ela aconteceria na região hidrofóbica das duas moléculas formando o complexo DDA/Tigeciclina. No entanto, este complexo deixaria exposta a região hidrofílica de carga negativa, fato que poderia explicar a neutralização das cargas, pois os dois compostos mostraram cargas positivas.

Na Figura 10E podemos observar a interação da Pseudomonas aeruginosa com Tigeciclina e DDA. Estes resultados mostram a neutralização da carga superficial da bactéria assim como o surgimento de quatro populações. Igualmente, o complexo DDA/Tigeciclina pode ser o responsável da neutralização de carga 
superficial como explicado no parágrafo anterior. O surgimento das quatro populações pode ser explicado como consequência da ação bactericida do composto, criando fragmentos aglomerados da bactéria com o complexo molecular DDA/Tigeciclina, obtendo teoricamente bactérias viáveis em menor quantidade que aquelas sem tratamento, porém com muitos fragmentos de bactéria em combinação com o complexo. Interessante ressaltar que as quatro populações surgiram após meia hora de interação do complexo e sua respectiva leitura no aparelho, fato que pode ser correlacionado com a morte celular total pelo ensaio “"Time-Kill” onde pode ser observado este efeito sinérgico a partir da primeira hora de interação (Figura 4). Em meia hora de tratamento (bactéria com Tigeciclina e DDA) já poderia estar acontecendo morte celular, mas não na sua totalidade.

A boa interação do complexo Tigeciclina/DDA com a superfície externa da bactéria acontece, muito provavelmente, devido a Tigeciclina possuir a capacidade de ser altamente solúvel em uma ampla faixa de $\mathrm{pH}$ (em decorrência dos seus diferentes $\mathrm{pKa}$ ), aliada a sua hidrofobicidade que a permite interagir com a região apolar do DDA (Figura 20) esse, por sua vez, pode desestruturar a membrana externa da bactéria com a subsequente perda de funcionalidade da bomba de efluxo, aumentando a sensibilidade da bactéria à Tigeciclina, além de sofrer a própria ação do lípide catiônico de DDA.

Figura 20 - Esquema da possível interação entre Tigeciclina e um fragmento de bicamada de DDA.

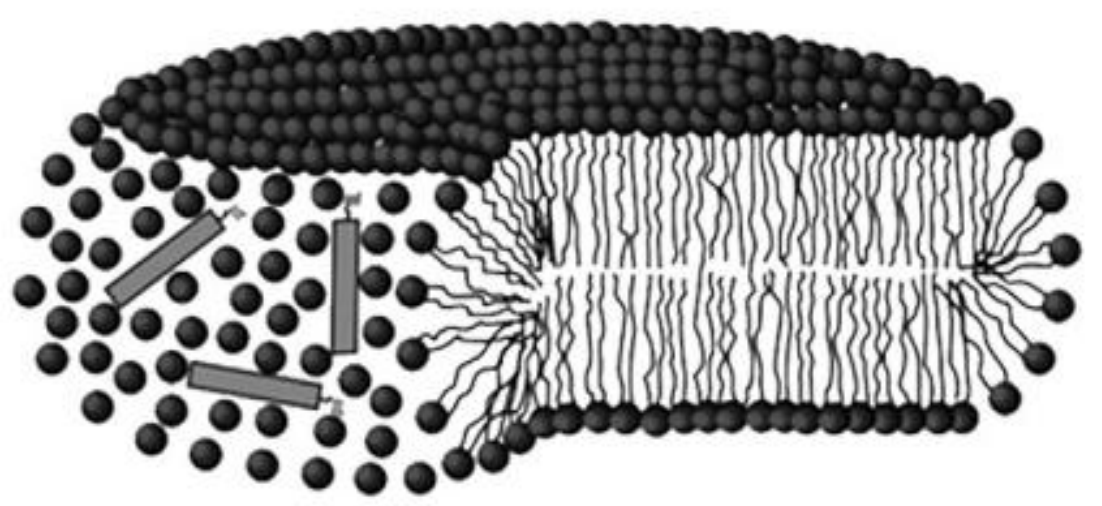

Nota: A Tigeciclina pode ser representada como um retângulo.

Fonte: Adaptado de Oliveira et al. (2011).

Da avaliação físico-química por espectrofotometria UV/Visível (Figura 8) podemos inferir que a interação Tigeciclina-DDA é favorecida pela força hidrofóbica 
decorrente da estrutura de ambos compostos. Deste modo, os nanofragmentos de bicamada de DDA apresentam regiões hidrofóbicas expostas que interagem com Tigeciclina formando complexos monodispersos, caracterizados pela monomerização da Tigeciclina, com preservação da sua estrutura primária o que resultaria na atividade bactericida sinérgica de ambos os compostos.

\subsection{Considerações finais}

É real a necessidade encontrada por pacientes com infecções ocasionadas por Pseudomonas aeruginosa MR, especialmente para casos de queimaduras, pneumonias e portadores de fibrose cística.

Os resultados apresentados são auspiciosos, mesmo as combinações que se mostraram ser parcialmente sinérgicas ou indiferentes, podem vir a ser úteis no tratamento de infecções ocasionadas por Pseudomonas aeruginosa MR, quando as opções terapêuticas forem escassas, uma vez que as combinações permitiram que pelo menos um dos antimicrobianos se tornasse sensível, quando que por separado nenhum teria efeito.

Já os resultados promissores do combinado [Piperacilina/Tazobactam $\mathrm{x}$ Aztreonam] respaldam o uso em esquemas terapêuticos, para tratamento da infecção produzida por de $P$. aeruginosa MR, produtora de SPM-1, endêmica no Brasil, atualmente considerada uma urgência clínica e epidemiológica, aliado a GIM1 e VIM-1.

A combinação [Piperacilina/Tazobactam $\times$ Aztreonam] tem potencial para vir a ser utilizada em situações as quais os antimicrobianos comumente utilizados não surtem resultados. Essa situação é evidente nos casos de pneumonia nosocomial, os quais as opções de tratamento são praticamente nulas, em se tratando de $P$. aeruginosa MR (Bouza, Muñoz, 2000; Gales et al., 2003a; Mah et al., 2012) e em casos de fibrose cística.

Analisando separadamente o [Aztreonam], Walton et al. (1997) destacou que o Aztreonam é uma boa droga, com toxicidade semelhante a de outros $\beta$-lactâmicos, aos quais apresentam mínimas reações cruzadas, podendo ser utilizadas em pacientes alérgicos à penicilinas ou cefalosporinas, tendo boa distribuição para os tecidos e fluidos, quando administrado por via intravenosa. Além do uso sistêmico, novas formulações têm sido aprovadas para o Aztreonam, como o Aztreonam lisina 
para inalação, sendo estável frente às $\beta$-lactamases. Essa nova metodologia permite a inalação desse antibiótico e, tem sido principalmente indicada para infecções pulmonares ocasionadas por $P$. aeruginosa em pacientes com fibrose cística (Zeitler et al., 2012).

Paralelamente às infecções do sistema respiratório, existe a necessidade de desenvolvimento e opções terapêuticas para pacientes com queimaduras, pois as infecções ocasionadas por $P$. aeruginosa são problemáticas, começando como uma lesão superficial, se espalhando por tecidos mais profundos e podendo vir causar a sepse. Esses eventos podem piorar dependendo da gravidade das lesões ocasionadas pelas queimaduras (Quadro 1), aumentando o grau de mortalidade conforme o estágio de infecção (Quadro 2). Por essas razões as queimaduras devem ser protegidas por agentes antimicrobianos de uso tópico, para evitar a proliferação das bactérias (Hammond et al., 2011; Pruitt, McManus, 1992).

Por outro lado, o uso combinado de nanofragmentos de [DDA/Tigeciclina] pode constituir a base para consolidar uma nova formulação farmacêutica de inovação tecnológica aplicada à saúde, como por exemplo, o desenvolvimento de um produto para inalação, nos casos de infecções respiratórias, ou medicamentos de uso tópico, para pacientes com queimaduras. 


\section{CONCLUSÕES}

1. A resistência a pelo menos três antibacterianos de classes diferentes foi confirmada em 9 de 10 cepas;

2. Todas as cepas foram sensíveis a Polimixina B e a Colistina;

3. O uso combinado de [Piperacilina/Tazobactam $\times$ Aztreonam] revelou atividade sinérgica contra as cepas clínicos MR de $P$. aeruginosa produtora de $M \beta L$ SPM-1, GIM-1 e VIM-1, com potencial clínico e terapêutico, considerando aspectos farmacocinéticos;

4. $\quad$ uso de DDA potencializa a atividade de Tigeciclina contra $P$. aeruginosa MR, cuja combinação exibe efeito sinérgico com atividade bactericida em poucas horas de interação;

5. Tigeciclina pode ser incorporada às bordas hidrofóbicas dos nanofragmentos de DDA, o que resulta na monomerização da Tigeciclina, com preservação da estrutura primária, favorecendo o efeito sinérgico de ambas drogas;

6. O uso combinado de DDA pode estender o potencial clínico da Tigeciclina para $P$. aeruginosa. 


\section{REFERÊNCIAS ${ }^{1}$}

Ambler RP. The structure of $\beta$-lactamase. Phil Trans R Soc Lond B Sci. 1980;289(36):321-31.

Azzopardi EA, Azzopardi SM, Boyce DE, Dickson WA. Emerging gram-negative infections in burn wounds. J Burn Care Res. 2011;32(5):570-6.

Bouza E, Muñoz P. Monotherapy versus combination therapy for bacterial infections. Med Clin North Am. 2000;84(6):1357-89.

Branski LK, Al-Mousawi A, Rivero H, Jeschke MG, Sanford AP, Herndon DN. Emerging Infections in Burns. Surg Infect (Larchmt). 2009;10(5):389-97.

Brasil: Ministério da Saúde. Dispõe sobre a obrigatoriedade da manutenção pelos hospitais do país, de programa de controle de infecções hospitalares. Diário Oficial da União, Brasília, DF, 13 de Maio de 1998. Disponível em: http://bvsms.saude.gov.br/bvs/saudelegis/gm/1998/prt2616_12_05_1998.html. [2012 Ago. 19].

Carvalho EM, Massarollo PC, Levin AS, Isern MR, Pereira WL, Abdala E, Rossi F, Mies S. Comparative study of etiological diagnosis of nosocomial pneumonia. Braz $\mathrm{J}$ Infect Dis. 2008;12(1):67-74.

Castanheira M, Toleman M, Jones R, Schmidt F, Walsh T. Molecular Characterization of a $\beta$-Lactamase Gene, blaGIM,Encoding a New Subclass of Metallo-beta-Lactamase Antimicrob Agents Chemother. 2004;48(12):4654-61.

Choi JY, Park YS, Cho CH, Seon, Y, Shin SY, Song G, Yong D, Lee K, Kim JM. Synergic in-vitro activity of imipenem and sulbactam againt Acinetobacter baumannii. Clin Microbiol Infect. 2004;10:1089-104.

Clinical and Laboratory Standards Institute. Performance Standards for Antimicrobial Disk Susceptibility Tests. Approved standard - Ninth edition. CLSI document M02A10. Wayne, PA: 2009.

Clinical and Laboratory Standards Institute. Performance Standards for Antimicrobial Susceptibility Testing. Approved standard - Twenty-First informational Supplement; CLSI document M100-S21. Wayne, PA:2011.

Clinical and Laboratory Standards Institute. Methods for dilution antimicrobial susceptibility tests for bacteria that grow aerobically. Approved standard - Eighth edition. CLSI document M07-A8. Wayne, PA: 2009.

Cystic Fibrosis Foundation. About cystic fibrosis [homepage on the internet]. Available from: http://www.cff.org/AboutCF. [2012 Jul. 31].

\footnotetext{
${ }^{1}$ De acordo com:

International Committee of Medical Journal Editors. Uniform requirements for manuscripts submitted to biomedical journals. [2011 Jul 15]. Available from: http://www.nlm.nih.gov/bsd/uniform_requirements.html.
} 
Davies J, Davies D. Origins and evolution of antibiotic resistance. Microbiol Mol Biol Rev. 2010;74(3):417-33.

De-Souza DA, Marchesan WG, Greenea'd LJ. Epidemiological data and mortality rate of patients hospitalized with burns in Brazil. Burns. 1998;24:433-8.

Doi Y, de Oliveira Garcia D, Adams J, Paterson DL. Coproduction of novel 16S rRNA methylase RmtD and metallo-beta-lactamase SPM-1 in a panresistant Pseudomonas aeruginosa isolate from Brazil. Antimicrob Agents Chemother. 2007;51(3):852-6.

Döring G, Conway SP, Heijerman HG, Hodson ME, Høiby N, Smyth A, Touw DJ. Antibiotic therapy against Pseudomonas aeruginosa in cystic fibrosis: a European consensus. Eur Respir J. 2000;16(4):749-67.

Drawz SM, Bonomo RA. Three decades of $\beta$-Lactamase inhibitors. Clin Microbiol Rev. 2010;23(1):160-201.

European Committee on Antimicrobial Susceptibility Testing (EUCAST): Breakpoint tables for interpretation of MICs and zone diameters. Enterobacteriaceae. Available from:http://www.eucast.org/fileadmin/src/media/PDFs/EUCAST_files/Disk_test_docu ments/EUCAST_breakpoints_v_2.0_120101.pdf. [2012a Feb 14]].

European Committee on Antimicrobial Susceptibility Testing (EUCAST): EUCAST Quality Control. Available from: http://www.eucast.org/fileadmin/src/media/PDFs/ EUCAST_files/Disk_test_documets/EUCAST_QC_tables_2.0.pdf. [2012b Feb 14].

Fass RJ, Prior RB. Comparative in vitro activities of piperacillin-tazobactam and ticarcillin-clavulanate. Antimicrob Agents Chemother. 1989;33(8):1268-74.

Food and Drug Administration (FDA): Clinical Pharmacology \& Biopharmaceutics Review. Tigecycline 2005. Available from: http://www.accessdata.fda.gov/ drugsatfda_docs/nda/2005/021821Orig1s000ClinPharmR.pdf [2012 Agu 31].

Fernández-Cuenca F, Martínez-Martínez L, Pascual A, Perea EJ. In vitro activity of azithromycin in combination with amikacin, ceftazidime, ciprofloxacin or imipenem against clinical isolates of Acinetobacter baumannii. Chemotherapy. 2003;49(1-2):246.

Fernández-Cuenca F, Egea P, López-Cerero L, Díaz-De Alba P, Vila J, Pascual A. [Comparison of 3 methods for determining sensitivity to imipenem and meropenem in Acinetobacter baumannii with a carbapenem-heteroresistant phenotype]. Enferm Infecc Microbiol Clin. 2008;26(8):485-8.

Fiates GMR, Barbosa E, Auler F, Feiten SF, Miranda F. Estado nutricional e ingestão alimentar de pessoas com fibrose cística. Rev Nut. 2001:14(2):95-101.

Firmida MC, Lopes AJ. Aspectos epidemiológicos da fibrose cística. Revista Hospital Universitário Pedro Ernesto. 2011;10(4):12-22. 
Fleiss PM, Richwald GA, Gordon J, Stern M, Frantz M, Devlin RG. Aztreonam in human serum and breast milk. Br J Clin Pharmacol. 1985;19(4):509-11.

Fontes LC, Neves PR, Oliveira S, Silva KC, Hachich EM, Sato MI, Lincopan N. Isolation of Pseudomonas aeruginosa coproducing metallo- $\beta$-lactamase SPM- 1 and 16S rRNA methylase RmtD1 in an urban river. Antimicrob Agents Chemother. 2011;55(6):3063-4.

Franco MR, Caiaffa-Filho HH, Burattini MN, Rossi F. Metallo-beta-lactamases among imipenem-resistant Pseudomonas aeruginosa in a Brazilian university hospital. Clinics (Sao Paulo). 2010;65(9):825-9.

Fritsche TR, Sader HS, Toleman MA, Walsh TR, Jones RN. Emerging metallo-betalactamase-mediated resistances: a summary report from the worldwide SENTRY antimicrobial surveillance program. Clin Infect Dis. 2005;41 Suppl 4:S276-8.

Frost LS, Leplae R, Summers AO, Toussaint A. Mobile genetic elements: the agents of open source evolution. Nat Rev Microbiol. 2005;3(9):722-32.

Furtado GH, Gales AC, Perdiz LB, Santos AF, de Medeiros EA. Prevalence and clinical outcomes of episodes of ventilator-associated pneumonia caused by SPM-1producing and non-producing imipenem-resistant Pseudomonas aeruginosa. Rev Soc Bras Med Trop. 2011;44(5):604-6.

Gales AC, Castanheira M, Jones RN, Sader HS. Antimicrobial resistance among Gram-negative bacilli isolated from Latin America: results from SENTRY Antimicrobial Surveillance Program (Latin America, 2008-2010). Diagn Microbiol Infect Dis. 2012;73(4):354-60.

Gales AC, Menezes LC, Silbert S, Sader HS. Dissemination in distinct Brazilian regions of an epidemic carbapenem-resistant Pseudomonas aeruginosa producing SPM metallo-ß-lactamase. J Antimicrob Chemother. 2003a;52:699-702.

Gales AC, Tognim MC, Reis AO, Jones RN, Sader HS. Emergence of an IMP-like metallo-enzyme in an Acinetobacter baumannii clinical strain from a Brazilian teaching hospital. Diagn Microbiol Infect Dis. 2003b;45(1):77-9.

Gales AC, Torres PL, Vilarinho DS, Melo RS, Silva CF, Cereda RF. Carbapenemresistant Pseudomonas aeruginosa outbreak in a intensive care unit of a teaching hospital. Braz J Infect Dis. 2004;8(4):267-71.

Georgopapadakou NH, Smith SA, Sykes RB. Mode of action of azthreonam.Antimicrob Agents Chemother. 1982;21(6):950-6.

Giamarellos-Bourboulis EJ, Grecka P, Giamarellou H. Comparative in vitro interactions of ceftazidime, meropenem, and imipenem with amikacin on multiresistant Pseudomonas aeruginosa. Diagn Microbiol Infect Dis. 1997;29(2):81-6.

Gilbert DN, Moellering JR RC, Elipoulos GM, Chambers HF, Saag MS. The Sanford guide to antimicrobial therapy. 40th ed. Sperryville: Antimicrobial Therapy; 2010. 
Girão E, Levin AS, Basso M, Gobara S, Gomes L B, Medeiros EA, Barone AA, Costa $S$. F. Trends and outcome of 1121 nosocomial bloodstream infections in intensive care units in a Brazilian hospital, 1999-2003. Int J Infect Dis. 2008;12:145-6.

Goldberg JB. Why is Pseudomonas aeruginosa a pathogen? F1000 Biol Rep. 2010;2(29):1-4.

Goossens H. Susceptibility of multi-drug-resistant Pseudomonas aeruginosa in intensive care units: results from the European MYSTIC study group. Clin Microbiol Infect. 2003;9(9):980-3

Hall MJ, Middleton R.F, Westmacott D. The fractional inhibitory concentration (FIC) index as a measure of synergy. J Antimicrob Chemother. 1983;11(5):427-33.

Hammond AA, Miller KG, Kruczek CJ, Dertien J, Colmer-Hamood JA, Griswold JA, Horswill AR, Hamood AN. An in vitro biofilm model to examine the effect of antibiotic ointments on biofilms produced by burn wound bacterial isolates. Burns. $2011 ; 37(2): 312-21$.

Hancock RE, Speert DP. Antibiotic resistance in Pseudomonas aeruginosa: mechanisms and impact on treatment. Drug Resist Updat. 2000;3(4):247-55.

Hauser AR, Jain M, Bar-Meir M, McColley SA. Clinical significance of microbial infection and adaptation in cystic fibrosis. Clin Microbiol Rev. 2011;24(1):29-70.

Hauser A, Ozer EA. Pseudomonas aeruginosa. Nature Reviews Microbiology. $2011 ; 9(3)$.

Høiby N. Recent advances in the treatment of Pseudomonas aeruginosa infections in cystic fibrosis. BMC Med. 2011;9:32.

Joyce LF, Downes J, Stockman K, Andrew JH. Comparison of five methods, including the PDM Epsilometer test (E-test), for antimicrobial susceptibility testing of Pseudomonas aeruginosa. J. Clin. Microbiol. 1992;30(10):2709-13.

Kanj SS, Kanafani ZA. Current concepts in antimicrobial therapy against resistant gram-negative organisms: extended-spectrum beta-lactamase-producing Enterobacteriaceae, carbapenem-resistant Enterobacteriaceae, and multidrugresistant Pseudomonas aeruginosa. Mayo Clin Proc. 2011;86(3):250-59.

Kiffer C, Hsiunq A, Oplustil C, Sampaio J, Sakaqami, Tuner P, Mendes C. MYSTIC Brazil Group. Antimicrobial susceptibility of Gram-negative bacteria in Brazilian hospitals: the MYSTIC Program Brazil 2003. Braz J Infect Dis. 2005;9(3):216-24.

Labiris NRC, Holbrook AM, Chrystyn H, Macleod SM, Newhouse MT. Dry Powder versus Intravenous and Nebulized Gentamicin in Cystic Fibrosis and Bronchiectasis: A Pilot Study. Am J Respir Crit Care Med. 1999;160:1711-6. 
Lacerda LA, Carneiro AC, Oliveira AF, Gragnani A, Ferreira LM. Estudo epidemiológico da Unidade de Tratamento de Queimaduras da Universidade Federal de São Paulo. Rev Bras Queimaduras. 2010;9(3):82-8.

Lambert ML, Suetens C, Savey A, Palomar M, Hiesmayr M, Morales I, Agodi A, Frank U, Mertens K, Schumacher M, Wolkewitz M. Clinical outcomes of health-careassociated infections and antimicrobial resistance in patients admitted to European intensive-care units: a cohort study. Lancet Infect Dis. 2011;11(1):30-8.

Lauretti L, Riccio ML, Mazzariol A, Cornaglia G, Amicosante G, Fontana R, Rossolini GM. Cloning and Characterization of blaVIM, a New Integron-Borne Metallo- $\beta$ Lactamase Gene from a Pseudomonas aeruginosa Clinical Isolate. 1999;43:1584-90.

Lee K, Yum J H, Yong D, Lee HM, Kim HD, Docquier JD, Rossolini GM, Chong Y. Novel acquired metallo-beta-lactamase gene, blaSIM-1, in a class 1 integron from Acinetobacter baumannii clinical isolates from Korea. Antimicrob Agents Chemother. 2005;49(11):4485-91.

Levin AS, Oliveira MS. The challenge of multidrug resistance: the treatment of gramnegative rod infections. Shock. 2008;30 Suppl 1:30-3.

Lincopan N, Mamizuka EM, Carmona-Ribeiro AM. In vivo activity of a novel amphotericin B formulation with synthetic cationic bilayer fragments. J Antimicrob Chemother. 2003;52(3):412-8.

Lincopan N. Atividade biológica de uma nova formulação de anfotericina $b$ solubilizada em nanofragmentos catiônicos de bicamada de brometo de dioctadecildimetilamônio. [tese (Doutorado em Análises Clínicas)]. São Paulo: Faculdade de Ciências Farmacêuticas, Universidade de São Paulo; 2004.

Lincopan N, Maccullock JA, Cassettari VC, Gales AC, Mamizuka EM. First isolation of metallo-beta-lactamase-producing multiresistant Klebsiella pneumoniae from a patient in Brazil. J Med Microbiol. 2005;43(1):516-9.

Lincopan N, Carmona-Ribeiro AM. Lipid-covered drug particles: combined action of dioctadecyldimethylammonium bromide and amphotericin B or miconazole. J Antimicrob Chemother. 2006;58(1):66-75.

Lincopan N, Leis R, Vianello MA, de Araújo MR, Ruiz AS, Mamizuka EM. Enterobacteria producing extended-spectrum beta-lactamases and IMP-1 metallobeta-lactamases isolated from Brazilian hospitals. J Med Microbiol. 2006;55(11):1611-3.

Lincopan N, Trabulsi LR. Pseudomonas aeruginosa. In: Trabulsi, L. R. e Alterthum, F. Microbiologia. 5th ed. São Paulo: Atheneu; 2008. p. 369-81.

Lincopan N, Neves P., Mamizuka EM, Levy, CE. Balanoposthitis caused by Pseudomonas aeruginosa co-producing metallo- $\beta$-lactamase and 16S rRNA methylase in children with hematological malignancies. Int J Infect Dis. 2010;14:3447. 
Lister PD. Beta-lactamase inhibitor combinations with extended-spectrum penicillins: factors influencing antibacterial activity against Enterobacteriaceae and Pseudomonas aeruginosa. Pharmacotherapy. 2000;20(9 Pt2):213S-218S.

Livermore DM. Multiple mechanisms of antimicrobial resistance in Pseudomonas aeruginosa: our worst nightmare? Clin Infect Dis. 2002;34(5):634-40.

Livermore DM. Tigecycline: what is it, and where should it be used? J Antimicrob Chemother. 2005;56(4):611-4.

Lauret D, Thrupp MD. Susceptibility testing of antibiotics in liquid media. Lorian V. Antibiotics in laboratory medicine manual of clinical microbiology. London: Williams e Wilkins, American Society for Microbiology; 1980.

Lyczak JB, Cannon CL, Pier GB. Lung infections associated with cystic fibrosis. Clin Microbiol Rev. 2002;15(2)194-222.

Macedo JLS, Rosa SC, Macedo KCS, Castro C. Fatores de risco da sepse em pacientes queimados. Rev Col Bras Cir. 2005;32(4):173-7.

Magiorakos AP, Srinivasan A, Carey RB, Carmeli Y, Falagas ME, Giske CG, Harbarth S, Hindler JF, Kahlmeter G, Olsson-Liljequist B, Paterson DL, Rice LB, Stelling J, Struelens MJ, Vatopoulos A, Weber JT, Monnet DL. Multidrug-resistant, extensively drug-resistant and pandrug-resistant bacteria: an international expert proposal for interim standard definitions for acquired resistance. Clin Microbiol Infect. 2012;18(3):268-81.

Mah GT, Mabasa VH, Chow I, Ensom MH. Evaluating outcomes associated with alternative dosing strategies for piperacillin/tazobactam: a qualitative systematic review. Ann Pharmacother. 2012;46(2):265-75.

Mariné J. Antibióticos por via inalatória - uma opção para prevenção e tratamento das pneumonias. Pulmão RJ. 2009;Suppl2:S64-S67.

Masgala A, Galani I, Souli M, Giamarellou H. Discrepancies between various methods in susceptibility testing and epidemiological analysis of Stenotrophomonas maltophilia clinical isolates. Cent Eur J Public Health. 2010; 18(2):119-123.

Mello-Jorge MHP, Koizumi MS. Gastos governamentais do SUS com internações hospitalares por causas externas: análise no Estado de São Paulo, 2000. Rev Bras Epidemiol. 2004;7(2):228-38.

Mendes RE, Castanheira M, Pignatari ACC, GALES AC. Metallo-ß-lactamase. J Bras Patol Med Lab. 2006;42(2):103-13.

Mitsugui CS, Tognim MC, Cardoso CL, Carrara-Marroni FE, Botelho Garcia L. In vitro activity of polymyxins in combination with $\beta$-lactams against clinical strains of Pseudomonas aeruginosa. Int J Antimicrob Agents. 2011;38(5):447-50. 
Molina-García L, Llorent-Martıínez EJ, Ortega-Barrales P, Fernández-de Córdova ML, Ruiz-Medina A. Photo-chemically induced fluorescence determination of tigecycline by a stopped-flow multicommutated flow-analysis assembly. Analytical Letters. 2011;44:127-36.

Montes SF, Barbosa MH, Sousa Neto AL. Aspectos clínicos e epidemiológicos de pacientes queimados internados em um Hospital de Ensino. Rev Esc Enferm USP. 2011;45(2):369-73.

Moura JP, Gir E. Conhecimento dos profissionais de enfermagem referente à resistência bacteriana a múltiplas drogas. Acta Paul Enferm. 2007;20(3):351-6.

Moura A, Henriques I, Smalla K, Correia A. Wastewater bacterial communities bring together broad-host range plasmids, integrons and a wide diversity of uncharacterized gene cassettes. Res Microbiol. 2010;161:58-66.

Muller $\mathrm{C}$, Plésiat $\mathrm{P}$, Jeannot $\mathrm{K}$. A two-component regulatory system interconnects resistance to polymyxins, aminoglycosides, fluoroquinolones, and $\beta$-lactams in Pseudomonas aeruginosa. Antimicrob Agents Chemother. 2011;55(3):1211-21.

Murphy TA, Simm AM, Toleman MA, Jones RN, Walsh TR. Biochemical characterization of the acquired metallo-beta-lactamase SPM-1 from Pseudomonas aeruginosa. Antimicrob Agents Chemother. 2003;47(2):582-7.

Nateche F, Martin A, Baraka S, Palomino JC, Khaled S, Portaels F. Application of the resazurin microtitre assay for detection of multidrug resistance in Mycobacterium tuberculosis in Algiers. J Med Microbiol. 2006;55(Pt 7):857-60.

National Committee for Clinical Laboratory Standards. Metodologia dos Testes de Sensibilidade a Agentes Antimicrobianos por Diluição para Bactérias de Crescimento Aeróbico. 6th ed; Approved standards M7-A6. Wayne, Pa: NCCLS; 2003.

Neves PR. Alterações da Permeabilidade e Expressão de Bombas de Efluxo em Isolados Clínicos de Pseudomonas aeruginosa Resistente ao Imipenem. [tese (Doutorado em Análises Clínicas)]. São Paulo: Faculdade de Ciências Farmacêuticas, Universidade de São Paulo; 2010.

Neves PR, Mamizuka EM, Levy CE, Lincopan N. Pseudomonas aeruginosa multirresistente: um problema endêmico no Brasil. J Bras Patol Med Lab. 2011;47(4):409-20.

Ng WW, Chau PY, Leung YK, Livermore DM. In vitro activities of Ro 17-2301 and aztreonam compared with those of other new beta-lactam antibiotics against clinical isolates of Pseudomonas aeruginosa. Antimicrob Agents Chemother. 1985;27(5):872-3.

Nichols DP, Konstan MW, Chmiel JF. Anti-inflammatory therapies for cystic fibrosisrelated lung disease. Clin Rev Allergy Immunol. 2008;35(3):135-53. 
Noguchi $\mathrm{H}$, Matsuhashi M, Mitsuhashi S. Comparative studies of penicillin-binding proteins in Pseudomonas aeruginosa and Escherichia coli. Eur $\mathrm{J}$ Biochem. $1979 ; 100(1): 41-9$.

Norman A, Hansen LH, Sørensen SJ. Conjugative plasmids: vessels of the communal gene pool. Philos Trans R Soc Lond B Biol Sci. 2009;364(1527):2275-89.

Oliveira TR, Benatti CR, Lamy MT. Structural characterization of the interaction of the polyene antibiotic Amphotericin B with DODAB bicelles and vesicles. Biochim Biophys Acta. 2011;1808(11):2629-37.

Osano E, Arakawa Y, Wacharotayankun R, Ohta M, Horii T, Ito H, Yoshimura F, Kato $\mathrm{N}$. Molecular characterization of an enterobacterial metallo-beta-lactamase found in a clinical isolate of Serratia marcescens that shows imipenem resistance. Antimicrob Agents Chemother. 1994;38(1):71-8.

Paterson DL, Lipman J. Returning to the pre-antibiotic era in the critically ill: the XDR problem. Crit Care Med. 2007;35(7):1789-1791.

Pavez M, Mamizuka EM, Lincopan N. Early dissemination of KPC-2-producing Klebsiella pneumoniae strains in Brazil. Antimicrob Agents Chemother. 2009;53(6):2702.

Pearson JP, Van Delden C, Iglewski BH. Active Efflux and Diffusion Are Involved in Transport of Pseudomonas aeruginosa Cell-to-Cell Signals. $J$ Bacteriol. 1999;181(4):1203-10.

Pellegrino FL, Teixeira LM, Carvalho MGS, Nouér SA, Oliveira MP, Sampaio JLM, Freitas D'A, Ferreira ALP, Amorim ELT, Riley LW, Moreira BM. Occurrence of a multidrug-resistant Pseudomonas aeruginosa clone in different hospitals in Rio de Janeiro, Brazil. J Clin Microbiol. 2002;40(7):2420-4.

Perez LR, Antunes AL, Freitas AL, Barth AL. When the resistance gets clingy: Pseudomonas aeruginosa harboring metallo- $\beta$-lactamase gene shows high ability to produce biofilm. Eur J Clin Microbiol Infect Dis. 2012;31(5):711-4.

Phillips I, Casewell M, Cox T, De Groot B, Friis C, Jones R, Nightingale C, Preston R, Waddell J. Does the use of antibiotics in food animals pose a risk to human health? A critical review of published data. J Antimicrob Chemother. 2004;53(1):28-52.

Poirel L, Magalhaes M, Lopes M, Nordmann P. Molecular analysis of metallo-betalactamase gene bla(SPM-1)-surrounding sequences from disseminated Pseudomonas aeruginosa isolates in Recife, Brazil. Antimicrob Agents Chemother. 2004;48(4):1406-9.

Poole K. Efflux-mediated antimicrobial resistance. J Antimicrob Chemother. 2005;56:20-51.

Poole K. Pseudomonas aeruginosa: resistance to the max. Front Microbiol. 2011;2(65):1-13. 
Pruitt BA Jr, McManus AT. The changing epidemiology of infection in burn patients. World J Surg. 1992;16(1):57-67.

Queenan AM, Bush K. Carbapenemases: the Versatile $\beta$-Lactamases. Clin Microbiol Rev. 2007;3:440-58.

Rahal JJ, Urban C, Horn D, et al . Class restriction of cephalosporin use to control total cephalosporin resistance in nosocomial Klebsiella. JAMA. 1998;280:1233-7.

Rahal JJ. Novel antibiotic combinations against infections with almost completely resistant Pseudomonas aeruginosa and Acinetobacter species. Clin Infect Dis. 2006;43 Suppl 2:S95-9.

Raskin S, Pereira-Ferrari L, Reis FC, Abreu F, Marostica P, Rozov T, Cardieri J, Ludwig N, Valentin L, Rosario-Filho NA, Camargo Neto E, Lewis E, Giugliani R, Diniz EM, Culpi L, Phillip JA 3rd, Chakraborty R. Incidence of cystic fibrosis in five different states of Brazil as determined by screening of p.F508del, mutation at the CFTR gene in newborns and patients. J Cyst Fibros. 2008;7(1):15-22.

Rempel LCT, Tizzot MRPA, Vasco JFM. Incidência de infecções bacterianas em pacientes queimados sob tratamento em hospital universitário de Curitiba. Rev Bras Queimaduras. 2011;10(1):3-9.

Rodloff AC, Goldstein EJC, Torres A. Two decades of imipenem therapy. J Antimicrob Chemother. 2006;58:916-29.

Rodvold KA, Gotfried MH, Cwik M, Korth-Bradley JM, Dukart G, Ellis-Grosse EJ. Serum, tissue and body fluid concentrations of tigecycline after a single $100 \mathrm{mg}$ dose. J Antimicrob Chemother. 2006;58(6):1221-9.

Romero-Vivas J, Rodríguez-Créixems M, Bouza E, Hellín T, Guerrero A, MartínezBeltrán J, García de la Torre M. Evaluation of aztreonam in the treatment of severe bacterial infections. Antimicrob Agents Chemother. 1985;28(2):222-6.

Rosa FR, Dias FG, Nobre LN, Morais HA. Fibrose cística: uma abordagem clínica e nutricional. Rev Nutr. 2008;21(6):725-37.

Rose WE, Rybak MJ. Tigecycline: first of a new class of antimicrobial agents. Pharmacotherapy. 2006;26(8):1099-110.

Rossi $F$. The challenges of antimicrobial resistance in Brazil. Clin Infect Dis. 2011;52(9):1138-43.

Sabath LD, Abraham EP. Zinc as a cofactor for cephalosporinase from Bacillus cereus 569. Biochem J. 1966;98(1):11C-3C.

Sader HS, Gales AC, Pfaller MA, Mendes RE, Zoccoli C, Barth A, Jones RN. Pathogen frequency and resistance patterns in Brazilian hospitals: summary of results from three years of the SENTRY Antimicrobial Surveillance Program. Braz J Infect Dis. 2001;5(4):200-14. 
Sader HS, Jones RN. Comprehensive in vitro evaluation of cefepime combined with aztreonam or ampicillin/sulbactam against multi-drug resistant Pseudomonas aeruginosa and Acinetobacter spp. Int J Antimicrob Agents. 2005;25(5):380-4.

Saino Y, Kobayashi F, Inoue M, Mitsuhashi S. Purification and properties of inducible penicillin beta-lactamase isolated from Pseudomonas maltophilia. Antimicrob Agents Chemother. 1982;22(4):564-70.

Salabi AE, Toleman MA, Weeks J, Bruderer T, Frei R, Walsh TR. First report of the metallo-beta-lactamase SPM-1 in Europe. Antimicrob Agents Chemother. 2010;54(1):582.

Santos Filho L, Santos IB, Assis AML, Xavier DE. Determinação da Produção de metalo beta-lactamases em amostras de Pseudomonas aeruginosa isoladas em João Pessoa, Paraíba. Revista Brasileira de Patologia. 2002;38(01):79-84.

Sistema Único de Saúde (SUS). Datasus. Informações de saúde. Sistema de Informações sobre Mortalidade (SIM) e Sistema de Informações Hospitalares do Sistema Único de Saúde (SIH/SUS) por ocorrência segundo causas externas do Brasil. 2009. Disponível em: http://www.datasus.gov.br [2011 Jul 28].

Souza AA, Mattar CA, De Almeida PCC, Faiwichow L, Fernandes FS, Neto ECA, Manzotti MS, De Paiva LGR. Perfil epidemiológico dos pacientes internados na Unidade de Queimaduras do Hospital do Servidor Público Estadual de São Paulo. Rev Bras Queimaduras. 2009;8(3):87-90.

Schurek KN, Sampaio JL, Kiffer CR, Sinto S, Mendes CM, Hancock RE. Involvement of pmrAB and phoPQ in polymyxin $B$ adaptation and inducible resistance in noncystic fibrosis clinical isolates of Pseudomonas aeruginosa. Antimicrob Agents Chemother. 2009;53(10):4345-51.

Strateva T, Yordanov D. Pseudomonas aeruginosa - a phenomenon of bacterial resistance. J Med Microbiol. 2009;58(Pt 9):1133-48.

Strayer AH, Gilbert DH, Pivarnik P, Medeiros AA, Zinner SH, Dudley MN. Pharmacodynamics of piperacillin alone and in combination with tazobactam against piperacillin-resistant and-susceptible organisms in an in vitro model of infection. Antimicrob Agents Chemother. 1994;38(10):2351-6.

Sykes RB, Bonner DP, Bush K, Georgopapadakou NH. Azthreonam (SQ 26,776), a synthetic monobactam specifically active against aerobic gram-negative bacteria. Antimicrob Agents Chemother. 1982;21(1):85-92.

Theuretzbacher $\mathrm{U}$. Accelerating resistance, inadequate antibacterial drug pipelines and international responses. Int J Antimicrob Agents. 2012;39(4):295-9.

Tillotson GS. Where does novel antibiotics ReD stand among other pharmaceutical products: an industrial perspective? Expert Rev Anti Infect Ther. 2008;6(5):551-2. 
Timurkaynak F, Can F, Azap OK, Demirbilek M, Arslan H, Karaman SO. In vitro activities of non-traditional antimicrobials alone or in combination against multidrugresistant strains of Pseudomonas aeruginosa and Acinetobacter baumannii isolated from intensive care units. Int J Antimicrob Agents. 2006;27(3):224-8.

Toleman MA, Simm AM, Murphy TA, Gales AC, Biedenbach DJ, Jones RN, Walsh TR. Molecular characterization of SPM-1, a novel metallo-beta-lactamase isolated in Latin America: report from the SENTRY antimicrobial surveillance programme. J Antimicrob Chemother. 2002;50(5):673-9.

Tripodi MF, Durante-Mangoni E, Fortunato R, Utili R, Zarrilli R. Comparation activities of Colistin, Rifampicina, Imipenem and Sulbactam/ampicillin alone or in combination agaist epidemic multidrug-resistant Acinetobacter baumannii isolates producing OXA-58 carbapenemases. Int J Antimicrob Agents. 2007;30:537-40.

Ubbink J, Schär-Zammaretti P. Colloidal properties and specific interactions of bacterial surfaces. Current Opinion in Colloid \& Interface Science. 2007;12:263-70.

Vale ECS. Primeiro atendimento em queimaduras: a abordagem do dermatologista. An Bras Dermatol. 2005;80(1):9-19.

Van Westreenen M, Tiddens HA. New antimicrobial strategies in cystic fibrosis. Paediatr Drugs. 2010;12(6):343-52.

Walsh TR, Toleman MA, Poirel L, Nordmann P. Metallo-ß-lactamases: the Quiet before the Storm? Clin Microbiol Rev. 2005;2:306-25.

Walton MA, Villarreal C, Herndon DN, Heggers JP. The use of aztreonam as an alternate therapy for multi-resistant Pseudomonas aeruginosa. Burns. 1997;23(3):225-7.

Watanabe M, lyobe S, Inoue M, Mitsuhashi S. Transferable imipenem resistance in Pseudomonas aeruginosa. Antimicrob Agents Chemother. 1991;35:147-51.

World Health Organization (WHO). The molecular genetic epidemiology of cystic fibrosis. 2004 Available from: http://www.cfww.org/docs/who/2002/who_hgn_cf_wg _04-02.pdf. [2012 Aug 14].

Yamane K, Wachin J, Suzuki S, Shibata N, Kato H, Shibayama, Kimura K, Kai K, Ishikawa S, Ozawa Y, Konda T, Arakawa Y. 16S rRNA Methylase-producting,Gramnegative Pathogens, Japan. Emerg Infect Dis. 2007;13:642-6.

Yim H, Woo H, Song W, Park MJ, Kim HS, Lee KM, Hur J, Park MS. Time-Kill synergy tests of tigecycline combined with imipenem, amikacin, and ciprofloxacin against clinical isolates of multidrug-resistant Klebsiella pneumoniae and Escherichia coli. Ann Clin Lab Sci. 2011;41(1):39-43.

Yoneda K, Chikumi H, Murata T, Gotoh N, Yamamoto H, Fujiwara H, Nishino T, Shimizu E. Measurement of Pseudomonas aeruginosa multidrug efflux pumps by 
quantitative real-time polymerase chain reaction. FEMS Microbiol Lett. 2005;243:125-31.

Yong D, Toleman MA, Giske CG, Cho HS, Sundman K, Lee K, Walsh TR. Characterization of a New Metallo-\{beta\}-Lactamase Gene, blaNDM-1, and a Novel Erythromycin Esterase Gene Carried on a Unique Genetic Structure in Klebsiella pneumoniae Sequence Type 14 from India. Antimicrob. Agents Chemother. 2009;53(12):5046-54.

Zavascki AP, Gaspareto PB, Martins AF, Gonçalves AL, Barth AL. Outbreak of carbapenem-resistant Pseudomonas aeruginosa producing SPM-1 metallo- $\beta$ lactamase in a teaching hospital in southern Brazil. J Antimicrob Chemother. 2005;56:1148-51.

Zavascki AP, Barth AL, Gonçalves AL, Moro AL, Fernandes JF, Martins AF, Ramos $F$, Goldani LZ. The influence of metallo-beta-lactamase production on mortality in nosocomial Pseudomonas aeruginosa infections. J Antimicrob Chemother. 2006;58(2):387-92.

Zavascki AP, Carvalhaes CG, Picão RC, Gales AC. Multidrug-resistant Pseudomonas aeruginosa and Acinetobacter baumannii: resistance mechanisms and implications for therapy. Expert Rev Anti Infect Ther. 2010;8(1):71-93.

Zeitler K, Salvas B, Stevens V, Brown J. Aztreonam lysine for inhalation: new formulation of an old antibiotic. Am J Health Syst Pharm. 2012;69(2):107-15.

Zhanel GG, Mayer M, Laing N, Adam HJ. Mutant Prevention Concentrations of Levofloxacin Alone and in Combination with Azithromycin, Ceftazidime, Colistin (Polymyxin E), Meropenem, Piperacillin Tazobactam, and Trobramycin against Pseudomonas aeruginosa. Antimicrob Agents Chemother. 2006;50:2228-30. 